\title{
1 Huntington disease: new insights into molecular pathogenesis and therapeutic opportunities
}

2 Sarah J. Tabrizi ${ }^{1,2,3, \dagger}$, Michael D. Flower ${ }^{1,2,3}$, Christopher A. Ross ${ }^{4}$ and Edward J. Wild ${ }^{1,2}$

3

1. Huntington's Disease Centre, University College London, London, UK

2. Department of Neurodegenerative Disease, Queen Square Institute of Neurology, University College London, London, UK

3. UK Dementia Research Institute, University College London, London, UK

4. Departments of Neurology, Neuroscience and Pharmacology, Johns Hopkins University School of Medicine, Baltimore, MD, USA.

These authors contributed equally to this work: Sarah J. Tabrizi and Michael D. Flower

†e-mail: $\underline{\text { s.tabrizi@ucl.ac.uk }}$

Huntington disease (HD) is a neurodegenerative disease caused by CAG repeat expansion in the HTT gene and involves a complex web of pathogenic mechanisms. Mutant HTT disrupts transcription, interferes with immune and mitochondrial function, and is aberrantly modified post-translationally. Evidence suggests that the mHTT RNA is toxic, and at the DNA level, somatic CAG repeat expansion in vulnerable cells influences disease course. Genome-wide association studies have identified DNA repair pathways as modifiers of somatic instability and disease course in HD and other repeat expansion diseases. In animal models of HD, nucleocytoplasmic transport is disrupted and its restoration is neuroprotective. Novel cerebrospinal fluid (CSF) and plasma biomarkers are amongst the earliest detectable changes in individuals with premanifest $\mathrm{HD}$, and have the sensitivity to detect therapeutic benefit. Therapeutically, the first human trial of a $H T T$-lowering antisense oligonucleotide successfully, and safely, reduced CSF concentration of mHTT in individuals with HD. A larger trial, powered to detect clinical efficacy, is underway, along with trials of other $H T T$-lowering approaches. In this Review, we discuss new insights into the molecular pathogenesis of HD and future therapeutic strategies, including the modulation of DNA repair and targeting the DNA mutation itself. 


\section{[H1] Introduction}

26 Huntington disease (HD) is caused by a dominantly inherited CAG repeat expansion in exon 1 of the

27 Huntingtin gene (HTT), and is characterised by progressive involuntary choreiform movements [G] , behavioural and psychiatric disturbances, and dementia ${ }^{1}$. HD is one of over 40 diseases that are caused by expansion of simple repeats, most of which, for unknown reasons, primarily affect the nervous system $^{2}$. CAG encodes the amino acid glutamine and a sequence of several glutamine units is referred to as a polyglutamine tract; HD is the most common of the nine polyglutamine diseases ${ }^{2}$. HD occurs worldwide and has a prevalence of $\sim 12$ per 100,000 individuals in populations of European descent ${ }^{3}$. Onset of the motor symptoms of HD, known as motor onset, can occur from childhood to old age, with a mean onset around 45 years, and is followed by inexorable disease progression ${ }^{4,5}$. Repeats of 36 or more CAG units are pathogenic, with longer repeats typically causing earlier onset ${ }^{1}$. Repeats of between 36 and 39 CAG units confer reduced penetrance ${ }^{1}$, and individuals carrying these reduced penetrance alleles are likely to be carriers of HD with disease onset beyond the normal lifespan.

Huntingtin (HTT) is a large, ubiquitously expressed protein, the evolution of which can be traced back over millions of years ${ }^{6}$. The polyglutamine tract first appeared in the sea urchin and increased in length throughout the evolution of vertebrates; humans have the longest tract $^{7}$. HTT contains both nuclear export and nuclear localisation signals, so the protein shuttles between nucleus and cytoplasm via active transport ${ }^{8-10}$. HTT is involved in CNS development, including neural tube formation and neuroblast migration, and HTT knockout mice die before birth, shortly after the formation of the nervous system $^{11,12}$. HTT is also involved in axonal transport, synaptic function and cell survival ${ }^{13}$.

The mutant huntingtin protein (mHTT) that results from CAG repeat expansion affects many cellular functions, leading to cell death, and establishing which of these effects are primary or secondary pathogenic processes is difficult. Striatal medium spiny neurons are most vulnerable to the presence of mHTT, although substantial neuronal dysfunction and death also occurs in the cerebral cortex ${ }^{14-18}$.

49 Polyglutamine tract length affects the post-translational modification of HTT, which in turn influences 50 the subcellular distribution, stability, cleavage and function of the protein ${ }^{19}$. HTT also binds and interacts with DNA in many genes, and the presence of an expanded polyglutamine tract in HTT results 
in transcriptional dysregulation ${ }^{20}$. Transcription is substantially disrupted in the brains of individuals with HD compared with healthy controls ${ }^{21}$. This disruption results in upregulation of the immune response and mRNA processing, and downregulation of metabolic processes and synaptic function. The anatomical distribution of transcriptional disruption correlates with areas of cell death, being most marked in the caudate nucleus ${ }^{21}$. Transcriptional dysregulation also occurs in the peripheral tissues of individuals with $\mathrm{HD}$, such as muscle and blood, and the sets of genes that are dysregulated significantly overlap with those that are dysregulated in the caudate ${ }^{20}$.

Animal models of HD have had a key role in increasing our understanding of pathogenesis and testing therapeutic compounds; genetic models are produced by introducing all or part of human mHTTin a transgene, or inserting an expanded CAG repeat into the endogenous HTT gene, which is known as a 'knock in' strategy ${ }^{22}$. Invertebrate models of HD, such as C. elegans and drosophila, show progressive neurodegeneration, motor abnormalities and reduced survival ${ }^{23}$. Rodent models of HD are the most commonly used, and show HTT aggregation, somatic instability, motor, cognitive and behavioural abnormalities, and reduced lifespan ${ }^{24}$. Large animal models, including sheep, pigs and non-human primates, are genetically more similar to humans, but use of these models has been limited by expense and the lag time to symptom onset. In this Review, we discuss the latest developments in our understanding of the pathogenesis of HD, and discuss new CSF and plasma biomarkers. We also review ground-breaking clinical trials of HTT-lowering therapies and discuss future therapeutic strategies that target the DNA mutation itself.

\section{[H1] Pathogenesis of HD}

In this section, we summarise the current understanding of the molecular mechanisms underlying HD, before introducing the latest developments in our understanding of disease pathogenesis in the sections that follow. In individuals with HD, the expanded polyglutamine tract causes mHTT to fold abnormally, which causes soluble monomers of HTT protein to combine, forming oligomers. These oligomers then act as seeds for the formation of mHTT fibrils and large inclusions in both the cytoplasm and nucleus ${ }^{25-}$ 27. Large mHTT inclusions were previously thought to be pathogenic ${ }^{28,29}$, but inclusions can occur without cell death, and vice versa ${ }^{30-32}$. More recent evidence suggests that $\mathrm{N}$-terminal mHTT oligomers 
are toxic ${ }^{33-38}$, and that the subsequent formation of inclusions might even be protective $\mathrm{e}^{31,34}$. This topic

80 is discussed in more detail below (Toxic exon1 protein). Endoplasmic reticulum stress precedes, and

81 then improves on mHTT aggregation, suggesting the toxicity of oligomers is mitigated by their aggregation into larger inclusions ${ }^{39,40}$. Small mHTT oligomers and fibrils, which are precursors of large inclusions, have been observed in the brains of individuals with $\mathrm{HD}^{41,42}$. In mouse and drosophila models of HD, the formation of mHTT oligomers and fibrils occured before the onset of symptoms, and levels increased as the disease progressed ${ }^{42}$. Polyglutamine-containing $\mathrm{N}$-terminal fragments of mHTT, which can be produced either by proteolytic cleavage ${ }^{26}$ or abnormal splicing ${ }^{43}$, aggregate in the brains of individuals with $\mathrm{HD}^{44}$ more rapidly than the full length protein does ${ }^{45-47}$.

Evidence also suggests that mHTT can transfer between cells. For example, synthetic polyglutamine peptides can be taken up by cells in culture ${ }^{48,49}$, and in co-culture experiments, fluorescently tagged mHTT can transfer between neighbouring cells ${ }^{50,51}$, including through tunnelling nanotubes. Furthermore, in Drosophila, mHTT can be released from synaptic terminals and taken up by neighbouring neurons by endocytosis ${ }^{52}$, and mHTT taken up phagocytically by Drosophila glia, can act as a seed for aggregation of wild-type HTT, which is properly folded and would not usually aggregate ${ }^{53}$. In one study, mHTT spread between neurons via functional synapses in three models, including from human HD iPSC-derived neurons to wild-type mouse brain slices, from HD mouse cortical neurons to medium spiny neurons in a wild-type mouse corticostriatal brain slice, and following injection of a mHTT fragment into wild-type mouse corte ${ }^{54}$. This contiguous propagation is distinct from truly 'prion-like' behaviour, which involves the infectious prion protein inducing the misfolding of the normal form and has not been demonstrated in $\mathrm{HD}^{55}$. Evidence for cell-to-cell spread of mHTT in humans is more limited; postmortems of individuals who had received fetal striatal transplants showed inclusions in the extracellular matrix of the graft, suggesting that mHTT is released by neurons, although no inclusions were found within cells ${ }^{56}$.

The two main protein degradation systems of the cell are the ubiquitin-proteasome system, which clears

104 damaged proteins, and autophagy, which degrades protein complexes and damaged organelles.

105 Evidence from human tissue and animal models suggests that these systems are compromised in 
$106 \mathrm{HD}^{57,58}$. Furthermore, inducing autophagy increases mHTT clearance and improves the phenotype in

107 animal models of the disease ${ }^{59}$. CNS inflammation has been implicated in several neurodegenerative 108 diseases, including Alzheimer disease, Parkinson disease, multiple sclerosis, prion disease and amyotrophic lateral sclerosis ${ }^{20,60,61}$, although whether this inflammation is a primary pathogenic process or a response to other pathologies remains unclear. The levels of reactive microglia and proinflammatory mediators in the brain are higher in individuals with HD than in healthy controls ${ }^{62,63}$, and immune activation is also observed in the peripheral blood of individuals with the disease ${ }^{61}$.

113 Mitochondria were implicated in HD pathogenesis after mitochondrial toxins, such as 3-nitropropionic 114 acid, were found to cause selective death of striatal medium spiny neurons ${ }^{64}$. Mitochondrial ATP 115 production, which is essential for the survival of neurons, is lower in postmortem brain samples from individuals with HD than in control samples ${ }^{65}$; this observation is supported by evidence from animal and cell models of $\mathrm{HD}^{47,66,67}$. Mitochondrial ultrastructure is disrupted in the brains of individuals with

$118 \mathrm{HD}^{68}$, and the number of mitochondria ${ }^{69}$ and the activity of enzyme complexes ${ }^{70-72}$ is lower than in 119 controls. Furthermore, mitochondrial membrane potential is lower in lymphoblasts derived from 120 individuals with HD than in lymphoblasts from controls ${ }^{73,74}$. Brain imaging studies showed that, in some 121 brain regions, individuals with HD had lower levels of glucose metabolism and higher lactate concentration than healthy individuals ${ }^{75-78}$, which could be a result of mitochondrial alterations. In animal models, mHTT disrupted anterograde and retrograde motility of mitochondria ${ }^{79-81}$, resulting in the accumulation of mitochondria in the soma ${ }^{82}$. In addition, the expression of PGC1 $\alpha$, which regulates

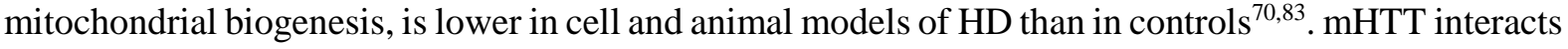
with the mitochondrial outer membrane, thus triggering calcium release that could cause cell death ${ }^{84,85}$, and also interacts with the inner mitochondrial membrane, thus disrupting the import of mitochondrial proteins $^{86,87}$.

129 Although a substantial body of evidence suggests that the mHTT protein is toxic, neurodegeneration was observed in animal models that express untranslated CAG repeat-containing transcripts, suggesting that mHTT RNA can also contribute to cell death ${ }^{88}$. RNA foci [G] were also toxic in animal models

132 with CAG repeats in $A T X N 3$ or $G F P^{89-91}$. Unconventional translation initiation, or repeat-associated 
non-ATG translation [G], occurs in the brains of individuals with HD in a CAG length-dependent

134 manner and produces monopeptides that aggregate, particularly in the striatum, but the toxicity of these 135 monopeptides has not yet been established ${ }^{92,93}$. Indeed, a very recent study has shown that HD knock136 in mice lack repeat-associated non-ATG translation-mediated toxicity, suggesting that the role of this 137 form of translation in HD pathogenesis is debatable ${ }^{94}$.

138 The HTT CAG repeat is somatically and meiotically unstable, progressively lengthens throughout life 139 and tends to expand between generations ${ }^{95-97}$. In studies that analysed samples of blood and post140 mortem cortex from individuals with HD, greater CAG expansion was associated with an earlier age of 141 disease onset ${ }^{97,98}$, suggesting that somatic instability [G] of the CAG repeat has a role in pathogenesis.

142 The degree of somatic instability varies among tissues, with expansion particularly prominent in 143 neurons from brain regions that show marked pathology such as the striatum and cortex ${ }^{99-101}$, in which repeats of over 1,000 CAG have been observed post-mortem ${ }^{102}$. In other tissues, such as cerebellum and blood, the CAG repeat was relatively stable, either not changing with age or increasing by only a

146 few CAG in a small proportion of cells ${ }^{103}$. In one study, a mathematical model fitted to data on repeat 147 length and phenotype in individuals with $\mathrm{HD}^{104}$ indicated that motor onset occurs when the repeat 148 expands beyond a threshold of around 115 CAG units in a sufficient number of vulnerable cells ${ }^{105}$. In 149 postmortem brain tissue from individuals with HD and animal models, the anatomical distribution of somatic CAG repeat instability often overlaps with areas of HD neuropathology, suggesting that somatic CAG expansion might underlie the selective vulnerability of striatal medium spiny neurons ${ }^{106}$.

\section{[H2] Genetic modifiers}

154 Pure CAG repeat length is the main determinant of the course of $\mathrm{HD}^{107}$ and accounts for around 50$15570 \%$ of variation in age at onset ${ }^{98,108}$, but up to half of the remaining variability is also heritable and 156 therefore results from differences elsewhere in the genome ${ }^{109}$. Large patient cohorts are now available 157 in which to carry out unbiased, genome-wide searches for disease course-modifying genetic variation. 158 The Genetic Modifiers of Huntington's Disease (GeM-HD ${ }^{110}$ consortium's genome-wide association 
study (GWAS) of 4,082 individuals with HD identified two loci, one on chromosome 8 and the other

160 on chromosome 15 , that were associated with age at onset ${ }^{107}$. Two independent signals identified on

161 chromosome 15 were likely to correspond to the gene encoding FAN1, which is a DNA endonuclease

162 and exonuclease that is involved in interstrand crosslink repair and replication fork recovery ${ }^{111}$. One of

163 these chromosome 15 signals was associated with disease onset $>6$ years earlier than would be expected

164 from CAG length alone, and the other was associated with disease onset 1.4 years later than expected.

165 Knockout or short hairpin RNA-mediated lowering of FAN1 increased somatic expansion of the HTT

166 CAG repeat in a human osteosarcoma cell line, patient-derived iPSCs and differentiated neurons ${ }^{112}$.

167 Although the known functions of FAN1 all involve nuclease activity, inactivation of the FAN1 nuclease

168 domain did not influence the rate of CAG expansion. This observation suggests that an unknown

169 function of FAN1, such as an interaction with other DNA repair components, is protective against CAG

170 repeat instability. Knockout of FAN1 in a mouse model of Fragile X syndrome increased the somatic

171 expansion of a CGG repeat, indicating that FAN1 also is also involved in other repeat expansion

172 diseases ${ }^{113}$. Curiously, FAN1 knockout did not alter intergenerational CGG repeat expansion, 173 suggesting that the mechanisms underlying somatic and meiotic instability could be distinct. The 174 chromosome 8 signal observed in the GeM-HD GWA study was associated with disease onset 1.6 years 175 earlier than expected from CAG repeat length and could correspond to $R R M 2 B$, which is involved in nucleotide synthesis, or UBR5, a ubiquitin ligase which might have a role in HTT aggregation ${ }^{114,115}$.

177 In another study, the disease onset-modifying variants identified by the GeM-HD ${ }^{110}$ were genotyped

178 in an independent cohort of 3,314 individuals from the European Huntington's Disease Network and 179 the signals on chromosome 8 and 15 were again associated with age at disease onset ${ }^{98}$. In addition, a 180 locus at $\mathrm{MLHI}$ on chromosome 3, that was not identified in the GeM-HD GWAS, was associated with 181 a 0.7 year delay in disease onset. MLH1, part of the mismatch repair MutL endonuclease complexes, which cut DNA, is required for somatic instability in HD mice ${ }^{116}$ and directly interacts with FAN1 ${ }^{112}$.

183 In a study by Hensman Moss, et al. ${ }^{117}$ a disease progression measure based on longitudinal motor, 184 cognitive and imaging data was used to conduct a GWAS in 216 participants from the TRACK-HD 185 study and 1,773 participants from the REGISTRY study. Variation at a chromosome 5 locus, which 
corresponds to MSH3 or DHFR, was associated with slower disease progression, as well as reduced

187 MSH3 expression in blood and fibroblasts. MSH3 identifies mis-paired bases or loop-outs and initiates

188 DNA mismatch repair ${ }^{118}$; knockout of $M S H 3$ in a mouse model of HD prevented somatic expansion

189 and decreased mHTT aggregation in striatal neurons ${ }^{119,120}$. DHFR is an enzyme involved in nucleotide

190 and amino acid synthesis ${ }^{121}$. Another study showed that the chromosome 5 signal was driven by a 9 bp

191 tandem repeat variant in exon 1 of $M S H 3^{122}$. In individuals with $\mathrm{HD}$, this variant was associated with

192 reduced $M S H 3$ expression in blood and brain ${ }^{122}$, decreased somatic CAG expansion, delayed disease

193 onset and slower progression ${ }^{122}$ In individuals with myotonic dystrophy type 1 (DM1), which is caused

194 by a CTG repeat expansion in $D M P K$, the same $M S H 3$ variant was associated with less somatic expansion and delayed disease onset ${ }^{122} . M S H 3$ and $D H F R$ share a bidirectional promoter, but increased expression of $\mathrm{MSH} 3$ was associated with more repeat expansion and earlier onset of $\mathrm{HD}$, whereas increased expression of DHFR was not ${ }^{122}$. The GeM-HD GWAS ${ }^{110}$ was recently extended to include a total of 9,064 individuals with $\mathrm{HD}^{98}$. This extended study replicated the findings of the original GeMHD GWAS and also identified new HD onset-associated loci that correspond to the DNA repair genes PMS1, MSH3, PMS2 and LIG1, as well as HTT, TCERG1 and CCDC82. TCERG1 is a nuclear regulator of transcriptional elongation and splicing, and was proposed as a potential HD modifier due to its interaction with $\mathrm{HTT}^{123,124}$, whereas CCDC82 is a relatively unknown coiled-coil domain protein that is phosphorylated in response to oxidative stress ${ }^{125}$. The $H T T$ signal resulted from sequence variation within the CAG repeat. At the very 3' end of the CAG tract there is a CAACAG motif, which encodes an extra two glutamines. In individuals lacking this CAA interruption the onset of HD occurred an average of 12.7 years earlier than would be expected from CAG repeat length, and in individuals with a duplication of the CAACAG motif, onset was delayed by an average of 5.7 years, despite the duplication increasing the total number of glutamines. Loss of the CAA interruption is also associated with increased somatic HTTCAG expansion in blood and sperm ${ }^{107}$. Such interruptions, which can have different sequences, limit expansion in many repeat disorders, including spinocerebellar ataxia (SCA) type 1, 2, 3 and 17; fragile X syndrome; Friedreich's ataxia and DM1 ${ }^{126}$. HTT CAG repeat length predicted the age of HD onset more accurately than the number of glutamines in the protein, suggesting that altered DNA repair, acting through somatic expansion, is the main modifier of pathogenesis ${ }^{98,107}$. 
214 Therefore, introducing interruptions into the HTT CAG could be a strategy for the treatment of HD.

215 The occurrence of HTT CAG sequence variation, although rare, means PCR fragment-sizing assays, 216 which assume that a single CAACAG motif is present, might overestimate or underestimate pure CAG 217 repeat length, and could contribute to the variable penetrance of alleles sized at 35-39 repeats ${ }^{107}$.

218 On chromosome 5, the extended GeM-HD GWAS ${ }^{98}$ replicated the findings from the Hensman Moss, 219 et al. ${ }^{117}$ study by identifying a locus corresponding to MSH3 or DHFR that was associated with 0.6 220 year delayed onset of $\mathrm{HD}^{81}$. Two additional, independent signals were also identified at MSH3 or 221 DHFR, one associated with an 0.8-year earlier onset and the other associated with a 6.1-year delay in onset. The onset-hastening variant was associated with higher expression of MSH3 and increased CAG expansion in blood. In $L I G 1$, which encodes a DNA ligase that seals DNA to complete replication and repair ${ }^{127}$, two signals were identified, one associated with a $<1$ year delay in onset and the other associated with $<1$ year earlier onset. In a transcriptome-wide association study, the onset-hastening variant was associated with higher $L I G 1$ expression in cortex $^{98}$, which is consistent with the increase in

227 CAG instability that was observed when LIG1 was overexpressed in human cells in vitro ${ }^{128}$, as well as the reduced expansion and increased CTG repeat contraction seen in DM1 mice with a mutation that impairs Lig1 activity ${ }^{129}$. A third, rare variant in LIG1 that was predicted to impair protein function was associated with a 7.7-year delay in onset of HD.

MLH1 heterodimerises with PMS2, PMS1 or MLH3 to form the MutL $\alpha$, MutL $\beta$ or MutL $\gamma$ mismatch repair endonuclease complexes, respectively. Variation in PMS2 was associated with 0.8 -year delayed onset, and PMS1 with 0.8-year earlier onset ${ }^{98}$. MLH3 was associated with age at disease onset in a gene-wide association analysis ${ }^{98}$, and is a component of DNA repair pathways that were also associated with disease onset. Interestingly, knockout of Pms 2 and $M l h 3$, but not $P m s 1$, reduced somatic instability in HD mice ${ }^{116,130}$. In a transcriptome-wide association study, increased expression of FANI and PMSI, and decreased expression of $M S H 3$, in cortex were associated with later onset of $\mathrm{HD}^{81}$. Taken together, these results suggest that MutL $\alpha$ and MutL $\gamma$ promote HD pathogenesis, and that MutL $\beta$ inhibits HD pathogenesis. 
240 Interestingly, one study showed that some of the variants identified as HD modifiers in the GeM-HD

241 GWAS ${ }^{110}$, including $F A N 1$ and $R R M 2 B$, also influenced the age of onset of other polyglutamine

242 diseases ${ }^{131}$. This observation suggests that DNA repair, probably acting through somatic expansion, is

243 a common contributor to pathogenesis in CAG expansion diseases. Genetic association studies ${ }^{132}{ }^{118}$, as

244 well as studies using mouse models ${ }^{118}$, human cell lines ${ }^{133-139}$, or patient-derived cells ${ }^{134,140,141}$, have also implicated MutS $\beta$ (MSH2 and MSH3), MutS $\alpha$ (MSH2 and MSH6), MutL $\alpha$ and MutL $\gamma$ in DM1,

246 Friedreich's ataxia and fragile X repeat instability.

\section{7 [H3] Implications for HD pathogenesis}

248 The results of these genetic association studies indicate that DNA repair activity is central to the pathogenesis of $\mathrm{HD}$, with variants in repair proteins likely to influence the rate of somatic expansion in tissues that are vulnerable to repeat instability and neurodegeneration ${ }^{126}$. The proposed models of CAG repeat instability all involve DNA slippage, with displacement of single stranded DNA at repeated sequences leading to mispairing of the complementary bases ${ }^{142}$. MutS $\beta$ identifies DNA loop-outs in the CAG tract and targets them for repair by MutL $\alpha$ or Mutl $\gamma$; incorrect repair of the loop-outs could introduce short incremental expansions ${ }^{143}$ (Fig. 1). MutS $\alpha$ does not seem to be involved in HTT CAG instability, which is likely to be because it recognises small DNA loop outs of 1-2 bases, rather than the longer loop outs targeted by MutS $\beta^{144}$. In individuals with DM1, clusters of slipped DNA structures are found in tissues with the highest levels of repeat instability, including heart and cortex, but not in the cerebellum, which shows little or no instability ${ }^{142}$. A study of DNA oligonucleotides showed that

259 the stability of these DNA loop-outs at CAG, CTG and CGG repeats is correlated with the threshold

260 for repeat expansion and the expansion rate ${ }^{145}$. CAG.CTG repeat expansion occurs in post-mitotic neurons ${ }^{112,146}$ and continues when the cell cycle is arrested ${ }^{147}$, suggesting that expansion occurs during DNA repair or transcription. However, evidence also exists for replication-associated trinucleotide repeat instability ${ }^{148}$. The result of this kind of instability depends on the direction of DNA replication, with expansion of CAG and CTG repeats occurring when CAG is on the lagging strand [G], as is the case in HD, SCA7 and DM1 ${ }^{149}$, and contraction occurring when CTG is on the lagging strand. This 
direction-dependence might be because CAG and CTG repeats have different propensities to form

267 slipped structures, or are processed differently by repair machinery.

268 Excitingly, most of the HD-modifying variants and pathways converge on specific DNA repair

269

270

271

272

273

274

275

276

277

278

279

280

281

282

283

284

285

286

287

mechanisms, particularly mismatch repair, and influence somatic instability ${ }^{98,110,112,117,122}$. These observations suggest that downregulation of MSH3, MutL $\alpha$, MutL $\gamma$ and LIG1, the inhibition of interactions between them, or the upregulation of FAN1 and PMS1, could reduce somatic CAG expansion and improve the course of HD (Acknowledgements

S.J.T. receives grant funding for her HD research from the Medical Research Council UK, the Wellcome Trust, the Rosetrees Trust, NIHR North Thames Local Clinical Research Network, UK Dementia Research Institute, Wolfson Foundation for Neurodegeneration and the CHDI Foundation. This work was in part supported by the UK Dementia Research Institute, and research grant funding from the Wellcome Trust to S.J.T. and M.F. (ref 200181/Z/15/Z). M.F. received a PhD studentship from the Medical Research Council UK, a Clinical Lectureship from the UK Dementia Research Institute and Health Education England, and grant funding from the Rosetrees Trust and the Academy of Medical Sciences. C.A.R. receives funding for HD research from NIH and CHDI. This work was supported in part by NINDS 2R01NS086452-06 (GRANT12516201). E.W. receives funding from the Medical Research Council UK (Clinician Scientist Fellowship MR/M008592/1), CHDI Foundation, the Wellcome Trust (Wellcome Collaborative Award In Science 200181/Z/15/Z), Huntington's Disease Society of America, the Hereditary Disease Foundation, the National Institute for Health Research Biomedical Research Centres funding scheme.

\section{Author contributions}

M.F and C.A.R researched data for the article, made substantial contributions to the discussion of the content of the article, wrote the article, and reviewed and edited the manuscript before submission. S.J.T. made a substantial contribution to the discussion of the content of the article, wrote the article, and reviewed and edited the manuscript before submission. E.W. made a substantial contribution to the discussion of the content of the article, and reviewed and edited the manuscript before submission.

\section{Competing interests}


293 In the past two years S.J.T has undertaken consultancy services, including advisory boards, with F.

294 Hoffmann-La Roche Ltd, Ixitech Technologies, Takeda Pharmaceuticals International and Triplet 295 therapeutics. All honoraria for these consultancies were paid to University College London, S.J.T's 296 employer. Through the offices of UCL Consultants Ltd, a wholly owned subsidiary of University 297 College London, S.J.T. has undertaken consultancy services for Alnylam Pharmaceuticals Inc., F. 298 Hoffmann-La Roche Ltd, GSK, Heptares Therapeutics, LoQus therapeutics, Takeda Pharmaceuticals 299 Ltd, TEVA Pharmaceuticals, Triplet therapeutics, UCB Pharma S.A., University College Irvine and 300 Vertex Pharmaceuticals Incorporated. S.J.T. receives grant funding for her research from Takeda 301 Pharmaceuticals and Cantervale Limited. C.A.R. is chair of the Research Advisory Board of the 302 Huntington Study Group. Within the past two years, C.A.R. has consulted for Annexon, Roche, Sage 303 and uniQure. Through UCL Consultants Ltd., a wholly owned subsidiary of University College London, 304 E.J.W. has served on scientific advisory boards for F. Hoffmann-La Roche, Ionis, Mitoconix, Novartis, 305 PTC Therapeutics, Shire, Takeda Pharmaceuticals and Wave Life Sciences. M.F. declares no competing interests. C.A.R. receives funding for $\mathrm{HD}$ research from Hoffman La Roche.

\section{Publisher's note}

Springer Nature remains neutral with regard to jurisdictional claims in published maps and institutional affiliations.

\section{Key points}

- Proteins involved in DNA repair, particularly mismatch repair, can modify the age of onset and rate of progression of $\mathrm{HD}$, likely by altering the rate of somatic expansion of CAG repeats in the Huntingtin gene.

- The modulation of DNA repair factors, such as MSH3, FAN1, PMS2 or LIG1, has therapeutic potential in HD and other repeat expansion diseases. 
- Nucleocytoplasmic transport is disrupted in HD by sequestration of nuclear pore components in Huntingtin (HTT) aggregates; modulation of nucleocytoplasmic transport is neuroprotective and might provide a novel therapeutic opportunity.

- Changes in cerebrospinal fluid and serum biomarkers, including neurofilament light chain and mHTT, are amongst the earliest detectable changes in HD and can predict disease onset and track progression.

- Intrathecally-delivered non-allele selective antisense oligonucleotides (ASOs) have successfully lowered HTT concentration in the central nervous system of individuals with HD, and trials of allele-specific ASOs are under way.

- Gene editing strategies for HTT lowering, including zinc finger proteins, transcription activator-like effector nucleases and CRISPR-Cas9, are currently in preclinical development, but need to be delivered via the injection of viral vectors, which can be challenging.

Fig. 1). Although variants in some mismatch repair components such as $M L H 1, M S H 2, M S H 6$ and PMS2 are associated with cancer, which indicates the need for caution ${ }^{150,151}$, the activity of these proteins can vary over a wide range in the general population without adverse effects and none of the modifiers of HD onset or progression have been identified as risk factors in GWA studies of cancer predisposition $^{98,152}$. Importantly, $M S H 3$ and $L I G 1$ are tolerant of loss of function mutations ${ }^{153}$, making them appealing targets for knockdown, which human genetic data suggest will be protective against $\mathrm{HD}^{98}$. Therefore, the modulation of DNA repair has great therapeutic potential in $\mathrm{HD}$, as well as other repeat expansion diseases.

\section{[H2] New findings in molecular pathogenesis}

Despite the decades that have passed since the discovery of the pathogenic HTT mutation in $1993^{154}$, the normal function of HTT and the primary pathogenic mechanism(s) of the mutation remain unclear. As our ability to intervene at the DNA, RNA and protein level improves, we need to understand the pathogenesis of HD to enable the identification of new therapeutic targets and understand the effects of modulating these targets. In this section we discuss key developments in our understanding of HD 
343 pathogenic mechanisms that have occurred in the last 5 years, including the toxicity of HTT fragments,

344 dysfunction of the nuclear pore and insights into the structure of the HTT protein.

\section{$345[$ [H3] Toxic exon 1 protein}

346 Two alternatively spliced transcripts arise from HTT. These transcripts differ in the length of their 3' 347 untranslated region (UTR) by $3 \mathrm{~kb}$, but give rise to the same HTT protein ${ }^{155}$. The longer transcript is 348 predominantly expressed in the brain, whereas the shorter version is more widespread ${ }^{155}$. However,

349 highly toxic N-terminal mHTT fragments also exist. Initially, these N-terminal fragments were 350 attributed to proteolytic cleavage of mHTT by caspases and calpains ${ }^{156}$, but $m H T T$ can also be misspliced to generate a short mRNA, which is translated into a highly toxic N-terminal fragment that contains exon $1^{43}$. This short exon 1 transcript was observed in mouse models of $\mathrm{HD}$ and in post-mortem

353 brain samples from individuals with the disease; levels were highest in the brains of individuals with 354 juvenile-onset $\mathrm{HD}^{43,157}$. The generation of exon $1 \mathrm{mRNA}$ is thought to result from splicing factors binding to the CAG repeat and allowing read-through into intron 1 , which contains a stop codon ${ }^{43}$. The aberrant splicing seems to be CAG length-dependent and is only seen in mutant alleles ${ }^{43}$. Mice expressing N-terminal huntingtin fragments develop a severe phenotype much earlier than those with a similar number of repeats in full-length $m H T T^{158}$. The extent to which the mis-splicing of HTT exon 1 contributes towards neuropathology in humans remains to be seen.

\section{[H3] Nuclear pore complex disruption}

361 The nuclear pore complex (NPC) is the main conduit by which proteins and RNA are actively transported between nucleus and cytoplasm, and consists of complexes of protein subunits called nucleoporins (NUP) that span the nuclear envelope (Fig. 2) ${ }^{159}$. Interestingly, recessive mutations in the gene encoding nucleoporin NUP62, which is located in the central channel of the NPC, cause infantile bilateral striatal necrosis ${ }^{160}$, suggesting a role for NPC dysfunction in the tissue specificity of HD pathology. Ran, which is a small protein involved in nuclear transport, is converted from its GDP-bound form (Ran-GDP) to its GTP-bound form (Ran-GTP) by RCC1 inside the nucleus, and is converted back 
369 NPC (Fig. 2a). Ran can diffuse freely within the cell, but because RCC1 is located in the nucleus and

370 RanGAP1 is located in the cytoplasm, a concentration gradient of Ran forms is established, with more

371 Ran-GTP in the nucleus and more Ran-GDP in the cytoplasm ${ }^{161}$. This gradient acts as a signal for

372 cellular processes ${ }^{161}$. During nuclear import, cargo proteins are released into the nucleus when their

373 transporter molecule, known as a karyopherin, interacts with Ran-GTP. Conversely, in nuclear export, cargo proteins are released into the cytoplasm when Ran-GTP is hydrolysed to Ran-GDP by RanGAP1

375 (Fig. 2a). The nuclear to cytoplasmic Ran gradient generated by RanGAP1 is critical, and its loss rapidly results in cell death ${ }^{162}$.

Interestingly, mHTT binds to RanGAP1 with greater affinity than the wild-type HTT protein does ${ }^{163}$. In one study, immunofluorescent detection of NPC proteins in brain tissue from mouse models of HD showed that RanGAP1 and the nucleoporins NUP62 and NUP88 are sequestered in mHTT aggregates, which grow with age and are most prominent in the striatum ${ }^{164}$. More RanGAP1 was sequestered as the disease progressed. Intrastriatal microRNA [G] (miRNA)-mediated knockdown of the small ubiquitinlike modifier (SUMO) ligase PIAS reduced mHTT aggregation ${ }^{153}$, and thereby restored RanGAP1 levels. In post-mortem brain samples from individuals with HD, mitochondrial, RanGAP1 and NUP62 were displaced from their normal perinuclear location into aggregates, the cytoplasm or the nucleus, consistent with disruption of nuclear transport ${ }^{164}$. Immunofluorescent detection of Ran showed that, compared with cells from healthy individuals, iPSC-derived neurons from individuals with HD had a disrupted Ran gradient, with more Ran-GDP in the cytoplasm and less Ran-GTP in the nucleus, which suggests a failure of active transport ${ }^{164}$. MAP2 is usually too large to cross the NPC by passive transport, but levels of nuclear MAP2 were higher in iPSC-derived neurons from individuals with HD than in cells from healthy individuals, suggesting that in HD the NPC is compromised and leaky. In mouse primary cortical neurons transfected with human HTT containing a wild-type 22 CAG repeat or an expanded 82 CAG repeat, a reporter bearing both nuclear import and export signals was observed mostly in the cytoplasm, suggesting nuclear import is particularly deficient. Interestingly, repeatassociated non-ATG translation HTT dipeptides also disturbed active and passive nuclear transport ${ }^{164}$. 
amyotrophic lateral sclerosis (ALS) and frontotemporal dementia (FTD) in humans, repeat-associated

397 non-ATG translation dipeptides sequestered NUPs in aggregates ${ }^{165}$, and in a human cell line these 398 dipeptides blocked the nuclear pore ${ }^{166}$.

399 Overexpression of RanGAP1 in mouse primary cortical neurons reduced the amount of cell death 400 caused by the expression of $\mathrm{mHTT}^{164}$. In Drosophila, overexpression of Ran rescued the neurodegeneration caused by expression of an N-terminal mHTT fragment, whereas overexpression of

402 a dominant negative form of Ran exacerbated neurodegeneration ${ }^{164}$. O-GlcNAcylation, a post403 translational modification in which an uncharged acetylated glucosamine (O-GlcNAc) is attached to a 404 serine or threonine residue, is vital for the localisation and function of nucleoporins ${ }^{167}$. A study that used immunofluorescent techniques to visualise O-GlcNAc residues in brain sections found that OGlcNAc levels in cortical cells were lower in a mouse model of HD than in wild-type mice ${ }^{164,127}$. OGlcNAcase removes O-GlcNAc modifications, and inhibition of O-GlcNAcase with Thiamet-G protected against mHTT-related cytotoxicity and restored nucleocytoplasmic transport in primary cortical neurons from a rodent model of $\mathrm{HD}^{164}$. Furthermore, inhibition of nuclear export with KPT350 was neuroprotective in a mouse model of demyelination ${ }^{168}$. A similar molecule, which also blocks nuclear export, reduced neurodegeneration in the eye of a drosophila model that expresses 30 GGGGCC repeats in $C 9 \operatorname{orf}^{7} 2^{169}$ and restored nucleocytoplasmic transport in rodent primary neurons that overexpress TDP4 $3^{170}$. These observations suggest that inhibition of nuclear export could compensate for the disruption of nuclear import that occurs in HD.

\section{5 [H3] HTT protein structure}

416 Some aspects of HTT protein structure were recently determined using cryo-electron microscopy

$417(\mathrm{EM})^{171}$. This new information could provide greater insight into the normal cellular functions of HTT, and the pathogenesis of $\mathrm{HD}^{171}$. The purification of HTT required co-expression and co-isolation with HAP-40 (Huntingtin-Associated Protein of $40 \mathrm{KDa}$ ), which binds tightly to HTT ${ }^{172}$. HAP-40 has roles in endosome function ${ }^{173}$, which is consistent with the role of HTT in vesicle transport. The cryo-EM

421 structure showed that HTT consists mainly of supercoiled alpha-helical structures termed "HEAT

422 Repeats", which had been suggested by the results of previous computational, biochemical, electron 
microscopy and mass spectrometry studies ${ }^{6,174-176}$. The full-length HTT protein bound to HAP-40 has a

424 compact shape, with three domains - an N-terminal domain, a bridge domain, and a C-terminal domain

425 - wrapped tightly around HAP-40. Unfortunately, several key domains of HTT were not resolved in

426 the cryo-EM structure. These unresolved domains include an $\mathrm{N}$-terminal domain that is approximately

427 the length of exon-1 and contains the poly-glutamine repeat, and a number of loops that are thought to

428 contain unstructured proteolytically sensitive regions. These loops contain many sites of post-

429 translational modification ${ }^{13,177}$, which can modulate the toxicity of mHTT, possibly by regulating HTT

430 proteolysis and the interaction of HTT with other proteins ${ }^{178}$. Thus, further studies of HTT structure and

431 biochemistry could provide more information on the normal function and pathogenic interactions of the

432 protein.

\section{3 [H1] New biofluid biomarkers}

434 Biomarkers are measurable indicators of the severity of a disease and can enable the measurement or

435 prediction of clinical progression, as well as the detection of therapeutically-induced improvement.

436 However, before a biomarker can be considered as a surrogate marker of a clinical endpoint, it must be

437 well understood in terms of disease pathobiology, and must meet strict requirements, including those

438 relating to measurability, accuracy, specificity and reproducibility ${ }^{179-181}$. mHTT is thought to be released

439 from damaged neurons ${ }^{182}$ and the concentration of mHTT in CSF samples can be reliably quantified

440 with ultra-sensitive immunoassays that have been validated for use in clinical trials ${ }^{183,184}$. The

441 concentration of mHTT in the CSF of individuals with HD correlates with disease stage and severity,

442 which is determined by age at onset, disease burden score, and Unified Huntington's Disease Rating

443 Scale (UHDRS) motor score ${ }^{183-185}$. CSF mHTT concentration was also the key pharmacodynamic

444 biomarker used in the first clinical trial to demonstrate dose-dependent mHTT-lowering with an

445 antisense oligonucleotide (ASO) in individuals with $\mathrm{HD}^{186}$.

446 Neurofilament light protein (NfL) is found principally in axons and is released by neuronal damage, for

447 example, in one study serum NfL concentration rose within two weeks of head trauma, compared with

448 uninjured participants, and normalised after 3 months ${ }^{187}$. In several studies, CSF NfL concentration was

449 higher in individuals with HD than in healthy individuals, increased with disease progression and 
predicted the rate of progression in individuals with $\mathrm{HD}^{188-192}$. A strong correlation between CSF and

451 plasma NfL levels was observed, which suggests that NfL originates in the CSF ${ }^{191}$. In a mouse model

452 of HD, both CSF and plasma levels of NfL were correlated with the degree of brain atrophy and the severity of disease, as determined by motor function and body weight ${ }^{193}$. Plasma NfL levels were also higher in individuals with HD than controls, increased with disease severity and predicted the degree of progressive brain atrophy ${ }^{191,194}$. In premanifest HD carriers, plasma NfL levels predicted the likelihood of clinical onset within the next three years and the rate of subsequent disease progression, as measured by cognitive, functional, and brain atrophy measures ${ }^{191,194}$. When compared with CSF NfL, plasma NfL was a better predictor of the rate of clinical progression, but CSF NfL was more strongly associated with brain volume measures than plasma NfL was. Rising concentrations of mHTT and NfL in biofluids seem to be the earliest detectable changes occurring in individuals with HD, and are followed by changes in brain imaging measures (for example, caudate atrophy), motor scores and then cognitive tests ${ }^{185}$. Plasma and CSF NfL were more strongly associated with clinical measures than CSF mHTT was, perhaps reflecting the direct link between brain atrophy and clinical manifestations of HD, or the complex contributions to the CSF mHTT assay signal, which is likely to be influenced by polyglutamine tract length, protein turnover and neuronal damage ${ }^{184}$.

466 In cross-sectional studies, CSF levels of the microglia-derived inflammatory mediator YKL40, the 467 immune-cell derived enzyme chitotriosidase, and the proinflammatory cytokine IL-6 were higher in 468 HD carriers than in healthy controls ${ }^{192,195}$. CSF levels of YKL40 also increased with disease 469 progression $^{192,195}$. These findings suggest a role for microglial activation and inflammation in HD and support the use of these biomarkers to study relevant pathways.

471 The concentration of tau was also robustly increased in the CSF of individuals with HD compared with 472 healthy controls ${ }^{196}$, and tau aggregation was observed in post-mortem brain tissue from individuals with $473 \mathrm{HD}^{162,197-199}$. Increased phosphorylation and abnormal splicing of tau were observed in the striata of 474 individuals with HD compared with controls ${ }^{200,201}$, and mHTT has been found to interact with tau in 475 cell and animal models of the disease ${ }^{202}$. However, whether tau pathology is involved in HD 
476 pathogenesis, is a general feature of neurodegeneration, or is an unrelated part of the aging process is

477 unclear $^{203}$.

478 It will be some time before any biomarker attains official regulatory approval for use as a surrogate 479 endpoint in studies of HD. However, biomarkers such as CSF and plasma NfL, and CSF mHTT, have 480 been used to interpret the effects of HTT-lowering therapies and are included in ongoing and planned 481 trials of similar agents ${ }^{204-206}$, which indicates that these markers are becoming increasingly useful and 482 informative.

\section{3 [H1] Therapeutic opportunities}

484 Currently, treatments for HD focus on the relief of symptoms like chorea, dystonia, and psychiatric and behavioural disturbance ${ }^{207}$. No disease-modifying treatments have been found, despite some candidate drugs showing positive results in preclinical studies ${ }^{208}$. Drugs for which efficacy trials have failed to meet their endpoints include the dopamine stabiliser Pridopidine ${ }^{209}$, phosphodiesterase 10A inhibitors $^{210-212}$, coenzyme Q10 ${ }^{213,214}$, creatine ${ }^{215}$, cysteamine ${ }^{216}$, the sirtuin-1 inhibitor Selisistat ${ }^{217,218}$, hydroxyquinoline $\mathrm{e}^{219}$, and the immunomodulators Sative ${ }^{220}$ and Laquinimod ${ }^{221}$. Limited evidence supports the use of human foetal striatal tissue transplants or autologous stem cell transplants to treat individuals with $\mathrm{HD}^{222-224}$, but much more work is needed to determine the efficacy of these cell replacement therapies. The failure of so many efficacy trials might be owing, in part, to the insensitivity of the selected endpoints, such as functional capacity and motor score, to subtle changes in disease course. A more likely explanation is that, because the pathogenic events that occur downstream from mHTT form a complex web, pharmacological targeting of individual pathways is either too difficult to achieve cleanly, or is insufficient to modify disease course.

497 Following these failed efficacy trials, the focus of research into HD therapeutics has shifted towards targeting the causative mutation at the RNA and DNA level ${ }^{225,226}$. HD is thought to be caused by toxic properties of $\mathrm{mHTT}^{5,227}$ and lowering expression of mHTT inhibits pathogenesis in cell and animal

500 models of the disease ${ }^{186,226,228-231}$. However, loss of normal wild-type HTT might also contribute to 501 pathogenesis ${ }^{13,232}$, and HTT-lowering therapies could exacerbate this potential haploinsufficiency. Htt 
502 knockout is embryonically lethal in mice ${ }^{11,12,233}$ and conditional deletion of $\mathrm{Htt}$ in the forebrain shortly

503 after birth leads to a progressive degenerative neurological phenotype ${ }^{234}$. Evidence suggests that, in 504 adult mice, HTT has several roles, including as a scaffold protein ${ }^{235,236}$, in intracellular trafficking ${ }^{237-241}$, 505 transcriptional regulation ${ }^{242-244}$ and synaptic connectivity ${ }^{245-247}$. The phosphorylation of HTT in 506 response to DNA damage suggests that the protein has a role in the DNA damage response ${ }^{248}$. Partial knockdown of HTT in adult animals is well tolerated in multiple species, including non-human

508 primates ${ }^{225,249-252}$. Deletion of $\mathrm{Htt}$ in 4-month-old and 8-month-old mice caused no pathological or motor 509 effects during 5 months of observation ${ }^{253}$. Individuals with heterozygous inactivation of $H T T$ have no 510 detectable symptoms ${ }^{254}$.

511 The approaches used to reduce HTT expression, a process known as "HTT lowering", include RNA interference (RNAi), ASOs and small molecule modulators of RNA processing (Fig. 3). The suppression of mHTT expression without affecting wild-type HTT expression, known as "alleleselective HTT lowering", by targeting the CAG tract ${ }^{255-257}$ or variants inherited along with the HTT

515 CAG expansion ${ }^{258-260}$, is desirable, but challenging. Such allele-selective agents could have off-target 516 effects, for example, at other CAG repeat-containing regions ${ }^{261}$. Therapies that target HTT CAG 517 expansion-linked variants would only be effective in individuals with the linked variant, and as no one variant is present in all individuals with expanded HD alleles, at least three such therapies would be needed to treat up to $80 \%$ of individuals with $\mathrm{HD}^{262-264}$. The assigning, or 'phasing', of variants to the mutant and wild-type alleles is critical, otherwise there could be a risk of lowering the wild-type allele.

521 Additionally, the need to target specific variants, as opposed to the whole gene or transcript, restricts 522 the choice of sequences, which might limit the potency and selectivity of the resulting therapy ${ }^{225}$.

523 Currently, both allele-selective and non-allele-selective methods are under development.

\section{4 [H2] RNA-targeting approaches}

\section{$525[$ [H3] RNAi}

526 RNAi is an endogenous cellular process that degrades mature, spliced mRNAs ${ }^{265}$. During this process, 527 non-coding miRNAs form hairpin structures, and the antisense guide strand of these structures guides 528 the RNA-induced silencing complex (RISC) to bind to a complimentary mRNA target, leading to 
529 mRNA cleavage and translational repression ${ }^{266}$. Small interfering RNAs (siRNAs) are similar to 530 miRNAs, but are derived from longer double-stranded RNA, do not form hairpins and are more target531 specific ${ }^{267}$. The main challenge facing the development of RNAi therapeutics for HD is introducing 532 synthetic siRNAs and/or miRNAs into cells most vulnerable to the disease, such as the striatum. The 533 lowering of HTT expression with siRNAs improved phenotype and neuropathology in mouse models of $\mathrm{HD}^{249,268-275}$.

535 Delivering RNAi-inducing therapies into brain cells is challenging ${ }^{226}$. Most commonly, viral 536 transduction of siRNAs or miRNAs is required for stable induction of RNAi and permanent suppression 537 of HTT translation, although cellular entry has been improved with chemical modifications, liposomes 538 and nanoparticles ${ }^{276}$. Recombinant adeno-associated viruses (AAV) and lentiviruses are non539 pathogenic, minimally immunogenic and cannot replicate ${ }^{277}$. AAVs provide stable expression of a 540 construct in non-dividing cells from nuclear episomes, which are extra-chromosomal genetic material, 541 as opposed to integrating into the host genome, as in the case of lentiviruses ${ }^{277}$. Viral vectors typically 542 need to be injected into the target brain regions such as the striatum, as they cannot cross the blood543 brain barrier. However, this route of administration carries additional risk and tissue distribution might 544 be limited ${ }^{278}$.Viruses that are designed to be administered by peripheral intravenous injection, cross the 545 blood brain barrier, and transduce neurons and glia are currently under development, and include 546 AAV9 ${ }^{279}$ and AAV-PHP.B ${ }^{280,281}$. The challenges involved in developing RNAi-inducing therapies 547 include the risks of off-target knockdown ${ }^{282}$, overwhelming the RNAi degradation pathway ${ }^{283,284}$, 548 immunogenicity ${ }^{285}$ and the presence of virus-neutralising antibodies ${ }^{286}$. Regardless, a phase II trial of 549 intracerebrally injected, AAV2-encapsulated nerve growth factor RNA in individuals with Alzheimer 550 disease has shown that virally-delivered gene therapy can be safe and well-tolerated ${ }^{287}$.

551 Patisiran, an siRNA designed to treat hereditary transthyretin (TTR)-mediated amyloidosis, is the first 552 FDA approved therapy that uses lipid nanoparticle delivery ${ }^{288,289}$. The lipid nanoparticles containing the 553 siRNA are administered intravenously and are delivered to the liver, which is the primary site of TTR 554 production, although studies have shown that lipid nanoparticles can also convey RNAi therapy to the $555 \mathrm{CNS}^{290-293}$. 
557 in individuals with HD. The therapy being tested in this trial is AMT-130 (uniQure), an AAV5558 delivered, non-allele selective $H T T$ miRNA $^{294}$. In rodent models of HD, bilateral striatal injection of

559

560

561

562

563

564

565

566

567

568

569

570

571

572

573

574

575

576

577

578

579

580

581

582 AMT-130 reduced striatal levels of HTT and improved neuropathology compared with saline injection $^{231}$. Similarly, in a minipig model of HD, AMT-130 produced a sustained, dose-dependent reduction in HTT in the striatum 3-6 months post-administration, as well as smaller reductions in other brain regions ${ }^{295}$. Spark Therapeutics and Voyager Therapeutics are developing AAV1-delivered nonallele selective $H T T$ miRNA therapies. Striatal injection of an miRNA developed by Spark Therapeutics improved neuropathology and motor phenotype in rodent models of HD compared with injection of an empty vector ${ }^{250}$, and safely lowered HTT in wild-type non-human primates ${ }^{251}$. Striatal injection of the miRNA developed by Voyager Therapeutics, VY-HTT01, lowered HTT levels in a mouse model of $\mathrm{HD}^{275}$, and in a preliminary study of combined putaminal and thalamic injection of VY-HTT01 in primates the treatment produced well-tolerated, sustained knockdown of mHTT RNA in the striatum, with a smaller reduction in cortex ${ }^{296,297}$.

\section{[H3] ASOs}

ASOs are synthetic, single-stranded, modified DNA molecules that bind to complimentary stretches of mRNA, thus inducing degradation of this mRNA by RNAse $\mathrm{H}^{298}$. ASOs act further upstream than RNAi approaches, binding pre-mRNA as opposed to mature transcripts. This pre-mRNA binding means that ASOs can bind intronic as well as exonic regions, providing more potential binding targets ${ }^{299}$. ASOs diffuse well through the CNS and are taken up by neuronal and glial cells, which means viral vectors are not needed for delivery. One benefit of not requiring viral vectors is that the effects of ASOs on gene expression are reversible and titratable $228,299,300$. However, ASOs are not suitable for oral administration and do not cross the blood brain barrier, so they must be injected intrathecally, intraventricularly or intraparanchymally, all of which result in limited spatial distribution of the ASO in the brain ${ }^{225,226,299}$. Following intrathecal delivery, ASO levels are highest in brain regions that are adjacent to the CSF spaces ${ }^{301}$, although in post-mortem studies in individuals treated with intrathecal Nusinersen (Spinraza; Biogen), an ASO that modulates splicing of survival motor neuron protein 2 
583 (SMN2), the ASO was observed in both cortical and brainstem neurons and glia ${ }^{302}$. In a conditional 584 mouse model of HD that expresses mHTT in either the striatum or cortex, lowering HTT expression in 585 the cortex was more beneficial than striatal HTT lowering, but simultaneously lowering HTT levels in 586 both brain regions resulted in the greatest reduction in motor and behavioural deficits and brain 587 atrophy ${ }^{303}$. Intrathecal delivery of ASOs to treat HD would require repeated lumbar puncture, which could be avoided by the use of medical devices such as implantable pumps, or by chemical modification of the ASOs to enable peripheral administration and CNS penetration, although such compounds are still in development and are not yet ready for clinical translation $299,300,304,305$. ASOs have shown efficacy in other neurodegenerative diseases; Nusinersen, which is delivered by intrathecal boluses, dramatically improved motor function and survival in infants with spinal muscular atrophy type $1^{306}$ and has been approved by the FDA. IONIS pharmaceuticals have developed an intrathecally delivered ASO that targets superoxide dismutase 1 (SOD1) and was well tolerated by individuals with ALS-causing SOD1 mutations ${ }^{307}$. Furthermore, in conjunction with Biogen, IONIS have begun a phase I-IIa trial ${ }^{308}$ of a more potent SOD1 ASO, Toferson (IONIS-SOD1 ${ }_{\mathrm{Rx}}{ }^{\circ}$ Biogen/Ionis). In mouse models of $\mathrm{HD}$, intraventricular infusion of a non-allele-selective HTT ASO reduced the expression both wild-type and mutant HTT mRNA and protein, leading to reduced transcriptional dysregulation, improved motor phenotype and increased survival compared with saline infusion ${ }^{186,228,230}$. These effects were particularly marked when the ASO was administered earlier in the disease course. Suppression of HTT mRNA and protein levels was sustained for 12 weeks after administration of the ASO and phenotypic improvement outlasted this knockdown by at least 4 weeks. In another study that used a mouse model of $\mathrm{HD}$, an ASO-mediated $\sim 50 \%-70 \%$ reduction in total HTT improved motor and cognitive deficits to a similar degree as a $~ 50 \%-70 \%$ reduction in mHTT only ${ }^{309}$. Although this evidence supports ongoing clinical trials of non-allele selective HTT ASOs, alleleselective strategies remain of interest as they are theoretically less likely to cause the long-term side effects that are associated with the reduction of the wild-type protein. Reductions of mHTT by $50 \%$ or more are consistently associated with phenotypic improvement in animal models of $\mathrm{HD}^{226}$. In wild-type non-human primates, a 21 day lumbar intrathecal infusion of a non-allele specific HTT ASO produced 
610 a sustained reduction in HTT for at least 3 months, relative to vehicle-treated control animals, and was

611 well-tolerated ${ }^{186,228}$.

612 The results of a phase I-IIa trial of IONIS pharmaceutical's non-allele selective ASO HTT $\mathrm{Rx}_{\mathrm{R}}$ 613 (RG6042/tominersen; Ionis/Roche) were published in 2019 ${ }^{186}$. In this trial, adults with early-stage HD 614 received a total of four administrations of $\mathrm{HTT}_{\mathrm{Rx}}$, one administration every 4 weeks as an intrathecal 615 bolus injection, via lumbar puncture. Of the 46 participants that were enrolled in the trial, 34 were 616 randomly assigned to receive $\mathrm{HTT}_{\mathrm{Rx}}$ and 12 were randomly assigned to receive placebo. The individuals 617 receiving $\mathrm{HTT}_{\mathrm{Rx}}$ were divided into five cohorts that each received a different dose of the treatment from 618 10-120 mg. HTT $_{\mathrm{Rx}}$ was well-tolerated, with all participants completing the trial and only mild, lumbar 619 puncture-related adverse effects, such as transient headache, being reported. Importantly, the groups of 620 participants who received the ASO showed dose-dependent reductions in CSF mHTT concentration compared with the participants who received placebo (Fig. 4a), which is clear evidence of target engagement. This mHTT lowering began by the first timepoint, which was 28 days after the first

623 administration, and the downward trend continued even between the final two administrations of the 624 ASO, suggesting that mHTT levels would fall further with continued treatment. In the groups receiving 625 the two highest HTT $_{\text {Rx }}$ doses, CSF mHTT was 40-60\% lower than in the group receiving placebo. This reduction exceeds the degree of mHTT lowering that produced clinical benefit in animal models 186,228,309. Pharmacokinetic modelling predicted that this $40-60 \%$ reduction in CSF mHTT would correspond to a $55-85 \%$ reduction in mHTT in the cortex and a $20-50 \%$ reduction in mHTT in the caudate. Ventricular volume was larger in the groups of participants receiving the two highest doses of

630 ASO than in the group of participants receiving placebo, but no concomitant decreases in whole-brain 631 volume were observed. This increase in ventricular volume might reflect local parenchymal 632 pseudoatrophy resulting from the resolution of inflammation or gliosis.

633 At the final timepoint, which was between 16 and 20 weeks after the first administration, CSF NfL concentration also showed a small dose-dependent increase in the groups of participants receiving

$635 \mathrm{HTT}_{\mathrm{Rx}}$ compared with the group receiving placebo; this increase had resolved 7-27 months later ${ }^{186,185}$.

636 After the $\mathrm{HTT}_{\mathrm{Rx}}$ trial, all participants were enrolled in a 15-month open-label extension study in which 
637 they received the $120 \mathrm{mg}$ of the ASO every 4 or 8 weeks. In the extension study, CSF NfL 638 concentrations increased between baseline and $\sim 5$ months, and then returned to baseline levels by $\sim 9$ 639 months despite continued ASO dosing ${ }^{310}$. These observations are as yet unexplained, and it remains to 640 be seen whether NfL levels will fall below baseline (or below the expected level after disease 641 progression is taken into account) with continued treatment. However, the resolution of this increase in 642 CSF NfL concentration despite continued treatment argues against a long-term adverse effect of total 643 huntingtin-lowering ${ }^{311}$.

644 Although this first-in-human trial was not powered to detect clinical change, HTT lowering was 645 associated with improvements in a novel clinical rating score, the composite Unified Huntington's 646 Disease Rating Scale (cUHDRS) (Fig. 4b). This rating scale combines four assessments: Total 647 Functional Capacity, Total Motor Score (TMS), Symbol Digit Modalities Test (SDMT) and Stroop 648 Word Reading. These assessments were selected, using data from large cohort studies, for their 649 sensitivity to clinical progression, correlation with brain atrophy, and coverage of motor and cognitive 650 domains ${ }^{312,313}$. Independent improvements in the TMS and SDMT components of the cUHDRS were 651 also seen with HTT lowering. Roche is now performing a phase III trial ${ }^{206}$ to investigate the clinical 652 efficacy of $\mathrm{HTT}_{\mathrm{Rx}}$, with cUHDRS and total functional capacity as primary endpoints.

$653 \mathrm{HTT}_{\mathrm{Rx}}$ targets mutant and wild-type HTT mRNA equally; however, Wave Life Sciences is currently performing phase Ib-IIa clinical trials of two allele-selective HTT ASOs that target SNPs inherited with the mutant allele ${ }^{204,205,314}$. Biomarin have another allele-specific HTT ASO in preclinical development,

656 that targets the expanded CAG repeat itself, although this strategy risks off-target knockdown of other

657 CAG repeat-containing genes ${ }^{315}$. Other potential non-allele selective ASO strategies for HTT lowering 658 include binding the AUG translation initiation site, or targeting intron-exon boundaries to modulate 659 splicing 299.

660 Alternative toxic species of HTT present a challenge to some HTT lowering therapies. A HTT exon 1 661 protein might not be affected by the RNAi and ASOs currently being trialled, but those binding exon 1 662 mRNA itself should be effective. Repeat-associated non-ATG translation of HTT dipeptides might not 
663 be fully prevented by RNAi, which acts on mature mRNA, but is expected to be inhibited by ASOs as

664 they target pre-mRNA ${ }^{226,316}$.

665 Whether total HTT lowering or allele-selective mHTT lowering is the optimal approach is unclear, but

666 the results of ongoing clinical trials will hopefully provide answers. Encouragingly, an expression-

667 lowering variant in the HTT promoter was associated with a delay in disease onset of 9.3 years when

668 on the expanded CAG allele, or 3.9 years when on the normal CAG allele, suggesting that total HTT

669 lowering is beneficial in $\mathrm{HD}^{317}$. Total HTT lowering approaches have several advantages over allele-

670 specific approaches, as they permit the targeting of any HTT region and mean a single agent can be

671 used in everyone with HD. Current total HTT lowering approaches aim for partial knockdown and are

672 initiated in adulthood, thus avoiding potential adverse effects on development.

\section{3 [H3] Small molecule approaches}

674 Given the challenges of delivering RNAi and ASO therapies to the brain, small molecules that reduce

675 HTT expression and can be taken orally are highly desirable. PTC Therapeutics have identified orally-

676 delivered compounds that can alter pre-mRNA splicing of $H T T$ and reduce levels of the protein in the

677 brains of HD mice ${ }^{318}$; however, owing to a lack of binding specificity, these compounds carry a higher

678 risk of off-target effects than targeted RNAi and ASOs. A similar approach has been developed for the

679 treatment of SMA; the orally available splicing modulator RG7800 (PTC Therapeutics/Roche) was

680 used to alter SMN2 splicing to include exon 7, which is the only difference between SMN1 and SMN2

681 proteins. Administration of RG7800 reduced the disease phenotype in a mouse model of SMA, relative

682 to vehicle-treated controls, by compensating for the lack of SMN1 ${ }^{319}$. A phase Ib-IIa trial of RG7800

683 was terminated because ocular complications of the treatment were observed in non-human primates ${ }^{320}$.

684 However, a phase I study of Risdiplam (RG7916; PTC Therapuetics/ Roche), which increases SMN

685 protein levels, was completed in $2016^{321}$, and phase II trials are now underway ${ }^{322-324}$. A different

686

approach, being taken by Nuredis, is to design small molecles that bind to transcription elongation

687 cofactors, which are required for transcription through expanded CAG repeats ${ }^{325,326}$. 
689 DNA-targeting approaches aim to modify the HTT genetic sequence or its transcription, and typically 690 combine a specific DNA-binding element with an effector, such as a nuclease. The three main DNA691 targeting approaches are zinc-finger nucleases $(\mathrm{ZFNs})^{327}$, transcription activator-like effector nucleases (TALENs) ${ }^{328}$, and CRISPR-Cas9 ${ }^{329}$. The ZFN DNA-binding element consists of an array of zinc-finger peptides, each of which binds a sequence of 3-5 nucleotides. Zinc-finger proteins (ZFPs) alone, or containing an active repressor, can selectively target the expanded CAG repeat and reduce its transcription $^{257}$. In one study, several allele-specific ZFP transcriptional repressors were identified from a series of ZFPs designed to target CAG repeats in different frames ${ }^{273}$. AAV-mediated delivery of one of these ZFPs selectively reduced mHTT expression in stem-cell derived neurons from individuals with HD. Furthermore, in three different mouse models of HD, striatal injection of the ZFP reduced the amount of neuropathology and improved some behavioural phenotypes, compared with injection of a GFP-only vector. This improvement was observed despite limited tissue distribution of the ZFP. Offtarget knockdown of several other CAG repeat-containing genes was observed, although this knockdown was not associated with toxicity in vivo. As an alternative to ZFPs with transcriptional repressors, genome editing with ZFNs could be used to disrupt or correct the CAG expansion ${ }^{330}$. have the potential to be more efficient and specific than ZFNs, and have been used to shorten the expanded CAG repeat ${ }^{331}$ and suppress $H T T$ transcription $^{332}$ in vitro. However, TALENs require a thymine base to be present at the end of the target sequence, which means they have fewer potential targets than $\mathrm{ZFNs}^{330}$.

709

CRISPR-Cas9 is a naturally occurring bacterial adaptive immune response to viruses ${ }^{329}$. A single-guide RNA (sgRNA) binds its complementary target sequence, such as the DNA of an invading viral pathogen; this binding requires the presence of a $3^{\prime}$ protospacer-adjacent motif sequence. Cas9 is a RNA-guided DNA nuclease that is recruited to the site of sgRNA binding and cleaves the DNA ${ }^{330}$. In cell and animal models of HD, CRISPR-Cas9 has been used to lower HTT levels via several different 
714 effectors, for example blocking HTT transcription ${ }^{333}$, excising CAG repeats ${ }^{334}$, or selectively

715 inactivating expanded CAG alleles by targeting associated SNPs ${ }^{259,260}$.

716 These three DNA-targeting approaches could provide long-term treatment for HD from a single

717 administration, and could prevent all of the pathogenic events that occur downstream of $m H T T$,

718 including RNA-mediated toxicity, alternative splicing and repeat-associated non-ATG translation.

719 Additionally, correction of the HTT mutation would eliminate intergenerational transmission of HD ${ }^{335}$.

720 However, these approaches require viral delivery, reach only limited brain regions and are usually

721 irreversible. In addition, DNA-targeting raises concerns about potential off-target effects elsewhere in

722 the genome ${ }^{336}$, insertional mutagenesis and immunogenicity ${ }^{337}$.

\section{$723[$ [H1] Conclusions}

724 Substantial progress has been made in our understanding of the pathogenesis of HD, while

725 developments in genetic technology and the availability of large cohorts of individuals with HD have

726 led to the identification of new genetic modifiers of the disease. Somatic instability of the CAG repeat

727 occurs in the tissues that are most vulnerable to HD pathology, particularly the striatum, and the degree

728 of instability negatively correlates with age at disease onset. Genetic association studies have shown

729 that DNA repair components, particularly those involved in mismatch repair, modify somatic instability

730 and disease course. The process underlying this instability is likely to involve DNA loop-outs in the

731 CAG tract, which are targeted by MutS $\beta$, leading to attempted repair that might introduce incremental

732 expansions. Reducing the levels of the pro-instability factors MSH3, PMS2 or LIG1, or inhibiting their

733 function, is expected to reduce somatic instability and be well tolerated. Increased FAN1 expression

734 decreases somatic instability and delays disease onset, suggesting its upregulation would be protective

735 against HD. Excitingly, modulation of these DNA repair components can also reduce the instability of

736 other pathogenic repeat sequences, suggesting that these potential therapeutic opportunities might also

737 be effective in other repeat expansion diseases. mHTT sequesters components of the NPC in aggregates,

738 disrupting nucleocytoplasmic transport. Modulation of nuclear transport pathways was protective in

739 cell models of $\mathrm{HD}$, which could open up new possibilities for therapeutic intervention. 
740 CSF can be readily sampled throughout a clinical trial, and offers more direct access to CNS proteins

741 than other biofluids. NfL is released into CSF, then into plasma, following neuronal damage. CSF and

742 plasma concentrations of NfL strongly correlate with disease progression, and could be used as

743 biomarkers and surrogate endpoints for clinical trials. mHTT is also likely to be released from damaged

744 neurons, and an increase in CSF mHTT is the earliest detectable change in premanifest HD.

745 After decades of disappointing clinical trial results, we finally seem to be seeing encouraging results

746 from trials of rationally-designed disease-modifying therapies for HD. The first trial of an ASO has

747 reported successful mHTT lowering, with good safety and tolerability ${ }^{186}$. A larger trial aimed at

748 assessing the efficacy of this ASO is underway, as well as trials of mutant allele-specific ASOs ${ }^{204,205,314}$.

749 These early trials are focussing on early manifest disease, looking to see whether we can preserve

750 function. The next step will be to try and push back disease onset in premanifest HD carriers, although

751

this approach presents its own challenges, and will require the development of a battery of clinical,

752

biochemical and imaging biomarkers to demonstrate efficacy. Ultimately, the aim is to find treatments

753

that offer lifelong, safe, sustained benefit from a single administration; this goal is still a long way off,

754 but might eventually be achieved by gene editing strategies that remove CAG repeats, introduce

interruptions or inactivate the mutant allele.

7561 Bates, G. P. et al. Huntington disease. Nature Reviews Disease Primers, 15005 (2015).

7572 Paulson, H. Repeat expansion diseases. Handbook of clinical neurology 147, 105-123

758 (2018).

7593 Evans, S. J. et al. Prevalence of adult Huntington's disease in the UK based on

760 diagnoses recorded in general practice records. Journal of neurology, neurosurgery,

761

762 and psychiatry 84, 1156-1160 (2013).

763

4 Langbehn, D. R., Hayden, M. R. \& Paulsen, J. S. CAG-repeat length and the age of onset in Huntington disease (HD): a review and validation study of statistical approaches. American journal of medical genetics. Part B, Neuropsychiatric genetics : the official publication of the International Society of Psychiatric Genetics 153b, 397-408 (2010). Ross, C. A. et al. Huntington disease: natural history, biomarkers and prospects for therapeutics. Nature reviews. Neurology 10, 204-216 (2014).

Palidwor, G. A. et al. Detection of alpha-rod protein repeats using a neural network and application to huntingtin. PLoS computational biology 5, e1000304 (2009). Tartari, M. et al. Phylogenetic comparison of huntingtin homologues reveals the appearance of a primitive polyQ in sea urchin. Mol Biol Evol 25, 330-338 (2008). export signal regulates trafficking and aggregation of Huntingtin $(\mathrm{Htt})$ protein exon 1. The Journal of biological chemistry 288, 6063-6071 (2013). 

functional nuclear localization signal in the Huntington disease protein. Brain Res Mol Brain Res 33, 165-173 (1995).

10 Xia, J., Lee, D. H., Taylor, J., Vandelft, M. \& Truant, R. Huntingtin contains a highly conserved nuclear export signal. Human molecular genetics 12, 1393-1403 (2003).

780

11 Nasir, J. et al. Targeted disruption of the Huntington's disease gene results in embryonic lethality and behavioral and morphological changes in heterozygotes. Cell 81, 811-823 (1995).

12 Zeitlin, S., Liu, J. P., Chapman, D. L., Papaioannou, V. E. \& Efstratiadis, A. Increased apoptosis and early embryonic lethality in mice nullizygous for the Huntington's disease gene homologue. Nat Genet 11, 155-163 (1995).

785

786

Saudou, F. \& Humbert, S. The Biology of Huntingtin. Neuron 89, 910-926 (2016).

Rosas, H. D. et al. Cerebral cortex and the clinical expression of Huntington's disease: complexity and heterogeneity. Brain 131, 1057-1068 (2008).

789

15 Johnson, E. B. et al. Dynamics of cortical degeneration over a decade in Huntington's

790 Disease. Preprint at https://www.biorxiv.org/content/10.1101/537977v1 (2019).

791 Mann, D. M., Oliver, R. \& Snowden, J. S. The topographic distribution of brain atrophy in Huntington's disease and progressive supranuclear palsy. Acta Neuropathol 85, 553559 (1993).

794

17 Heinsen, H. et al. Cortical and striatal neurone number in Huntington's disease. Acta Neuropathol 88, 320-333 (1994).

795

796

Han, I., You, Y., Kordower, J.H., Brady, S.T. \& Morfini, G.A. Differential vulnerability of neurons in Huntington's disease: the role of cell type-specific features. $J$ Neurochem

798

799 113, 1073-1091 (2010).

19 Ehrnhoefer, D. E., Sutton, L. \& Hayden, M. R. Small changes, big impact: 800 posttranslational modifications and function of huntingtin in Huntington disease. Neuroscientist 17, 475-492 (2011).

801

802

20 Hensman Moss, D. J. et al. Huntington's disease blood and brain show a common gene

803

804 expression pattern and share an immune signature with Alzheimer's disease. Scientific Reports 7, 44849 (2017).

805 Hodges, A. et al. Regional and cellular gene expression changes in human Huntington's disease brain. Human molecular genetics 15, 965-977 (2006).

808

22 Pouladi, M. A., Morton, A. J. \& Hayden, M. R. Choosing an animal model for the study of Huntington's disease. Nature reviews. Neuroscience 14, 708-721 (2013).

809 Ramaswamy, S., McBride, J. L. \& Kordower, J. H. Animal models of Huntington's disease. ILAR J 48, 356-373 (2007).

812

$24 \mathrm{Li}, \mathrm{X}$. J. \& Li, S. Large Animal Models of Huntington's Disease. Current topics in behavioral neurosciences 22, 149-160 (2015). dystrophic neurites in brain. Science 277, 1990-1993 (1997).

26 Hoffner, G., Island, M. L. \& Djian, P. Purification of neuronal inclusions of patients with Huntington's disease reveals a broad range of $\mathrm{N}$-terminal fragments of expanded huntingtin and insoluble polymers. J Neurochem 95, 125-136 (2005). glutamine repeats form nuclear and cytoplasmic aggregates in cell culture. Human molecular genetics 7, 783-790 (1998). 
28 Ross, C. A. Intranuclear neuronal inclusions: a common pathogenic mechanism for glutamine-repeat neurodegenerative diseases? Neuron 19, 1147-1150 (1997).

29 Davies, S. W. et al. Are neuronal intranuclear inclusions the common neuropathology of triplet-repeat disorders with polyglutamine-repeat expansions? Lancet 351, 131133 (1998).

30 Saudou, F., Finkbeiner, S., Devys, D. \& Greenberg, M. E. Huntingtin acts in the nucleus to induce apoptosis but death does not correlate with the formation of intranuclear inclusions. Cell 95, 55-66 (1998).

31 Arrasate, M., Mitra, S., Schweitzer, E. S., Segal, M. R. \& Finkbeiner, S. Inclusion body formation reduces levels of mutant huntingtin and the risk of neuronal death. Nature 431, 805-810 (2004).

32 Slow, E. J. et al. Absence of behavioral abnormalities and neurodegeneration in vivo despite widespread neuronal huntingtin inclusions. Proceedings of the National Academy of Sciences of the United States of America 102, 11402-11407 (2005).

33 Pieri, L., Madiona, K., Bousset, L. \& Melki, R. Fibrillar alpha-synuclein and huntingtin exon 1 assemblies are toxic to the cells. Biophys J 102, 2894-2905 (2012).

34 Nucifora, L. G. et al. Identification of novel potentially toxic oligomers formed in vitro from mammalian-derived expanded huntingtin exon-1 protein. The Journal of biological chemistry 287, 16017-16028 (2012).

35 Lajoie, P. \& Snapp, E. L. Formation and toxicity of soluble polyglutamine oligomers in living cells. PLoS One 5, e15245 (2010).

36 Nagai, Y. et al. A toxic monomeric conformer of the polyglutamine protein. Nature structural \& molecular biology 14, 332-340 (2007).

37 Miller, J. et al. Identifying polyglutamine protein species in situ that best predict neurodegeneration. Nature chemical biology 7, 925-934 (2011).

38 Sahl, S. J., Weiss, L. E., Duim, W. C., Frydman, J. \& Moerner, W. E. Cellular inclusion bodies of mutant huntingtin exon 1 obscure small fibrillar aggregate species. Sci Rep 2, 895 (2012).

39 Leitman, J., Ulrich Hartl, F. \& Lederkremer, G. Z. Soluble forms of polyQ-expanded huntingtin rather than large aggregates cause endoplasmic reticulum stress. Nature communications 4, 2753 (2013).

40 Takahashi, T. et al. Soluble polyglutamine oligomers formed prior to inclusion body formation are cytotoxic. Human molecular genetics 17, 345-356 (2008).

41 Legleiter, J. et al. Mutant huntingtin fragments form oligomers in a polyglutamine length-dependent manner in vitro and in vivo. The Journal of biological chemistry 285, 14777-14790 (2010).

42 Ast, A. et al. mHTT Seeding Activity: A Marker of Disease Progression and Neurotoxicity in Models of Huntington's Disease. Molecular cell 71, 675-688 e676 (2018).

43 Sathasivam, K. et al. Aberrant splicing of HTT generates the pathogenic exon 1 protein in Huntington disease. Proc. Natl. Acad. Sci. U.S.A. 110, 2366-2370 (2013).

44 Sieradzan, K. A. et al. Huntington's disease intranuclear inclusions contain truncated, ubiquitinated huntingtin protein. Exp Neurol 156, 92-99 (1999).

45 Wang, C. E. et al. Accumulation of N-terminal mutant huntingtin in mouse and monkey models implicated as a pathogenic mechanism in Huntington's disease. Human molecular genetics 17, 2738-2751 (2008). 
46 Castiglioni, V., Onorati, M., Rochon, C. \& Cattaneo, E. Induced pluripotent stem cell lines from Huntington's disease mice undergo neuronal differentiation while showing alterations in the lysosomal pathway. Neurobiology of disease 46, 30-40 (2012).

47 The HD iPSC Consortium. Induced pluripotent stem cells from patients with Huntington's disease show CAG-repeat-expansion-associated phenotypes. Cell stem cell 11, 264-278 (2012).

48 Yang, W., Dunlap, J. R., Andrews, R. B. \& Wetzel, R. Aggregated polyglutamine peptides delivered to nuclei are toxic to mammalian cells. Human molecular genetics 11, 2905-2917 (2002).

875

876

877

878

Monsellier, E., Bousset, L. \& Melki, R. alpha-Synuclein and huntingtin exon 1 amyloid

879

50 Costanzo, M. et al. Transfer of polyglutamine aggregates in neuronal cells occurs in tunneling nanotubes. J Cell Sci 126, 3678-3685 (2013).

880

51 Herrera, F., Tenreiro, S., Miller-Fleming, L. \& Outeiro, T. F. Visualization of cell-to-cell transmission of mutant huntingtin oligomers. PLoS currents 3, RRN1210 (2011).

882

Babcock, D. T. \& Ganetzky, B. Transcellular spreading of huntingtin aggregates in the

883

884 Drosophila brain. Proc. Natl. Acad. Sci. U.S.A. 112, E5427-5433 (2015).

53 Pearce, M. M. P., Spartz, E. J., Hong, W., Luo, L. \& Kopito, R. R. Prion-like transmission of neuronal huntingtin aggregates to phagocytic glia in the Drosophila brain. Nature communications 6, 6768 (2015).

886

887

Pecho-Vrieseling, E. et al. Transneuronal propagation of mutant huntingtin contributes to non-cell autonomous pathology in neurons. Nat Neurosci 17, 10641072 (2014).

891

892

893

894

895

896

897

898

899

900

901

902

903

904

905

906

907

908

909

910

911

912

Kovacs, G. G. \& Budka, H. Prion diseases: from protein to cell pathology. Am J Pathol 172, 555-565 (2008).

56 Cicchetti, F. et al. Mutant huntingtin is present in neuronal grafts in Huntington disease patients. Ann Neurol 76, 31-42 (2014).

57 Lin, J. T. et al. Regulation of feedback between protein kinase A and the proteasome system worsens Huntington's disease. Mol Cell Biol 33, 1073-1084 (2013).

58 Cortes, C. J. \& La Spada, A. R. The many faces of autophagy dysfunction in Huntington's disease: from mechanism to therapy. Drug discovery today 19, 963-971 (2014).

59 Ravikumar, B. et al. Inhibition of mTOR induces autophagy and reduces toxicity of polyglutamine expansions in fly and mouse models of Huntington disease. Nat Genet 36, 585-595 (2004).

60 Liu, B. \& Hong, J. S. Role of microglia in inflammation-mediated neurodegenerative diseases: mechanisms and strategies for therapeutic intervention. The Journal of pharmacology and experimental therapeutics 304, 1-7 (2003).

61 Miller, J. R. et al. RNA-Seq of Huntington's disease patient myeloid cells reveals innate transcriptional dysregulation associated with proinflammatory pathway activation. Human molecular genetics 25, 2893-2904 (2016).

62 Ellrichmann, G., Reick, C., Saft, C. \& Linker, R. A. The Role of the Immune System in Huntington's Disease. Clinical and Developmental Immunology 2013, 1-11 (2013).

63 Palpagama, T. H., Waldvogel, H. J., Faull, R. L. M. \& Kwakowsky, A. The Role of Microglia and Astrocytes in Huntington's Disease. Frontiers in molecular neuroscience 12, 258 (2019).

913

Beal, M. F. et al. Neurochemical and histologic characterization of striatal excitotoxic lesions produced by the mitochondrial toxin 3-nitropropionic acid. The Journal of 

(1993).

65 Browne, S. E. \& Beal, M. F. The energetics of Huntington's disease. Neurochem Res 29, 531-546 (2004).

66 Mochel, F. et al. Abnormal response to cortical activation in early stages of Huntington disease. Mov. Disord. 27, 907-910 (2012).

920

67 Mochel, F. et al. Early alterations of brain cellular energy homeostasis in Huntington

921

922 disease models. The Journal of biological chemistry 287, 1361-1370 (2012).

923

924

925

926

927

928

929

930

931

932

933

934

935

936

937

938

939

940

941

942

943

944

945

946

947

948

949

950

951

952

953

954

955

956

957

958

959

68 Goebel, H. H., Heipertz, R., Scholz, W., Iqbal, K. \& Tellez-Nagel, I. Juvenile Huntington chorea: clinical, ultrastructural, and biochemical studies. Neurology 28, 23-31 (1978).

$69 \mathrm{Kim}, \mathrm{J}$. et al. Mitochondrial loss, dysfunction and altered dynamics in Huntington's disease. Human molecular genetics 19, 3919-3935 (2010).

70 Johri, A., Chandra, A. \& Flint Beal, M. PGC-1alpha, mitochondrial dysfunction, and Huntington's disease. Free Radic Biol Med 62, 37-46 (2013).

$71 \mathrm{Gu}, \mathrm{M}$. et al. Mitochondrial defect in Huntington's disease caudate nucleus. Ann Neurol 39, 385-389 (1996).

72 Browne, S. E. et al. Oxidative damage and metabolic dysfunction in Huntington's disease: selective vulnerability of the basal ganglia. Ann Neurol 41, 646-653 (1997).

73 Napoli, E. et al. Defective mitochondrial disulfide relay system, altered mitochondrial morphology and function in Huntington's disease. Human molecular genetics 22, 9891004 (2013).

74 Naia, L. et al. Activation of IGF-1 and insulin signaling pathways ameliorate mitochondrial function and energy metabolism in Huntington's Disease human lymphoblasts. Molecular neurobiology 51, 331-348 (2015).

75 Reynolds, N. C., Jr., Prost, R. W. \& Mark, L. P. Heterogeneity in 1H-MRS profiles of presymptomatic and early manifest Huntington's disease. Brain Res 1031, 82-89 (2005).

76 Jenkins, B. G., Koroshetz, W. J., Beal, M. F. \& Rosen, B. R. Evidence for impairment of energy metabolism in vivo in Huntington's disease using localized $1 \mathrm{H}$ NMR spectroscopy. Neurology 43, 2689-2695 (1993).

77 Antonini, A. et al. Striatal glucose metabolism and dopamine D2 receptor binding in asymptomatic gene carriers and patients with Huntington's disease. Brain 119 ( Pt 6), 2085-2095 (1996).

78 Feigin, A. et al. Metabolic network abnormalities in early Huntington's disease: an [(18)F]FDG PET study. J Nucl Med 42, 1591-1595 (2001).

79 Orr, A. L. et al. N-terminal mutant huntingtin associates with mitochondria and impairs mitochondrial trafficking. The Journal of neuroscience : the official journal of the Society for Neuroscience 28, 2783-2792 (2008).

80 Trushina, E. et al. Mutant huntingtin impairs axonal trafficking in mammalian neurons in vivo and in vitro. Mol Cell Biol 24, 8195-8209 (2004).

81 Shirendeb, U. et al. Abnormal mitochondrial dynamics, mitochondrial loss and mutant huntingtin oligomers in Huntington's disease: implications for selective neuronal damage. Human molecular genetics 20, 1438-1455 (2011).

82 Shirendeb, U.P. et al. Mutant huntingtin's interaction with mitochondrial protein Drp1 impairs mitochondrial biogenesis and causes defective axonal transport and synaptic degeneration in Huntington's disease. Human molecular genetics 21, 406-420 (2012). 
83 Cui, L. et al. Transcriptional repression of PGC-1alpha by mutant huntingtin leads to mitochondrial dysfunction and neurodegeneration. Cell 127, 59-69 (2006).

84 Choo, Y. S., Johnson, G. V., MacDonald, M., Detloff, P. J. \& Lesort, M. Mutant huntingtin directly increases susceptibility of mitochondria to the calcium-induced permeability transition and cytochrome c release. Human molecular genetics 13 , 1407-1420 (2004).

85 Panov, A. V. et al. Early mitochondrial calcium defects in Huntington's disease are a direct effect of polyglutamines. Nat Neurosci 5, 731-736 (2002).

86 Yano, H. et al. Inhibition of mitochondrial protein import by mutant huntingtin. Nat Neurosci 17, 822-831 (2014).

87 Yablonska, S. et al. Mutant huntingtin disrupts mitochondrial proteostasis by interacting with TIM23. Proc. Natl. Acad. Sci. U.S.A. 116, 16593-16602 (2019).

88 Marti, E. RNA toxicity induced by expanded CAG repeats in Huntington's disease. Brain Pathol 26, 779-786 (2016).

89 Li, L. B., Yu, Z., Teng, X. \& Bonini, N. M. RNA toxicity is a component of ataxin-3 degeneration in Drosophila. Nature 453, 1107-1111 (2008).

$90 \mathrm{Hsu}, \mathrm{R}$. J. et al. Long tract of untranslated CAG repeats is deleterious in transgenic mice. PLoS One 6, e16417 (2011).

91 Wang, L. C. et al. Muscleblind participates in RNA toxicity of expanded CAG and CUG repeats in Caenorhabditis elegans. Cell Mol Life Sci 68, 1255-1267 (2011).

92 Banez-Coronel, M. et al. RAN Translation in Huntington Disease. Neuron 88, 667-677 (2015).

93 Gao, F. B., Richter, J. D. \& Cleveland, D. W. Rethinking Unconventional Translation in Neurodegeneration. Cell 171, 994-1000 (2017).

94 Yang, S. et al. Lack of RAN-mediated toxicity in Huntington's disease knock-in mice. Proc. Natl. Acad. Sci. U.S.A. 117, 4411-4417 (2020).

95 Kennedy, L. et al. Dramatic tissue-specific mutation length increases are an early molecular event in Huntington disease pathogenesis. Human molecular genetics 12, 3359-3367 (2003).

96 Shelbourne, P. F. et al. Triplet repeat mutation length gains correlate with cell-type specific vulnerability in Huntington disease brain. Human molecular genetics 16, 11331142 (2007).

97 Swami, M. et al. Somatic expansion of the Huntington's disease CAG repeat in the brain is associated with an earlier age of disease onset. Human molecular genetics $\mathbf{1 8 ,}$ 3039-3047 (2009).

98 Genetic Modifiers of Huntington's Disease (GeM-HD) consortium. CAG Repeat Not Polyglutamine Length Determines Timing of Huntington's Disease Onset. Cell 178, 887-900.e814 (2019).

99 Telenius, $\mathrm{H}$. et al. Molecular analysis of juvenile Huntington disease: the major influence on (CAG)n repeat length is the sex of the affected parent. Human molecular genetics 2, 1535-1540 (1993).

100 Aronin, N. et al. CAG expansion affects the expression of mutant Huntingtin in the Huntington's disease brain. Neuron 15, 1193-1201 (1995).

101 Shelbourne, P. F. et al. Triplet repeat mutation length gains correlate with cell-type specific vulnerability in Huntington disease brain. Human molecular genetics 16, 11331142 (2007). 
102 Kennedy, L. Dramatic tissue-specific mutation length increases are an early molecular event in Huntington disease pathogenesis. Human molecular genetics 12, 3359-3367 (2003).

103 Ansved, T., Lundin, A. \& Anvret, M. Larger CAG expansions in skeletal muscle compared with lymphocytes in Kennedy disease but not in Huntington disease. Neurology 51, 1442-1444 (1998).

104 Squitieri, F., Ciarmiello, A., Di Donato, S. \& Frati, L. The search for cerebral biomarkers of Huntington's disease: a review of genetic models of age at onset prediction. European journal of neurology : the official journal of the European Federation of Neurological Societies 13, 408-415 (2006).

105 Kaplan, S., Itzkovitz, S. \& Shapiro, E. A universal mechanism ties genotype to phenotype in trinucleotide diseases. PLoS computational biology 3 (2007).

106 La Spada, A. R. Trinucleotide repeat instability: genetic features and molecular mechanisms. Brain Pathol 7, 943-963 (1997).

107 Wright, G. E. B. et al. Length of uninterrupted CAG repeats, independent of polyglutamine size, results in increased somatic instability and hastened age of onset in Huntington disease. Preprint at https://www.biorxiv.org/content/10.1101/533414v2 (2019).

108 Gusella, J. F., MacDonald, M. E. \& Lee, J. M. Genetic modifiers of Huntington's disease. Mov. Disord. 29, 1359-1365 (2014).

109 Wexler, N. S. et al. Venezuelan kindreds reveal that genetic and environmental factors modulate Huntington's disease age of onset. Proc. Natl. Acad. Sci. U.S.A. 101, 34983503 (2004).

110 Genetic Modifiers of Huntington's Disease (GeM-HD) consortium. Identification of Genetic Factors that Modify Clinical Onset of Huntington's Disease. Cell 162, 516-526 (2015).

111 Porro, A. et al. FAN1 interaction with ubiquitylated PCNA alleviates replication stress and preserves genomic integrity independently of BRCA2. Nature communications $\mathbf{8}$, 1073 (2017).

112 Goold, R. et al. FAN1 modifies Huntington's disease progression by stabilising the expanded HTT CAG repeat. Human molecular genetics 28, 650-661 (2018).

113 Zhao, X. N. \& Usdin, K. FAN1 protects against repeat expansions in a Fragile X mouse model. DNA repair $69,1-5$ (2018).

114 Ortega, Z. \& Lucas, J. J. Ubiquitin-proteasome system involvement in Huntington's disease. Frontiers in molecular neuroscience 7, 77 (2014).

115 Koyuncu, S. et al. The ubiquitin ligase UBR5 suppresses proteostasis collapse in pluripotent stem cells from Huntington's disease patients. Nature communications $\mathbf{9}$, 2886 (2018).

116 Pinto, R. M. et al. Mismatch repair genes Mlh1 and Mlh3 modify CAG instability in Huntington's disease mice: genome-wide and candidate approaches. PLoS genetics $\mathbf{9}$, e1003930 (2013).

117 Hensman Moss, D. J. H. et al. Identification of genetic variants associated with Huntington's disease progression: a genome-wide association study. The Lancet. Neurology 16, 701-711 (2017).

118 Iyer, R. R., Pluciennik, A., Napierala, M. \& Wells, R. D. DNA triplet repeat expansion and mismatch repair. Annual review of biochemistry 84, 199-226 (2015). 
1052

1053

1054

1055

1056

1057

1058

1059

1060

1061

1062

1063

1064

1065

1066

1067

1068

1069

1070

1071

1072

1073

1074

1075

1076

1077

1078

1079

1080

1081

1082

1083

1084

1085

1086

1087

1088

1089

1090

1091

1092

1093

1094

1095

1096

119 Dragileva, E. et al. Intergenerational and striatal CAG repeat instability in Huntington's disease knock-in mice involve different DNA repair genes. Neurobiology of disease 33, 37-47 (2009).

120 Tome, S. et al. MSH3 polymorphisms and protein levels affect CAG repeat instability in Huntington's disease mice. PLoS genetics 9, e1003280 (2013).

121 Anderson, D. D., Quintero, C. M. \& Stover, P. J. Identification of a de novo thymidylate biosynthesis pathway in mammalian mitochondria. Proc. Natl. Acad. Sci. U.S.A. 108, 15163-15168 (2011).

122 Flower, $\mathrm{M}$. et al. MSH3 modifies somatic instability and disease severity in Huntington's and myotonic dystrophy type 1. Brain 142, 1876-1886 (2019).

123 Andresen, J. M. et al. Replication of twelve association studies for Huntington's disease residual age of onset in large Venezuelan kindreds. J Med Genet 44, 44-50 (2007).

124 Holbert, S. et al. The GIn-Ala repeat transcriptional activator CA150 interacts with huntingtin: neuropathologic and genetic evidence for a role in Huntington's disease pathogenesis. Proc. Natl. Acad. Sci. U.S.A. 98, 1811-1816 (2001).

125 Kozlov, S. V. et al. Reactive Oxygen Species (ROS)-Activated ATM-Dependent Phosphorylation of Cytoplasmic Substrates Identified by Large-Scale Phosphoproteomics Screen. Molecular \& cellular proteomics : MCP 15, 1032-1047 (2016).

126 Massey, T. H. \& Jones, L. The central role of DNA damage and repair in CAG repeat diseases. Disease Models \& Mechanisms 11 (2018).

127 Howes, T. R. \& Tomkinson, A. E. DNA ligase I, the replicative DNA ligase. Sub-cellular biochemistry 62, 327-341 (2012).

128 Lopez Castel, A., Tomkinson, A. E. \& Pearson, C. E. CTG/CAG repeat instability is modulated by the levels of human DNA ligase I and its interaction with proliferating cell nuclear antigen: a distinction between replication and slipped-DNA repair. The Journal of biological chemistry 284, 26631-26645 (2009).

129 Tome, S. et al. Maternal germline-specific effect of DNA ligase I on CTG/CAG instability. Human molecular genetics 20, 2131-2143 (2011).

130 Gomes-Pereira, M., Fortune, M. T., Ingram, L., McAbney, J. P. \& Monckton, D. G. Pms2 is a genetic enhancer of trinucleotide CAG.CTG repeat somatic mosaicism: implications for the mechanism of triplet repeat expansion. Human molecular genetics 13, 1815-1825 (2004).

131 Bettencourt, C. et al. DNA repair pathways underlie a common genetic mechanism modulating onset in polyglutamine diseases. Ann Neurol 79, 983-990 (2016).

132 Morales, F. et al. A polymorphism in the MSH3 mismatch repair gene is associated with the levels of somatic instability of the expanded CTG repeat in the blood DNA of myotonic dystrophy type 1 patients. DNA repair 40, 57-66 (2016).

133 Nakatani, R., Nakamori, M., Fujimura, H., Mochizuki, H. \& Takahashi, M. P. Large expansion of $\mathrm{CTG} \cdot \mathrm{CAG}$ repeats is exacerbated by MutS $\beta$ in human cells. Scientific reports 5, 11020-11020 (2015).

134 Halabi, A., Fuselier, K. T. B. \& Grabczyk, E. GAA•TTC repeat expansion in human cells is mediated by mismatch repair complex MutL $\gamma$ and depends upon the endonuclease domain in MLH3 isoform one. Nucleic acids research 46, 4022-4032 (2018). 
135 Panigrahi, G. B., Slean, M. M., Simard, J. P. \& Pearson, C. E. Human Mismatch Repair Protein hMutL Is Required to Repair Short Slipped-DNAs of Trinucleotide Repeats. Journal of Biological Chemistry 287, 41844-41850 (2012).

136 Lin, Y., Dion, V. \& Wilson, J. H. Transcription promotes contraction of CAG repeat tracts in human cells. Nature structural \& molecular biology 13, 179-180 (2006).

137 Lin, Y. \& Wilson, J. H. Diverse effects of individual mismatch repair components on transcription-induced CAG repeat instability in human cells. DNA repair $\mathbf{8}, 878-885$ (2009).

138 Gannon, A. M., Frizzell, A., Healy, E. \& Lahue, R. S. MutSbeta and histone deacetylase complexes promote expansions of trinucleotide repeats in human cells. Nucleic Acids Res 40, 10324-10333 (2012).

139 Keogh, N., Chan, K. Y., Li, G. M. \& Lahue, R. S. MutSbeta abundance and Msh3 ATP hydrolysis activity are important drivers of CTG*CAG repeat expansions. Nucleic Acids Res 45, 10068-10078 (2017).

140 Seriola, A. et al. Huntington's and myotonic dystrophy hESCs: down-regulated trinucleotide repeat instability and mismatch repair machinery expression upon differentiation. Human molecular genetics 20, 176-185 (2011).

141 Du, J., Campau, E., Soragni, E., Jespersen, C. \& Gottesfeld, J. M. Length-dependent CTG.CAG triplet-repeat expansion in myotonic dystrophy patient-derived induced pluripotent stem cells. Human molecular genetics 22, 5276-5287 (2013).

142 Axford, M. M. et al. Detection of slipped-DNAs at the trinucleotide repeats of the myotonic dystrophy type I disease locus in patient tissues. PLoS genetics 9, e1003866 (2013).

143 Schmidt, M. H. \& Pearson, C. E. Disease-associated repeat instability and mismatch repair. DNA repair 38, 117-126 (2016).

144 Carethers, J. M. Microsatellite Instability Pathway and EMAST in Colorectal Cancer. Curr Colorectal Cancer Rep 13, 73-80 (2017).

145 Gacy, A. M., Goellner, G., Juranic, N., Macura, S. \& McMurray, C. T. Trinucleotide repeats that expand in human disease form hairpin structures in vitro. Cell 81, 533540 (1995).

146 Gonitel, R. et al. DNA instability in postmitotic neurons. Proc. Natl. Acad. Sci. U.S.A. 105, 3467-3472 (2008).

147 Gomes-Pereira, M. et al. Disease-associated CAG.CTG triplet repeats expand rapidly in non-dividing mouse cells, but cell cycle arrest is insufficient to drive expansion. Nucleic Acids Research 42, 7047-7056 (2014).

148 Slean, M. M. et al. Absence of MutSbeta leads to the formation of slipped-DNA for CTG/CAG contractions at primate replication forks. DNA repair 42, 107-118 (2016).

149 Liu, G., Chen, X., Bissler, J. J., Sinden, R. R. \& Leffak, M. Replication-dependent instability at (CTG) x (CAG) repeat hairpins in human cells. Nature chemical biology 6 , 652-659 (2010).

150 Muro, Y., Sugiura, K., Mimori, T. \& Akiyama, M. DNA mismatch repair enzymes: genetic defects and autoimmunity. Clinica chimica acta; international journal of clinical chemistry 442, 102-109 (2015).

151 Sehgal, R. et al. Lynch syndrome: an updated review. Genes (Basel) 5, 497-507 (2014). 152 Buniello, A. et al. The NHGRI-EBI GWAS Catalog of published genome-wide association studies, targeted arrays and summary statistics 2019. Nucleic Acids Res 47, D1005D1012 (2019). 
153 Ochaba, J. et al. PIAS1 Regulates Mutant Huntingtin Accumulation and Huntington's Disease-Associated Phenotypes In Vivo. Neuron 90, 507-520 (2016).

154 The Huntington's Disease Collaborative Research Group. A novel gene containing a trinucleotide repeat that is expanded and unstable on Huntington's disease chromosomes. Cell 72, 971-983 (1993).

155 Lin, B. et al. Differential 3' polyadenylation of the Huntington disease gene results in two mRNA species with variable tissue expression. Human molecular genetics 2,1541 1545 (1993).

156 Landles, C. et al. Proteolysis of Mutant Huntingtin Produces an Exon 1 Fragment That Accumulates as an Aggregated Protein in Neuronal Nuclei in Huntington Disease. The Journal of biological chemistry 285, 8808-8823 (2010).

157 Neueder, A. et al. The pathogenic exon $1 \mathrm{HTT}$ protein is produced by incomplete splicing in Huntington's disease patients. Scientific reports 7, 1307-1307 (2017).

158 Bates, G., Tabrizi, S. \& Jones, L. Huntington's disease. (Oxford University Press, 2014). 159 Beck, M. \& Hurt, E. The nuclear pore complex: understanding its function through structural insight. Nat Rev Mol Cell Biol 18, 73-89 (2017).

160 Basel-Vanagaite, L. et al. Mutated nup62 causes autosomal recessive infantile bilateral striatal necrosis. Ann Neurol 60, 214-222 (2006).

161 Cavazza, T. \& Vernos, I. The RanGTP Pathway: From Nucleo-Cytoplasmic Transport to Spindle Assembly and Beyond. Front Cell Dev Biol 3, 82 (2015).

162 Hetzer, M., Gruss, O. J. \& Mattaj, I. W. The Ran GTPase as a marker of chromosome position in spindle formation and nuclear envelope assembly. Nat Cell Biol 4, E177184 (2002).

163 Hosp, F. et al. Quantitative interaction proteomics of neurodegenerative disease proteins. Cell Rep 11, 1134-1146 (2015).

164 Grima, J. C. et al. Mutant Huntingtin Disrupts the Nuclear Pore Complex. Neuron 94, 93-107 e106 (2017).

165 Zhang, Y. J. et al. C9ORF72 poly(GA) aggregates sequester and impair HR23 and nucleocytoplasmic transport proteins. Nat Neurosci 19, 668-677 (2016).

166 Shi, K. Y. et al. Toxic PRn poly-dipeptides encoded by the C9orf72 repeat expansion block nuclear import and export. Proc. Natl. Acad. Sci. U.S.A. 114, E1111-E1117 (2017).

167 Ruba, A. \& Yang, W. O-GlcNAc-ylation in the Nuclear Pore Complex. Cell Mol Bioeng 9, 227-233 (2016).

168 Haines, J. D. et al. Nuclear export inhibitors avert progression in preclinical models of inflammatory demyelination. Nat Neurosci 18, 511-520 (2015).

169 Zhang, K. et al. The C9orf72 repeat expansion disrupts nucleocytoplasmic transport. Nature 525, 56-61 (2015).

170 Archbold, H. C. et al. TDP43 nuclear export and neurodegeneration in models of amyotrophic lateral sclerosis and frontotemporal dementia. Sci Rep 8, 4606 (2018).

171 Guo, Q. et al. The cryo-electron microscopy structure of huntingtin. Nature 555, 117120 (2018).

172 Peters, M. F. \& Ross, C. A. Isolation of a 40-kDa Huntingtin-associated protein. The Journal of biological chemistry 276, 3188-3194 (2001).

173 Pal, A., Severin, F., Lommer, B., Shevchenko, A. \& Zerial, M. Huntingtin-HAP40 complex is a novel Rab5 effector that regulates early endosome motility and is up-regulated in Huntington's disease. The Journal of cell biology 172, 605-618 (2006). 
1190

1191

1192

1193

1194

1195

1196

1197

1198

1199

1200

1201

1202

1203

1204

1205

1206

1207

1208

1209

1210

1211

1212

1213

1214

1215

1216

1217

1218

1219

1220

1221

1222

1223

1224

1225

1226

1227

1228

1229

1230

1231

1232

1233

1234

174 Li, W., Serpell, L. C., Carter, W. J., Rubinsztein, D. C. \& Huntington, J. A. Expression and characterization of full-length human huntingtin, an elongated HEAT repeat protein. The Journal of biological chemistry 281, 15916-15922 (2006).

175 Andrade, M. A. \& Bork, P. HEAT repeats in the Huntington's disease protein. Nat Genet 11, 115-116 (1995).

176 Seong, I. S. et al. Huntingtin facilitates polycomb repressive complex 2. Human molecular genetics 19, 573-583 (2010).

177 Ratovitski, T. et al. Post-Translational Modifications (PTMs), Identified on Endogenous Huntingtin, Cluster within Proteolytic Domains between HEAT Repeats. J Proteome Res 16, 2692-2708 (2017).

178 Arbez, N. et al. Post-translational modifications clustering within proteolytic domains decrease mutant huntingtin toxicity. The Journal of biological chemistry 292, 1923819249 (2017).

179 Yee, L. M., Lively, T. G. \& McShane, L. M. Biomarkers in early-phase trials: fundamental issues. Bioanalysis 10, 933-944 (2018).

180 Rodrigues, F. B., Byrne, L. M. \& Wild, E. J. Biofluid Biomarkers in Huntington's Disease. Methods in molecular biology (Clifton, N.J.) 1780, 329-396 (2018).

181 Silajdzic, E. \& Bjorkqvist, M. A Critical Evaluation of Wet Biomarkers for Huntington's Disease: Current Status and Ways Forward. Journal of Huntington's disease 7, 109-135 (2018).

182 Southwell, A. L. et al. Ultrasensitive measurement of huntingtin protein in cerebrospinal fluid demonstrates increase with Huntington disease stage and decrease following brain huntingtin suppression. Sci Rep 5, 12166 (2015).

183 Wild, E. J. et al. Quantification of mutant huntingtin protein in cerebrospinal fluid from Huntington's disease patients. The Journal of clinical investigation 125, 1979-1986 (2015).

184 Fodale, V. et al. Validation of Ultrasensitive Mutant Huntingtin Detection in Human Cerebrospinal Fluid by Single Molecule Counting Immunoassay. Journal of Huntington's disease 6, 349-361 (2017).

185 Byrne, L. M. et al. Evaluation of mutant huntingtin and neurofilament proteins as potential markers in Huntington's disease. Science translational medicine 10 (2018).

186 Tabrizi, S. J. et al. Targeting Huntingtin Expression in Patients with Huntington's Disease. The New England journal of medicine 380, 2307-2316 (2019).

187 Shahim, P., Zetterberg, H., Tegner, Y. \& Blennow, K. Serum neurofilament light as a biomarker for mild traumatic brain injury in contact sports. Neurology 88, 1788-1794 (2017).

188 Constantinescu, R., Romer, M., Oakes, D., Rosengren, L. \& Kieburtz, K. Levels of the light subunit of neurofilament triplet protein in cerebrospinal fluid in Huntington's disease. Parkinsonism \& related disorders 15, 245-248 (2009).

189 Vinther-Jensen, T. et al. Selected CSF biomarkers indicate no evidence of early neuroinflammation in Huntington disease. Neurology-Neuroimmunology Neuroinflammation 3, e287 (2016).

190 Niemelä, V., Landtblom, A.-M., Blennow, K. \& Sundblom, J. Tau or neurofilament light-Which is the more suitable biomarker for Huntington's disease? PloS one 12, e0172762 (2017). 
1235

1236

1237

1238

1239

1240

1241

1242

1243

1244

1245

1246

1247

1248

1249

1250

1251

1252

1253

1254

1255

1256

1257

1258

1259

1260

1261

1262

1263

1264

1265

1266

1267

1268

1269

1270

1271

1272

1273

1274

1275

1276

1277

1278

1279

1280

1281

191 Byrne, L. M. et al. Neurofilament light protein in blood as a potential biomarker of neurodegeneration in Huntington's disease: a retrospective cohort analysis. The Lancet. Neurology 16, 601-609 (2017).

192 Rodrigues, F. B. et al. Cerebrospinal fluid inflammatory biomarkers reflect clinical severity in Huntington's disease. PloS one 11, e0163479 (2016).

193 Soylu-Kucharz, R. et al. Neurofilament light protein in CSF and blood is associated with neurodegeneration and disease severity in Huntington's disease R6/2 mice. Scientific reports 7, 14114 (2017).

194 Johnson, E. B. et al. Neurofilament light protein in blood predicts regional atrophy in Huntington disease. Neurology 90, e717-e723 (2018).

195 Vinther-Jensen, T., Budtz-Jorgensen, E., Simonsen, A. H., Nielsen, J. E. \& Hjermind, L. E. YKL-40 in cerebrospinal fluid in Huntington's disease--a role in pathology or a nonspecific response to inflammation? Parkinsonism \& related disorders 20, 13011303 (2014).

196 Rodrigues, F. B. et al. Cerebrospinal fluid total tau concentration predicts clinical phenotype in Huntington's disease. Journal of neurochemistry 139, 22-25 (2016).

197 Davis, M. Y., Keene, C. D., Jayadev, S. \& Bird, T. The co-occurrence of Alzheimer's disease and Huntington's disease: a neuropathological study of 15 elderly Huntington's disease subjects. Journal of Huntington's disease 3, 209-217 (2014).

198 Jellinger, K. A. Alzheimer-type lesions in Huntington's disease. J Neural Transm (Vienna) 105, 787-799 (1998).

199 Vuono, R. et al. The role of tau in the pathological process and clinical expression of Huntington's disease. Brain 138, 1907-1918 (2015).

200 St-Amour, I., Turgeon, A., Goupil, C., Planel, E. \& Hebert, S. S. Co-occurrence of mixed proteinopathies in late-stage Huntington's disease. Acta Neuropathol 135, 249-265 (2018).

201 Fernandez-Nogales, M. et al. Huntington's disease is a four-repeat tauopathy with tau nuclear rods. Nature medicine 20, 881-885 (2014).

202 Blum, D. et al. Mutant huntingtin alters Tau phosphorylation and subcellular distribution. Human molecular genetics 24, 76-85 (2015).

203 Baskota, S. U., Lopez, O. L., Greenamyre, J. T. \& Kofler, J. Spectrum of tau pathologies in Huntington's disease. Lab Invest 99, 1068-1077 (2019).

204 US National Library of Medicine. ClinicalTrials.gov Safety and Tolerability of WVE120102 in Patients With Huntington's Disease https://clinicaltrials.gov/ct2/show/NCT03225846 (2020).

205 US National Library of Medicine. ClinicalTrials.gov Safety and Tolerability of WVE120101 in Patients With Huntington's Disease https://clinicaltrials.gov/ct2/show/NCT03225833 (2020).

206 US National Library of Medicine. ClinicalTrials.gov A Study to Evaluate the Efficacy and Safety of Intrathecally Administered RO7234292 (RG6042) in Patients With Manifest Huntington's Disease https://clinicaltrials.gov/ct2/show/NCT03761849 (2020).

207 McColgan, P. \& Tabrizi, S. J. Huntington's disease: a clinical review. European journal of neurology : the official journal of the European Federation of Neurological Societies 25, 24-34 (2018).

208 Estévez-Fraga, C., Avilés Olmos, I., Mañanes Barral, V. \& López-Sendón Moreno, J. L. Therapeutic advances in Huntington's disease. Expert Opinion on Orphan Drugs 4, 809-821 (2016). 
1282

1283

1284

1285

1286

1287

1288

1289

1290

1291

1292

1293

1294

1295

1296

1297

1298

1299

1300

1301

1302

1303

1304

1305

1306

1307

1308

1309

1310

1311

1312

1313

1314

1315

1316

1317

1318

1319

1320

1321

1322

1323

1324

1325

1326

1327
209 Reilmann, R. et al. Safety and efficacy of pridopidine in patients with Huntington's disease (PRIDE-HD): a phase 2, randomised, placebo-controlled, multicentre, doseranging study. The Lancet. Neurology 18, 165-176 (2019).

210 US National Library of Medicine. ClinicalTrials.gov Randomized, Placebo Controlled Study Of The Efficacy And Safety Of PF-02545920 In Subjects With Huntington's Disease, https://clinicaltrials.gov/ct2/show/results/NCT02197130 (2019).

211 Delnomdedieu, M. PDE10i and HD: Learnings from the Amaryllis studies, https://chdifoundation.org/2018-conference/\#delnomdedieu (2018).

212 Wild, E. C. J. Pfizer Amaryllis trial ends in disappointment: no improvement in Huntington's disease symptoms, https://en.hdbuzz.net/229 (2016).

213 McGarry, A. et al. A randomized, double-blind, placebo-controlled trial of coenzyme Q10 in Huntington disease. Neurology 88, 152-159 (2017).

214 The Huntington Study Group. A randomized, placebo-controlled trial of coenzyme Q10 and remacemide in Huntington's disease. Neurology 57, 397-404 (2001).

215 Hersch, S. M. et al. The CREST-E study of creatine for Huntington disease: A randomized controlled trial. Neurology 89, 594-601 (2017).

216 Verny, C. et al. A randomized, double-blind, placebo-controlled trial evaluating cysteamine in Huntington's disease. Mov disord 32, 932-936 (2017).

217 Reilmann, R. et al. Safety and Tolerability of Selisistat for the Treatment of Huntington's Disease: Results from a Randomized, Double-Blind, Placebo-Controlled Phase II Trial (S47.004). Neurology 82 (10 suppl.), abstr. S47.004 (2014).

218 Süssmuth, S. D. et al. An exploratory double-blind, randomized clinical trial with selisistat, a SirT1 inhibitor, in patients with Huntington's disease. British journal of clinical pharmacology 79, 465-476 (2015).

219 Huntington Study Group Reach2HD Investigators. Safety, tolerability, and efficacy of PBT2 in Huntington's disease: a phase 2, randomised, double-blind, placebocontrolled trial. The Lancet. Neurology 14, 39-47 (2015).

220 Lopez-Sendon Moreno, J. L. et al. A double-blind, randomized, cross-over, placebocontrolled, pilot trial with Sativex in Huntington's disease. Journal of neurology 263, 1390-1400 (2016).

221 Active biotech. Active Biotech provides update on laquinimod in Huntington's disease, http://hugin.info/1002/R/2208124/858841.pdf (2018).

222 Cicchetti, F. et al. Neural transplants in patients with Huntington's disease undergo disease-like neuronal degeneration. Proc. Natl. Acad. Sci. U.S.A. 106, 12483-12488 (2009).

223 Freeman, T. B. et al. Transplanted fetal striatum in Huntington's disease: phenotypic development and lack of pathology. Proc. Natl. Acad. Sci. U.S.A. 97, 13877-13882 (2000).

224 Bachoud-Levi, A. C. From open to large-scale randomized cell transplantation trials in Huntington's disease: Lessons from the multicentric intracerebral grafting in Huntington's disease trial (MIG-HD) and previous pilot studies. Prog Brain Res 230, 227-261 (2017).

225 Wild, E. J. \& Tabrizi, S. J. Therapies targeting DNA and RNA in Huntington's disease. Lancet Neurology 16, 837-847 (2017).

226 Tabrizi, S. J., Ghosh, R. \& Leavitt, B. R. Huntingtin Lowering Strategies for Disease Modification in Huntington's Disease. Neuron 102, 899 (2019). 
227 Lee, J. M. et al. CAG repeat expansion in Huntington disease determines age at onset in a fully dominant fashion. Neurology 78, 690-695 (2012).

228 Kordasiewicz, H. B. et al. Sustained therapeutic reversal of Huntington's disease by transient repression of huntingtin synthesis. Neuron 74, 1031-1044 (2012).

229 Lu, X.-H. \& Yang, X. W. "Huntingtin holiday": progress toward an antisense therapy for Huntington's disease. Neuron 74, 964-966 (2012).

230 Stanek, L. M. et al. Antisense oligonucleotide-mediated correction of transcriptional dysregulation is correlated with behavioral benefits in the YAC128 mouse model of Huntington's disease. Journal of Huntington's disease 2, 217-228 (2013).

231 Miniarikova, J. et al. AAV5-miHTT gene therapy demonstrates suppression of mutant huntingtin aggregation and neuronal dysfunction in a rat model of Huntington's disease. Gene therapy 24, 630-639 (2017).

232 Gauthier, L. R. et al. Huntingtin controls neurotrophic support and survival of neurons by enhancing BDNF vesicular transport along microtubules. Cell 118, 127-138 (2004).

233 Duyao, M. P. et al. Inactivation of the mouse Huntington's disease gene homolog Hdh. Science 269, 407-410 (1995).

234 Dragatsis, I., Levine, M. S. \& Zeitlin, S. Inactivation of Hdh in the brain and testis results in progressive neurodegeneration and sterility in mice. Nat Genet 26, 300-306 (2000).

235 Hoffner, G., Kahlem, P. \& Djian, P. Perinuclear localization of huntingtin as a consequence of its binding to microtubules through an interaction with beta-tubulin: relevance to Huntington's disease. J Cell Sci 115, 941-948 (2002).

236 Caviston, J. P., Ross, J. L., Antony, S. M., Tokito, M. \& Holzbaur, E. L. Huntingtin facilitates dynein/dynactin-mediated vesicle transport. Proc. Natl. Acad. Sci. U.S.A. 104, 10045-10050 (2007).

237 Colin, E. et al. Huntingtin phosphorylation acts as a molecular switch for anterograde/retrograde transport in neurons. The EMBO journal 27, 2124-2134 (2008).

238 Strehlow, A. N., Li, J. Z. \& Myers, R. M. Wild-type huntingtin participates in protein trafficking between the Golgi and the extracellular space. Human molecular genetics 16, 391-409 (2007).

239 Velier, J. et al. Wild-type and mutant huntingtins function in vesicle trafficking in the secretory and endocytic pathways. Exp Neurol 152, 34-40 (1998).

240 Brandstaetter, H., Kruppa, A. J. \& Buss, F. Huntingtin is required for ER-to-Golgi transport and for secretory vesicle fusion at the plasma membrane. Disease Models \& Mechanisms 7, 1335-1340 (2014).

241 Caviston, J. P. \& Holzbaur, E. L. Huntingtin as an essential integrator of intracellular vesicular trafficking. Trends in cell biology 19, 147-155 (2009).

242 Kegel, K. B. et al. Huntingtin is present in the nucleus, interacts with the transcriptional corepressor C-terminal binding protein, and represses transcription. The Journal of biological chemistry 277, 7466-7476 (2002).

243 Zuccato, C. et al. Huntingtin interacts with REST/NRSF to modulate the transcription of NRSE-controlled neuronal genes. Nat Genet 35, 76-83 (2003).

244 McFarland, K. N. et al. MeCP2: a novel Huntingtin interactor. Human molecular genetics 23, 1036-1044 (2014).

245 DiFiglia, M. et al. Huntingtin is a cytoplasmic protein associated with vesicles in human and rat brain neurons. Neuron 14, 1075-1081 (1995). 
246 Marcora, E. \& Kennedy, M. B. The Huntington's disease mutation impairs Huntingtin's role in the transport of NF-kappaB from the synapse to the nucleus. Human molecular genetics 19, 4373-4384 (2010).

247 McKinstry, S. U. et al. Huntingtin is required for normal excitatory synapse development in cortical and striatal circuits. The Journal of neuroscience : the official journal of the Society for Neuroscience 34, 9455-9472 (2014).

248 Anne, S. L., Saudou, F. \& Humbert, S. Phosphorylation of huntingtin by cyclindependent kinase 5 is induced by DNA damage and regulates wild-type and mutant huntingtin toxicity in neurons. The Journal of neuroscience : the official journal of the Society for Neuroscience 27, 7318-7328 (2007).

249 Harper, S. Q. et al. RNA interference improves motor and neuropathological abnormalities in a Huntington's disease mouse model. Proc. Natl. Acad. Sci. U.S.A. 102, 5820-5825 (2005).

250 Franich, N. R. et al. AAV vector-mediated RNAi of mutant huntingtin expression is neuroprotective in a novel genetic rat model of Huntington's disease. Molecular therapy : the journal of the American Society of Gene Therapy 16, 947-956 (2008).

251 McBride, J. L. et al. Preclinical safety of RNAi-mediated HTT suppression in the rhesus macaque as a potential therapy for Huntington's disease. Molecular therapy : the journal of the American Society of Gene Therapy 19, 2152-2162 (2011).

252 Grondin, R. et al. Six-month partial suppression of Huntingtin is well tolerated in the adult rhesus striatum. Brain 135, 1197-1209 (2012).

253 Wang, G., Liu, X., Gaertig, M. A., Li, S. \& Li, X. J. Ablation of huntingtin in adult neurons is nondeleterious but its depletion in young mice causes acute pancreatitis. Proc. Natl. Acad. Sci. U.S.A. 113, 3359-3364 (2016).

254 Ambrose, C. M. et al. Structure and expression of the Huntington's disease gene: evidence against simple inactivation due to an expanded CAG repeat. Somat Cell Mol Genet 20, 27-38 (1994).

255 Gagnon, K. T. et al. Allele-selective inhibition of mutant huntingtin expression with antisense oligonucleotides targeting the expanded CAG repeat. Biochemistry 49, 10166-10178 (2010).

256 Yu, D. et al. Single-stranded RNAs use RNAi to potently and allele-selectively inhibit mutant huntingtin expression. Cell 150, 895-908 (2012).

257 Garriga-Canut, M. et al. Synthetic zinc finger repressors reduce mutant huntingtin expression in the brain of R6/2 mice Proc. Natl. Acad. Sci. U.S.A. 109, E3136-3145 (2012).

258 van Bilsen, P. H. et al. Identification and allele-specific silencing of the mutant huntingtin allele in Huntington's disease patient-derived fibroblasts. Human gene therapy 19, 710-719 (2008).

259 Monteys, A. M., Ebanks, S. A., Keiser, M. S. \& Davidson, B. L. CRISPR/Cas9 Editing of the Mutant Huntingtin Allele In Vitro and In Vivo. Molecular therapy: the journal of the American Society of Gene Therapy 25, 12-23 (2017).

260 Shin, J. W. et al. Permanent inactivation of Huntington's disease mutation by personalized allele-specific CRISPR/Cas9. Human molecular genetics 25, 4566-4576 (2016).

261 Lindow, M. et al. Assessing unintended hybridization-induced biological effects of oligonucleotides. Nat Biotechnol 30, 920-923 (2012). 
262 Kay, C. et al. Huntingtin Haplotypes Provide Prioritized Target Panels for Allele-specific Silencing in Huntington Disease Patients of European Ancestry. Molecular therapy : the journal of the American Society of Gene Therapy 23, 1759-1771 (2015).

263 Lombardi, M. S. et al. A majority of Huntington's disease patients may be treatable by individualized allele-specific RNA interference. Exp Neurol 217, 312-319 (2009).

264 Pfister, E. L. et al. Five siRNAs targeting three SNPs may provide therapy for threequarters of Huntington's disease patients. Current biology : CB 19, 774-778 (2009).

265 Setten, R. L., Rossi, J. J. \& Han, S. P. The current state and future directions of RNAibased therapeutics. Nat Rev Drug Discov 18, 421-446 (2019).

$266 \mathrm{Ha}, \mathrm{M}$. \& Kim, V. N. Regulation of microRNA biogenesis. Nat Rev Mol Cell Biol 15, 509524 (2014).

267 Ahmadzada, T., Reid, G. \& McKenzie, D. R. Fundamentals of siRNA and miRNA therapeutics and a review of targeted nanoparticle delivery systems in breast cancer. Biophys Rev 10, 69-86 (2018).

268 Rodriguez-Lebron, E., Denovan-Wright, E. M., Nash, K., Lewin, A. S. \& Mandel, R. J. Intrastriatal rAAV-mediated delivery of anti-huntingtin shRNAs induces partial reversal of disease progression in R6/1 Huntington's disease transgenic mice. Mol Ther 12, 618-633 (2005).

269 Wang, Y. L. et al. Clinico-pathological rescue of a model mouse of Huntington's disease by siRNA. Neurosci Res 53, 241-249 (2005).

270 DiFiglia, M. et al. Therapeutic silencing of mutant huntingtin with siRNA attenuates striatal and cortical neuropathology and behavioral deficits. Proc. Natl. Acad. Sci. U.S.A. 104, 17204-17209 (2007).

271 Machida, Y. et al. rAAV-mediated shRNA ameliorated neuropathology in Huntington disease model mouse. Biochem Biophys Res Commun 343, 190-197 (2006).

272 Boudreau, R. L. et al. Nonallele-specific silencing of mutant and wild-type huntingtin demonstrates therapeutic efficacy in Huntington's disease mice. Mol Ther 17, 10531063 (2009).

273 McBride, J. L. et al. Artificial miRNAs mitigate shRNA-mediated toxicity in the brain: implications for the therapeutic development of RNAi. Proc. Natl. Acad. Sci. U.S.A. 105, 5868-5873 (2008).

274 Drouet, V. et al. Sustained effects of nonallele-specific Huntingtin silencing. Ann Neurol 65, 276-285 (2009).

275 Stanek, L. M. et al. Silencing mutant huntingtin by adeno-associated virus-mediated RNA interference ameliorates disease manifestations in the YAC128 mouse model of Huntington's disease. Human gene therapy 25, 461-474 (2014).

276 de Fougerolles, A. R. Delivery vehicles for small interfering RNA in vivo. Human gene therapy 19, 125-132 (2008).

277 Wang, D., Tai, P. W. L. \& Gao, G. Adeno-associated virus vector as a platform for gene therapy delivery. Nature reviews. Drug discovery 18, 358-378 (2019).

278 Lykken, E. A., Shyng, C., Edwards, R. J., Rozenberg, A. \& Gray, S. J. Recent progress and considerations for AAV gene therapies targeting the central nervous system. $J$ Neurodev Disord 10, 16 (2018).

279 Dufour, B. D., Smith, C. A., Clark, R. L., Walker, T. R. \& McBride, J. L. Intrajugular vein delivery of AAV9-RNAi prevents neuropathological changes and weight loss in Huntington's disease mice. Mol Ther 22, 797-810 (2014). 
280 Deverman, B. E. et al. Cre-dependent selection yields AAV variants for widespread gene transfer to the adult brain. Nat Biotechnol 34, 204-209 (2016).

281 Matsuzaki, Y. et al. Intravenous administration of the adeno-associated virus-PHP.B capsid fails to upregulate transduction efficiency in the marmoset brain. Neuroscience letters 665, 182-188 (2018).

282 Jackson, A. L. \& Linsley, P. S. Recognizing and avoiding siRNA off-target effects for target identification and therapeutic application. Nat Rev Drug Discov 9, 57-67 (2010).

283 Grimm, D. et al. Fatality in mice due to oversaturation of cellular microRNA/short hairpin RNA pathways. Nature 441, 537-541 (2006).

284 Borel, F. et al. In vivo knock-down of multidrug resistance transporters ABCC1 and ABCC2 by AAV-delivered shRNAs and by artificial miRNAs. J RNAi Gene Silencing 7, 434-442 (2011).

285 Meng, Z. \& Lu, M. RNA Interference-Induced Innate Immunity, Off-Target Effect, or Immune Adjuvant? Front Immunol 8, 331 (2017).

286 Louis Jeune, V., Joergensen, J. A., Hajjar, R. J. \& Weber, T. Pre-existing anti-adenoassociated virus antibodies as a challenge in AAV gene therapy. Hum Gene Ther Methods 24, 59-67 (2013).

287 Rafii, M. S. et al. Adeno-Associated Viral Vector (Serotype 2)-Nerve Growth Factor for Patients With Alzheimer Disease: A Randomized Clinical Trial. JAMA neurology 75, 834-841 (2018).

288 Kristen, A. V. et al. Patisiran, an RNAi therapeutic for the treatment of hereditary transthyretin-mediated amyloidosis. Neurodegener Dis Manag 9, 5-23 (2019).

289 Adams, D. et al. Patisiran, an RNAi Therapeutic, for Hereditary Transthyretin Amyloidosis. The New England journal of medicine 379, 11-21 (2018).

290 Shankar, R., Joshi, M. \& Pathak, K. Lipid Nanoparticles: A Novel Approach for Brain Targeting. Pharm Nanotechnol 6, 81-93 (2018).

291 Cullis, P. R. \& Hope, M. J. Lipid Nanoparticle Systems for Enabling Gene Therapies. Mol Ther 25, 1467-1475 (2017).

292 Neves, A. R., Queiroz, J. F. \& Reis, S. Brain-targeted delivery of resveratrol using solid lipid nanoparticles functionalized with apolipoprotein E. J Nanobiotechnology 14, 27 (2016).

293 Salvalaio, M. et al. Targeted Polymeric Nanoparticles for Brain Delivery of High Molecular Weight Molecules in Lysosomal Storage Disorders. PLoS One 11, e0156452 (2016).

294 uniQure. uniQure Announces FDA Clearance of Investigational New Drug Application for AMT-130 in Huntington's Disease, https://www.globenewswire.com/newsrelease/2019/01/22/1703263/0/en/uniQure-Announces-FDA-Clearance-ofInvestigational-New-Drug-Application-for-AMT-130-in-Huntington-s-Disease.html (2019).

295 Evers, M. M. et al. AAV5-miHTT Gene Therapy Demonstrates Broad Distribution and Strong Human Mutant Huntingtin Lowering in a Huntington's Disease Minipig Model. Molecular therapy : the journal of the American Society of Gene Therapy 26, 21632177 (2018).

296 Hadaczek, P. et al. Widespread AAV1- and AAV2-mediated transgene expression in the nonhuman primate brain: implications for Huntington's disease. Mol Ther Methods Clin Dev 3, 16037 (2016). 
1512

1513

1514

1515

1516

1517

1518

1519

1520

1521

1522

1523

1524

1525

1526

1527

1528

1529

1530

1531

1532

1533

1534

1535

1536

1537

1538

1539

1540

1541

1542

1543

1544

1545

1546

1547

1548

1549

1550

1551

1552

1553

1554

1555

1556

1557

297 Voyager Therapeutics. Voyager Therapeutics Announces Preclinical Data for Huntington's Disease and Amyotrophic Lateral Sclerosis Programs at the Congress of the European Society of Gene and Cell Therapy, https://www.globenewswire.com/newsrelease/2018/10/16/1621781/0/en/Voyager-Therapeutics-Announces-PreclinicalData-for-Huntington-s-Disease-and-Amyotrophic-Lateral-Sclerosis-Programs-at-theCongress-of-the-European-Society-of-Gene-and-Cell-Therapy.html (2018).

298 Bennett, C. F. \& Swayze, E. E. RNA targeting therapeutics: molecular mechanisms of antisense oligonucleotides as a therapeutic platform. Annual review of pharmacology and toxicology 50, 259-293 (2010).

299 Rinaldi, C. \& Wood, M. J. A. Antisense oligonucleotides: the next frontier for treatment of neurological disorders. Nat Rev Neurol 14, 9-21 (2018).

300 Bennett, C. F. Therapeutic Antisense Oligonucleotides Are Coming of Age. Annu Rev Med 70, 307-321 (2019).

301 Wolf, D. A. et al. Dynamic dual-isotope molecular imaging elucidates principles for optimizing intrathecal drug delivery. JCI Insight 1, e85311 (2016).

302 Finkel, R. S. et al. Treatment of infantile-onset spinal muscular atrophy with nusinersen: a phase 2, open-label, dose-escalation study. Lancet 388, 3017-3026 (2016).

303 Wang, N. et al. Neuronal targets for reducing mutant huntingtin expression to ameliorate disease in a mouse model of Huntington's disease. Nature medicine 20, 536-541 (2014).

304 Hammond, S. M. et al. Systemic peptide-mediated oligonucleotide therapy improves long-term survival in spinal muscular atrophy. Proc. Natl. Acad. Sci. U.S.A. 113, 1096210967 (2016).

305 Min, H. S. et al. Systemic Brain Delivery of Antisense Oligonucleotides across the Blood-Brain Barrier with a Glucose-Coated Polymeric Nanocarrier. Angew Chem Int Ed Engl (2020).

306 Finkel, R. S. et al. Nusinersen versus Sham Control in Infantile-Onset Spinal Muscular Atrophy. The New England journal of medicine 377, 1723-1732 (2017).

307 Miller, T. M. et al. An antisense oligonucleotide against SOD1 delivered intrathecally for patients with SOD1 familial amyotrophic lateral sclerosis: a phase 1, randomised, first-in-man study. The Lancet. Neurology 12, 435-442 (2013).

308 US National Library of Medicine. ClinicalTrials.gov. An Efficacy, Safety, Tolerability, Pharmacokinetics and Pharmacodynamics Study of BllB067 in Adults With Inherited Amyotrophic Lateral Sclerosis (ALS) https://clinicaltrials.gov/ct2/show/NCT02623699 (2020).

309 Southwell, A. L. et al. Huntingtin suppression restores cognitive function in a mouse model of Huntington's disease. Science translational medicine 10 (2018).

310 Roche. AAN Presentation 2019: Translational pharmacokinetic/pharmacodynamic (PK/PD) modeling strategy to support RG6042 dose selection in Huntington's disease (HD), https://medically.roche.com/en/search/pdfviewer.2e65a24a-ffc3-4736-915417d3383c8a60.html?cid=slprxx1905nehdaan2019 (2019).

311 Ducray, P. S. et al. Translational Pharmacokinetic/Pharmacodynamic (PK/PD) Modeling Strategy to Support RG6042 Dose Selection in Huntington's Disease (HD) (S16.005). Neurology 92 (15 suppl.), abstr S16.005 (2019). 
312 Schobel, S. A. et al. Motor, cognitive, and functional declines contribute to a single progressive factor in early HD. Neurology 89, 2495-2502 (2017).

313 Trundell, D. et al. F23 Validity, reliability, ability to detect change and meaningful within-patient change of the CUHDRS. Journal of Neurology, Neurosurgery \& Psychiatry 89 (suppl. 1), abstr A48 (2018).

314 Hersch, S. et al. Multicenter, Randomized, Double-blind, Placebo-controlled Phase 1b/2a Studies of WVE-120101 and WVE-120102 in Patients with Huntington's Disease (P2.006). Neurology 88 (16 suppl.), abstr P2.006 (2017).

315 Datson, N. A. et al. The expanded CAG repeat in the huntingtin gene as target for therapeutic RNA modulation throughout the HD mouse brain. PLoS One 12, e0171127 (2017).

316 Jiang, J. et al. Gain of Toxicity from ALS/FTD-Linked Repeat Expansions in C9ORF72 Is Alleviated by Antisense Oligonucleotides Targeting GGGGCC-Containing RNAs. Neuron 90, 535-550 (2016).

317 Becanovic, K. et al. A SNP in the HTT promoter alters NF-kappaB binding and is a bidirectional genetic modifier of Huntington disease. Nat Neurosci 18, 807-816 (2015).

318 Bhattacharyya, A. Identification and development of orally administered, CNSpenetrant small molecules that lower huntingtin protein levels by inducing a novel splicing event that alters the stability of huntingtin $m R N A$, https://chdifoundation.org/2019-conference/\#bhattacharyva (2019).

319 Naryshkin, N. A. et al. Motor neuron disease. SMN2 splicing modifiers improve motor function and longevity in mice with spinal muscular atrophy. Science 345, 688-693 (2014).

320 US National Library of Medicine. ClinicalTrials.gov. A Study of R06885247 in Adult and Pediatric Patients With Spinal Muscular Atrophy (MOONFISH) https://clinicaltrials.gov/ct2/show/NCT02240355 (2016).

321 US National Library of Medicine. ClinicalTrials.gov. A Study to Investigate the Safety, Tolerability, Pharmacokinetics and Pharmacodynamics of Risdiplam (R07034067) Given by Mouth in Healthy Volunteers https://clinicaltrials.gov/ct2/show/NCT02633709 (2018).

322 US National Library of Medicine. ClinicalTrials.gov. A Study of Risdiplam (RO7034067) in Adult and Pediatric Participants With Spinal Muscular Atrophy https://clinicaltrials.gov/ct2/show/NCT03032172 (2020).

323 US National Library of Medicine. ClinicalTrials.gov. A Study to Investigate the Safety, Tolerability, Pharmacokinetics, Pharmacodynamics and Efficacy of Risdiplam (R07034067) in Type 2 and 3 Spinal Muscular Atrophy (SMA) Participants https://clinicaltrials.gov/ct2/show/NCT02908685 (2020).

324 US National Library of Medicine. ClinicalTrials.gov. Investigate Safety, Tolerability, PK, PD and Efficacy of Risdiplam (RO7034067) in Infants With Type1 Spinal Muscular Atrophy https://clinicaltrials.gov/ct2/show/NCT02913482 (2020).

325 Liu, C. R. et al. Spt4 is selectively required for transcription of extended trinucleotide repeats. Cell 148, 690-701 (2012).

326 Cheng, H. M. et al. Effects on murine behavior and lifespan of selectively decreasing expression of mutant huntingtin allele by supt4h knockdown. PLoS genetics 11, e1005043 (2015).

327 Klug, A. The discovery of zinc fingers and their applications in gene regulation and genome manipulation. Annual review of biochemistry 79, 213-231 (2010). 
328 Nemudryi, A. A., Valetdinova, K. R., Medvedev, S. P. \& Zakian, S. M. TALEN and CRISPR/Cas Genome Editing Systems: Tools of Discovery. Acta Naturae 6, 19-40 (2014).

329 Adli, M. The CRISPR tool kit for genome editing and beyond. Nature communications 9, 1911 (2018).

330 Malankhanova, T. B., Malakhova, A. A., Medvedev, S. P. \& Zakian, S. M. Modern Genome Editing Technologies in Huntington's Disease Research. Journal of Huntington's disease 6, 19-31 (2017).

331 Richard, G. F. et al. Highly specific contractions of a single CAG/CTG trinucleotide repeat by TALEN in yeast. PLoS One 9, e95611 (2014).

332 Fink, K. D. et al. Allele-Specific Reduction of the Mutant Huntingtin Allele Using Transcription Activator-Like Effectors in Human Huntington's Disease Fibroblasts. Cell transplantation 25, 677-686 (2016).

333 Heman-Ackah, S. M., Bassett, A. R. \& Wood, M. J. Precision Modulation of Neurodegenerative Disease-Related Gene Expression in Human iPSC-Derived Neurons. Sci Rep 6, 28420 (2016).

334 Dabrowska, M., Juzwa, W., Krzyzosiak, W. J. \& Olejniczak, M. Precise Excision of the CAG Tract from the Huntingtin Gene by Cas9 Nickases. Frontiers in neuroscience 12, 75 (2018).

335 Ledford, H. CRISPR babies: when will the world be ready? Nature 570, 293-296 (2019).

336 Zhang, X. H., Tee, L. Y., Wang, X. G., Huang, Q. S. \& Yang, S. H. Off-target Effects in CRISPR/Cas9-mediated Genome Engineering. Mol Ther Nucleic Acids 4, e264 (2015).

337 Milone, M. C. \& O'Doherty, U. Clinical use of lentiviral vectors. Leukemia 32, 15291541 (2018).

\section{Acknowledgements}

S.J.T. receives grant funding for her HD research from the Medical Research Council UK, the Wellcome Trust, the Rosetrees Trust, NIHR North Thames Local Clinical Research Network, UK Dementia Research Institute, Wolfson Foundation for Neurodegeneration and the CHDI Foundation. This work was in part supported by the UK Dementia Research Institute, and research grant funding from the Wellcome Trust to S.J.T. and M.F. (ref 200181/Z/15/Z). M.F. received a PhD studentship from the Medical Research Council UK, a Clinical Lectureship from the UK Dementia Research Institute and Health Education England, and grant funding from the Rosetrees Trust and the Academy of Medical Sciences. C.A.R. receives funding for HD research from NIH and CHDI. This work was supported in part by NINDS 2R01NS086452-06 (GRANT12516201). E.W. receives funding from the Medical Research Council UK (Clinician Scientist Fellowship MR/M008592/1), CHDI Foundation, the Wellcome Trust (Wellcome Collaborative Award In Science 200181/Z/15/Z), Huntington's Disease 
1641 Society of America, the Hereditary Disease Foundation, the National Institute for Health Research

1642 Biomedical Research Centres funding scheme.

1643 Author contributions

1644 M.F and C.A.R researched data for the article, made substantial contributions to the discussion of the 1645 content of the article, wrote the article, and reviewed and edited the manuscript before submission. 1646 S.J.T. made a substantial contribution to the discussion of the content of the article, wrote the article, 1647 and reviewed and edited the manuscript before submission. E.W. made a substantial contribution to the 1648 discussion of the content of the article, and reviewed and edited the manuscript before submission.

\section{Competing interests}

1650 In the past two years S.J.T has undertaken consultancy services, including advisory boards, with F. 1651 Hoffmann-La Roche Ltd, Ixitech Technologies, Takeda Pharmaceuticals International and Triplet therapeutics. All honoraria for these consultancies were paid to University College London, S.J.T's employer. Through the offices of UCL Consultants Ltd, a wholly owned subsidiary of University

1654 College London, S.J.T. has undertaken consultancy services for Alnylam Pharmaceuticals Inc., F. 1655 Hoffmann-La Roche Ltd, GSK, Heptares Therapeutics, LoQus therapeutics, Takeda Pharmaceuticals Ltd, TEVA Pharmaceuticals, Triplet therapeutics, UCB Pharma S.A., University College Irvine and Vertex Pharmaceuticals Incorporated. S.J.T. receives grant funding for her research from Takeda Pharmaceuticals and Cantervale Limited. C.A.R. is chair of the Research Advisory Board of the

1659 Huntington Study Group. Within the past two years, C.A.R. has consulted for Annexon, Roche, Sage 1660 and uniQure. Through UCL Consultants Ltd., a wholly owned subsidiary of University College London, 1661 E.J.W. has served on scientific advisory boards for F. Hoffmann-La Roche, Ionis, Mitoconix, Novartis, 1662 PTC Therapeutics, Shire, Takeda Pharmaceuticals and Wave Life Sciences. M.F. declares no competing interests. C.A.R. receives funding for HD research from Hoffman La Roche.

\section{Publisher's note}


Springer Nature remains neutral with regard to jurisdictional claims in published maps and institutional

1667 affiliations.

1668 Key points

- Proteins involved in DNA repair, particularly mismatch repair, can modify the age of onset and rate of progression of $\mathrm{HD}$, likely by altering the rate of somatic expansion of CAG repeats in the Huntingtin gene.

- The modulation of DNA repair factors, such as MSH3, FAN1, PMS2 or LIG1, has therapeutic potential in HD and other repeat expansion diseases.

- Intrathecally-delivered non-allele selective antisense oligonucleotides (ASOs) have successfully lowered HTT concentration in the central nervous system of individuals with HD, and trials of allele-specific ASOs are under way.

- Gene editing strategies for HTT lowering, including zinc finger proteins, transcription activator-like effector nucleases and CRISPR-Cas9, are currently in preclinical development, but need to be delivered via the injection of viral vectors, which can be challenging.

Fig. 1 | The potential roles of DNA repair Huntington disease modifiers in somatic instability. a | DNA loop-outs form in the CAG.CTG repeat tract (red). Loop-outs of 1-15 bases are identified by MutS $\beta$, which is a heterodimer of the DNA mismatch repair proteins MSH2 and MSH3 ${ }^{118}$. b. | The MutS $\beta$ complex moves along DNA like a sliding clamp, inducing cleavage of the DNA by endonuclease complexes such as MutL $\alpha$ (a heterodimer of MLH1 and PMS2) or Mutl $\gamma$ (a heterodimer of MLH1 and MLH3). FAN1, a DNA endonuclease and exonuclease, stabilises repeat tracts. The mechanism 
underlying this stabilisation by FAN1 is not yet clear, but it might involve sequestration of MutL $\alpha$, blocking MutS $\beta$ access to the loop out, or direct loop-out repair ${ }^{112}$. c. | The cut DNA strand is resysnthesised by a DNA polymerase, and repair is completed by DNA ligase 1 (LIG1). This repair process can induce incremental expansion, represented by the longer repeat tract in part $\mathrm{c}$ than in part a. Increased expression of MSH3, MutL $\alpha, \operatorname{MutL} \gamma$ and LIG1 promotes somatic instability and accelerates onset of Huntington disease (HD), whereas FAN1 and the MutL $\beta$ heterodimer (MLH1 and PMS1) protect against somatic instability and delay onset of HD..

\section{Fig. 2 The nuclear transport cycle is disrupted by sequestration of RanGAP1 and nucleoporins} in mutant huntingtin aggregates. a | During nuclear import, cargos (purple) with nuclear localisation signals (NLS) are released into the nucleoplasm when their karyopherin (transport factor or importin; grey) interacts with Ran-GTP. Conversely, during export, cargoes with a nuclear export signal (NES), are released into the cytoplasm when Ran-GTP is hydrolysed to Ran-GDP by RanGAP1, located on the cytoplasmic filaments of the nuclear pore complex (blue). This establishes a gradient of Ran forms, with more Ran-GTP in the nucleus and more Ran-GDP in the cytoplasm b | In Huntington disease (HD), RanGAP1 and nucleoporins, including NUP62 and NUP88, are sequestered in mutant Huntingtin (mHTT) aggregates. This sequestration results in a loss of the Ran gradient, and a failure of nucleocytoplasmic transport.

Fig. 3 | Therapeutic methods for lowering huntingtin expression. The red sections of DNA, RNA, and protein represent the pathogenic expanded CAG tract and its polyglutamine product. The orange boxes are therapeutic approaches. ASO, antisense oligonucleotide; mHTT, mutant huntingtin; RISC, RNA-induced silencing complex; RNAi, RNA interference; RNase, ribonuclease; TALEN, transcription activator-like effector nuclease; ZFP, zinc-finger protein.

Fig. 4 | Phase I-IIa clinical trial of the HTT $_{R x}$ antisense oligonucleotide. HTT $_{R x}$ was administered to adults with early-stage HD every 4 weeks as an intrathecal bolus, via lumbar puncture. Of 46 participants, 34 were randomly assigned to receive $\mathrm{HTT}_{\mathrm{Rx}}$ and 12 received placebo. The individuals receiving $\mathrm{HTT}_{\mathrm{Rx}}$ were divided into five cohorts that each received a different dose of the ASO, from 
1718 10-120 mg. a | Percentage change in the concentration of mutant Huntingtin (mHTT) in the 1719 cerebrospinal fluid (CSF) of groups of participants who received one of five different doses of HTTRx 1720 or placebo, from baseline (dotted line) to the last available time point, which was 28 days after the last 1721 dose and 85-113 days after baseline measurement. Circles indicate individual participants, and 1722 horizontal lines indicate group means; 95\% confidence intervals are also shown for the groups of 1723 participants receiving HTTRx. b | Relationship between CSF mHTT reduction at Study Day 85 and 1724 composite Unified Huntington's Disease Rating Scale (cUHDRS). The 95\% confidence intervals have 1725 not been adjusted for multiplicity and should be treated as exploratory. Direction of benefit is shown to 1726 the left of the plot. Scale properties (range; clinically meaningful change) are -8-24;2. Reproduced with 1727 permission from Tabrizi, et al. ${ }^{186}$.

\section{Glossary:}

1729 Choreiform movements: Repetitive and rapid, jerky, involuntary movements.

1730 RNA foci: Expanded RNA repeats that are retained in the nucleus, adopt unusual secondary structures, sequester RNA binding proteins, and can become toxic to the cell.

Repeat-associated non-ATG translation: A repeat-length-dependent process that enables translation initiation at noncanonical codons either within or adjacent to the expanded repeat tract.

1734 Somatic instability: Expansion or contraction of repeat units within a repetitive DNA tract, the rate of 1735 which is tissue specific. microRNA: A small non-coding RNA molecule that functions in RNA silencing and posttranscriptional regulation of gene expression

1738 Lagging strand: The strand of nascent DNA that is synthesised in the opposite direction to the direction 1739 of the growing replication fork.

1740 Loop-outs: Formed when one DNA strand is extruded from a CAG CTG repeat region; intrastrand links 1741 then lead to the formation of a hairpin, with A-A or T-T base mispairing when the CAG or CTG strand is extruded, respectively. 
$17451 \quad$ Bates, G. P. et al. Huntington disease. Nature Reviews Disease Primers, 15005 (2015).

17462 Paulson, H. Repeat expansion diseases. Handbook of clinical neurology 147, 105-123 (2018).

17483 Evans, S. J. et al. Prevalence of adult Huntington's disease in the UK based on diagnoses recorded in general practice records. Journal of neurology, neurosurgery, and psychiatry 84, 1156-1160 (2013).

1752

4 Langbehn, D. R., Hayden, M. R. \& Paulsen, J. S. CAG-repeat length and the age of onset in Huntington disease (HD): a review and validation study of statistical approaches. American journal of medical genetics. Part B, Neuropsychiatric genetics : the official publication of the International Society of Psychiatric Genetics 153b, 397-408 (2010). Ross, C. A. et al. Huntington disease: natural history, biomarkers and prospects for therapeutics. Nature reviews. Neurology 10, 204-216 (2014).

1758 Palidwor, G. A. et al. Detection of alpha-rod protein repeats using a neural network and application to huntingtin. PLoS computational biology 5, e1000304 (2009). Tartari, M. et al. Phylogenetic comparison of huntingtin homologues reveals the appearance of a primitive polyQ in sea urchin. Mol Biol Evol 25, 330-338 (2008).

8 Zheng, Z., Li, A., Holmes, B. B., Marasa, J. C. \& Diamond, M. I. An N-terminal nuclear export signal regulates trafficking and aggregation of Huntingtin $(\mathrm{Htt})$ protein exon 1. The Journal of biological chemistry 288, 6063-6071 (2013). Bessert, D. A., Gutridge, K. L., Dunbar, J. C. \& Carlock, L. R. The identification of a functional nuclear localization signal in the Huntington disease protein. Brain Res $\mathrm{Mol}$ Brain Res 33, 165-173 (1995). Xia, J., Lee, D. H., Taylor, J., Vandelft, M. \& Truant, R. Huntingtin contains a highly conserved nuclear export signal. Human molecular genetics 12, 1393-1403 (2003).

11 Nasir, J. et al. Targeted disruption of the Huntington's disease gene results in embryonic lethality and behavioral and morphological changes in heterozygotes. Cell 81, 811-823 (1995).

12 Zeitlin, S., Liu, J. P., Chapman, D. L., Papaioannou, V. E. \& Efstratiadis, A. Increased apoptosis and early embryonic lethality in mice nullizygous for the Huntington's disease gene homologue. Nat Genet 11, 155-163 (1995). Saudou, F. \& Humbert, S. The Biology of Huntingtin. Neuron 89, 910-926 (2016). Rosas, H. D. et al. Cerebral cortex and the clinical expression of Huntington's disease: complexity and heterogeneity. Brain 131, 1057-1068 (2008). Johnson, E. B. et al. Dynamics of cortical degeneration over a decade in Huntington's Disease. bioRxiv, 537977 (2019). in Huntington's disease and progressive supranuclear palsy. Acta Neuropathol 85, 553559 (1993).

17 Heinsen, H. et al. Cortical and striatal neurone number in Huntington's disease. Acta Neuropathol 88, 320-333 (1994). of neurons in Huntington's disease: the role of cell type-specific features. J Neurochem 113, 1073-1091 (2010). 
19 Ehrnhoefer, D. E., Sutton, L. \& Hayden, M. R. Small changes, big impact: posttranslational modifications and function of huntingtin in Huntington disease. Neuroscientist 17, 475-492 (2011).

20 Hensman Moss, D. J. et al. Huntington's disease blood and brain show a common gene expression pattern and share an immune signature with Alzheimer's disease. Scientific Reports 7, 44849 (2017).

21 Hodges, A. et al. Regional and cellular gene expression changes in human Huntington's disease brain. Human molecular genetics 15, 965-977 (2006).

22 Pouladi, M. A., Morton, A. J. \& Hayden, M. R. Choosing an animal model for the study of Huntington's disease. Nature reviews. Neuroscience 14, 708-721 (2013).

23 Ramaswamy, S., McBride, J. L. \& Kordower, J. H. Animal models of Huntington's disease. ILAR J 48, 356-373 (2007).

$24 \mathrm{Li}, \mathrm{X}$. J. \& Li, S. Large Animal Models of Huntington's Disease. Current topics in behavioral neurosciences 22, 149-160 (2015).

25 Difiglia, M. et al. Aggregation of huntingtin in neuronal intranuclear inclusions and dystrophic neurites in brain. Science (New York, N.Y.) 277, 1990-1993 (1997).

26 Hoffner, G., Island, M. L. \& Djian, P. Purification of neuronal inclusions of patients with Huntington's disease reveals a broad range of $\mathrm{N}$-terminal fragments of expanded huntingtin and insoluble polymers. J Neurochem 95, 125-136 (2005).

27 Cooper, J. K. et al. Truncated N-terminal fragments of huntingtin with expanded glutamine repeats form nuclear and cytoplasmic aggregates in cell culture. Human molecular genetics 7, 783-790 (1998).

28 Ross, C. A. Intranuclear neuronal inclusions: a common pathogenic mechanism for glutamine-repeat neurodegenerative diseases? Neuron 19, 1147-1150 (1997).

29 Davies, S. W. et al. Are neuronal intranuclear inclusions the common neuropathology of triplet-repeat disorders with polyglutamine-repeat expansions? Lancet 351, 131133 (1998).

30 Saudou, F., Finkbeiner, S., Devys, D. \& Greenberg, M. E. Huntingtin acts in the nucleus to induce apoptosis but death does not correlate with the formation of intranuclear inclusions. Cell 95, 55-66 (1998).

31 Arrasate, M., Mitra, S., Schweitzer, E. S., Segal, M. R. \& Finkbeiner, S. Inclusion body formation reduces levels of mutant huntingtin and the risk of neuronal death. Nature 431, 805-810 (2004).

32 Slow, E. J. et al. Absence of behavioral abnormalities and neurodegeneration in vivo despite widespread neuronal huntingtin inclusions. Proceedings of the National Academy of Sciences of the United States of America 102, 11402-11407 (2005).

33 Pieri, L., Madiona, K., Bousset, L. \& Melki, R. Fibrillar alpha-synuclein and huntingtin exon 1 assemblies are toxic to the cells. Biophys J 102, 2894-2905 (2012).

34 Nucifora, L. G. et al. Identification of novel potentially toxic oligomers formed in vitro from mammalian-derived expanded huntingtin exon-1 protein. The Journal of biological chemistry 287, 16017-16028 (2012).

35 Lajoie, P. \& Snapp, E. L. Formation and toxicity of soluble polyglutamine oligomers in living cells. PLoS One 5, e15245 (2010).

36 Nagai, Y. et al. A toxic monomeric conformer of the polyglutamine protein. Nature structural \& molecular biology 14, 332-340 (2007).

37 Miller, J. et al. Identifying polyglutamine protein species in situ that best predict neurodegeneration. Nature chemical biology 7, 925-934 (2011). 
38 Sahl, S. J., Weiss, L. E., Duim, W. C., Frydman, J. \& Moerner, W. E. Cellular inclusion bodies of mutant huntingtin exon 1 obscure small fibrillar aggregate species. Sci Rep 2, 895 (2012).

39 Leitman, J., Ulrich Hartl, F. \& Lederkremer, G. Z. Soluble forms of polyQ-expanded huntingtin rather than large aggregates cause endoplasmic reticulum stress. Nature communications 4, 2753 (2013).

40 Takahashi, T. et al. Soluble polyglutamine oligomers formed prior to inclusion body formation are cytotoxic. Human molecular genetics 17, 345-356 (2008).

41 Legleiter, J. et al. Mutant huntingtin fragments form oligomers in a polyglutamine length-dependent manner in vitro and in vivo. The Journal of biological chemistry 285, 14777-14790 (2010).

42 Ast, A. et al. mHTT Seeding Activity: A Marker of Disease Progression and Neurotoxicity in Models of Huntington's Disease. Molecular cell 71, 675-688 e676 (2018).

43 Sathasivam, K. et al. Aberrant splicing of HTT generates the pathogenic exon 1 protein in Huntington disease. Proceedings of the National Academy of Sciences of the United States of America 110, 2366-2370 (2013).

44 Sieradzan, K. A. et al. Huntington's disease intranuclear inclusions contain truncated, ubiquitinated huntingtin protein. Exp Neurol 156, 92-99 (1999).

45 Wang, C. E. et al. Accumulation of N-terminal mutant huntingtin in mouse and monkey models implicated as a pathogenic mechanism in Huntington's disease. Human molecular genetics 17, 2738-2751 (2008).

46 Castiglioni, V., Onorati, M., Rochon, C. \& Cattaneo, E. Induced pluripotent stem cell lines from Huntington's disease mice undergo neuronal differentiation while showing alterations in the lysosomal pathway. Neurobiology of disease 46, 30-40 (2012).

47 Consortium, H. i. Induced pluripotent stem cells from patients with Huntington's disease show CAG-repeat-expansion-associated phenotypes. Cell stem cell 11, 264278 (2012).

48 Yang, W., Dunlap, J. R., Andrews, R. B. \& Wetzel, R. Aggregated polyglutamine peptides delivered to nuclei are toxic to mammalian cells. Human molecular genetics 11, 2905-2917 (2002).

49 Monsellier, E., Bousset, L. \& Melki, R. alpha-Synuclein and huntingtin exon 1 amyloid fibrils bind laterally to the cellular membrane. Sci Rep 6, 19180 (2016).

50 Costanzo, M. et al. Transfer of polyglutamine aggregates in neuronal cells occurs in tunneling nanotubes. J Cell Sci 126, 3678-3685 (2013).

51 Herrera, F., Tenreiro, S., Miller-Fleming, L. \& Outeiro, T. F. Visualization of cell-to-cell transmission of mutant huntingtin oligomers. PLoS currents 3, RRN1210 (2011).

52 Babcock, D. T. \& Ganetzky, B. Transcellular spreading of huntingtin aggregates in the Drosophila brain. Proceedings of the National Academy of Sciences of the United States of America 112, E5427-5433 (2015).

53 Pearce, M. M. P., Spartz, E. J., Hong, W., Luo, L. \& Kopito, R. R. Prion-like transmission of neuronal huntingtin aggregates to phagocytic glia in the Drosophila brain. Nature communications 6, 6768 (2015).

54 Pecho-Vrieseling, E. et al. Transneuronal propagation of mutant huntingtin contributes to non-cell autonomous pathology in neurons. Nat Neurosci 17, 10641072 (2014). 
1881

1882

1883

1884

1885

1886

1887

1888

1889

1890

1891

1892

1893

1894

1895

1896

1897

1898

1899

1900

1901

1902

1903

1904

1905

1906

1907

1908

1909

1910

1911

1912

1913

1914

1915

1916

1917

1918

1919

1920

1921

1922

1923

1924

1925

1926

55 Kovacs, G. G. \& Budka, H. Prion diseases: from protein to cell pathology. Am J Pathol 172, 555-565 (2008).

56 Cicchetti, F. et al. Mutant huntingtin is present in neuronal grafts in Huntington disease patients. Ann Neurol 76, 31-42 (2014).

57 Lin, J. T. et al. Regulation of feedback between protein kinase $A$ and the proteasome system worsens Huntington's disease. Mol Cell Biol 33, 1073-1084 (2013).

58 Cortes, C. J. \& La Spada, A. R. The many faces of autophagy dysfunction in Huntington's disease: from mechanism to therapy. Drug discovery today 19, 963-971 (2014).

59 Ravikumar, B. et al. Inhibition of mTOR induces autophagy and reduces toxicity of polyglutamine expansions in fly and mouse models of Huntington disease. Nat Genet 36, 585-595 (2004).

60 Liu, B. \& Hong, J. S. Role of microglia in inflammation-mediated neurodegenerative diseases: mechanisms and strategies for therapeutic intervention. The Journal of pharmacology and experimental therapeutics 304, 1-7 (2003).

61 Miller, J. R. et al. RNA-Seq of Huntington's disease patient myeloid cells reveals innate transcriptional dysregulation associated with proinflammatory pathway activation. Human molecular genetics 25, 2893-2904 (2016).

62 Ellrichmann, G., Reick, C., Saft, C. \& Linker, R. A. The Role of the Immune System in Huntington's Disease. Clinical and Developmental Immunology 2013, 1-11 (2013).

63 Palpagama, T. H., Waldvogel, H. J., Faull, R. L. M. \& Kwakowsky, A. The Role of Microglia and Astrocytes in Huntington's Disease. Frontiers in molecular neuroscience 12, 258 (2019).

64 Beal, M. F. et al. Neurochemical and histologic characterization of striatal excitotoxic lesions produced by the mitochondrial toxin 3-nitropropionic acid. The Journal of neuroscience : the official journal of the Society for Neuroscience 13, 4181-4192 (1993).

65 Browne, S. E. \& Beal, M. F. The energetics of Huntington's disease. Neurochem Res 29, 531-546 (2004).

66 Mochel, F. et al. Abnormal response to cortical activation in early stages of Huntington disease. Movement disorders : official journal of the Movement Disorder Society 27, 907-910 (2012).

67 Mochel, F. et al. Early alterations of brain cellular energy homeostasis in Huntington disease models. The Journal of biological chemistry 287, 1361-1370 (2012).

68 Goebel, H. H., Heipertz, R., Scholz, W., Iqbal, K. \& Tellez-Nagel, I. Juvenile Huntington chorea: clinical, ultrastructural, and biochemical studies. Neurology 28, 23-31 (1978).

69 Kim, J. et al. Mitochondrial loss, dysfunction and altered dynamics in Huntington's disease. Human molecular genetics 19, 3919-3935 (2010).

70 Johri, A., Chandra, A. \& Flint Beal, M. PGC-1alpha, mitochondrial dysfunction, and Huntington's disease. Free Radic Biol Med 62, 37-46 (2013).

$71 \mathrm{Gu}, \mathrm{M}$. et al. Mitochondrial defect in Huntington's disease caudate nucleus. Ann Neurol 39, 385-389 (1996).

72 Browne, S. E. et al. Oxidative damage and metabolic dysfunction in Huntington's disease: selective vulnerability of the basal ganglia. Ann Neurol 41, 646-653 (1997).

73 Napoli, E. et al. Defective mitochondrial disulfide relay system, altered mitochondrial morphology and function in Huntington's disease. Human molecular genetics 22, 9891004 (2013). 
74 Naia, L. et al. Activation of IGF-1 and insulin signaling pathways ameliorate mitochondrial function and energy metabolism in Huntington's Disease human lymphoblasts. Molecular neurobiology 51, 331-348 (2015).

75 Reynolds, N. C., Jr., Prost, R. W. \& Mark, L. P. Heterogeneity in 1H-MRS profiles of presymptomatic and early manifest Huntington's disease. Brain Res 1031, 82-89 (2005).

76 Jenkins, B. G., Koroshetz, W. J., Beal, M. F. \& Rosen, B. R. Evidence for impairment of energy metabolism in vivo in Huntington's disease using localized $1 \mathrm{H}$ NMR spectroscopy. Neurology 43, 2689-2695 (1993).

77 Antonini, A. et al. Striatal glucose metabolism and dopamine D2 receptor binding in asymptomatic gene carriers and patients with Huntington's disease. Brain 119 ( Pt 6), 2085-2095 (1996).

78 Feigin, A. et al. Metabolic network abnormalities in early Huntington's disease: an [(18)F]FDG PET study. J Nucl Med 42, 1591-1595 (2001).

79 Orr, A. L. et al. N-terminal mutant huntingtin associates with mitochondria and impairs mitochondrial trafficking. The Journal of neuroscience : the official journal of the Society for Neuroscience 28, 2783-2792 (2008).

80 Trushina, E. et al. Mutant huntingtin impairs axonal trafficking in mammalian neurons in vivo and in vitro. Mol Cell Biol 24, 8195-8209 (2004).

81 Shirendeb, U. et al. Abnormal mitochondrial dynamics, mitochondrial loss and mutant huntingtin oligomers in Huntington's disease: implications for selective neuronal damage. Human molecular genetics 20, 1438-1455 (2011).

82 Shirendeb, U. P. et al. Mutant huntingtin's interaction with mitochondrial protein Drp1 impairs mitochondrial biogenesis and causes defective axonal transport and synaptic degeneration in Huntington's disease. Human molecular genetics 21, 406-420 (2012).

83 Cui, L. et al. Transcriptional repression of PGC-1alpha by mutant huntingtin leads to mitochondrial dysfunction and neurodegeneration. Cell 127, 59-69 (2006).

84 Choo, Y. S., Johnson, G. V., MacDonald, M., Detloff, P. J. \& Lesort, M. Mutant huntingtin directly increases susceptibility of mitochondria to the calcium-induced permeability transition and cytochrome c release. Human molecular genetics 13, 1407-1420 (2004).

85 Panov, A. V. et al. Early mitochondrial calcium defects in Huntington's disease are a direct effect of polyglutamines. Nat Neurosci 5, 731-736 (2002).

86 Yano, H. et al. Inhibition of mitochondrial protein import by mutant huntingtin. Nat Neurosci 17, 822-831 (2014).

87 Yablonska, S. et al. Mutant huntingtin disrupts mitochondrial proteostasis by interacting with TIM23. Proceedings of the National Academy of Sciences of the United States of America 116, 16593-16602 (2019).

88 Marti, E. RNA toxicity induced by expanded CAG repeats in Huntington's disease. Brain Pathol 26, 779-786 (2016).

89 Li, L. B., Yu, Z., Teng, X. \& Bonini, N. M. RNA toxicity is a component of ataxin-3 degeneration in Drosophila. Nature 453, 1107-1111 (2008).

$90 \mathrm{Hsu}, \mathrm{R}$. J. et al. Long tract of untranslated CAG repeats is deleterious in transgenic mice. PLoS One 6, e16417 (2011).

91 Wang, L. C. et al. Muscleblind participates in RNA toxicity of expanded CAG and CUG repeats in Caenorhabditis elegans. Cell Mol Life Sci 68, 1255-1267 (2011). 
1973

1974

1975

1976

1977

1978

1979

1980

1981

1982

1983

1984

1985

1986

1987

1988

1989

1990

1991

1992

1993

1994

1995

1996

1997

1998

1999

2000

2001

2002

2003

2004

2005

2006

2007

2008

2009

2010

2011

2012

2013

2014

2015

2016

2017

2018
92 Banez-Coronel, M. et al. RAN Translation in Huntington Disease. Neuron 88, 667-677 (2015).

93 Gao, F. B., Richter, J. D. \& Cleveland, D. W. Rethinking Unconventional Translation in Neurodegeneration. Cell 171, 994-1000 (2017).

94 Yang, S. et al. Lack of RAN-mediated toxicity in Huntington's disease knock-in mice. Proceedings of the National Academy of Sciences of the United States of America 117, 4411-4417 (2020).

95 Kennedy, L. et al. Dramatic tissue-specific mutation length increases are an early molecular event in Huntington disease pathogenesis. Human molecular genetics 12, 3359-3367 (2003).

96 Shelbourne, P. F. et al. Triplet repeat mutation length gains correlate with cell-type specific vulnerability in Huntington disease brain. Human molecular genetics 16, 11331142 (2007).

97 Swami, M. et al. Somatic expansion of the Huntington's disease CAG repeat in the brain is associated with an earlier age of disease onset. Human molecular genetics 18 , 3039-3047 (2009).

98 GeM-HD, G. M. o. H. s. D. G.-H. C.-. CAG Repeat Not Polyglutamine Length Determines Timing of Huntington's Disease Onset. Cell 178, 887-900.e814 (2019).

99 Telenius, $\mathrm{H}$. et al. Molecular analysis of juvenile Huntington disease: the major influence on (CAG)n repeat length is the sex of the affected parent. Human molecular genetics 2, 1535-1540 (1993).

100 Aronin, N. et al. CAG expansion affects the expression of mutant Huntingtin in the Huntington's disease brain. Neuron 15, 1193-1201 (1995).

101 Shelbourne, P. F. et al. Triplet repeat mutation length gains correlate with cell-type specific vulnerability in Huntington disease brain. Human molecular genetics 16, $1133-$ 1142 (2007).

102 Kennedy, L. Dramatic tissue-specific mutation length increases are an early molecular event in Huntington disease pathogenesis. Human molecular genetics 12, 3359-3367 (2003).

103 Ansved, T., Lundin, A. \& Anvret, M. Larger CAG expansions in skeletal muscle compared with lymphocytes in Kennedy disease but not in Huntington disease. Neurology 51, 1442-1444 (1998).

104 Squitieri, F., Ciarmiello, A., Di Donato, S. \& Frati, L. The search for cerebral biomarkers of Huntington's disease: a review of genetic models of age at onset prediction. European journal of neurology : the official journal of the European Federation of Neurological Societies 13, 408-415 (2006).

105 Kaplan, S., Itzkovitz, S. \& Shapiro, E. A universal mechanism ties genotype to phenotype in trinucleotide diseases. PLoS computational biology 3 (2007).

106 La Spada, A. R. Trinucleotide repeat instability: genetic features and molecular mechanisms. Brain Pathol 7, 943-963 (1997).

107 Wright, G. E. B. et al. Length of uninterrupted CAG repeats, independent of polyglutamine size, results in increased somatic instability and hastened age of onset in Huntington disease. 533414 (2019).

108 Gusella, J. F., MacDonald, M. E. \& Lee, J. M. Genetic modifiers of Huntington's disease. Movement disorders : official journal of the Movement Disorder Society 29, 1359-1365 (2014). 
2019

2020

2021

2022

2023

2024

2025

2026

2027

2028

2029

2030

2031

2032

2033

2034

2035

2036

2037

2038

2039

2040

2041

2042

2043

2044

2045

2046

2047

2048

2049

2050

2051

2052

2053

2054

2055

2056

2057

2058

2059

2060

2061

2062

2063

2064

109 Wexler, N. S. et al. Venezuelan kindreds reveal that genetic and environmental factors modulate Huntington's disease age of onset. Proceedings of the National Academy of Sciences of the United States of America 101, 3498-3503 (2004).

110 GeM-HD, G. M. o. H. s. D. G.-H. C.-. Identification of Genetic Factors that Modify Clinical Onset of Huntington's Disease. Cell 162, 516-526 (2015).

111 Porro, A. et al. FAN1 interaction with ubiquitylated PCNA alleviates replication stress and preserves genomic integrity independently of BRCA2. Nature communications $\mathbf{8}$, 1073 (2017).

112 Goold, R. et al. FAN1 modifies Huntington's disease progression by stabilising the expanded HTT CAG repeat. Human molecular genetics 28, 650-661 (2018).

113 Zhao, X. N. \& Usdin, K. FAN1 protects against repeat expansions in a Fragile $X$ mouse model. DNA repair $69,1-5$ (2018).

114 Ortega, Z. \& Lucas, J. J. Ubiquitin-proteasome system involvement in Huntington's disease. Frontiers in molecular neuroscience 7, 77 (2014).

115 Koyuncu, S. et al. The ubiquitin ligase UBR5 suppresses proteostasis collapse in pluripotent stem cells from Huntington's disease patients. Nature communications $\mathbf{9}$, 2886 (2018).

116 Pinto, R. M. et al. Mismatch repair genes Mlh1 and Mlh3 modify CAG instability in Huntington's disease mice: genome-wide and candidate approaches. PLoS genetics 9 , e1003930 (2013).

117 Hensman Moss, D. J. H. et al. Identification of genetic variants associated with Huntington's disease progression: a genome-wide association study. The Lancet. Neurology 16, 701-711 (2017).

118 Iyer, R. R., Pluciennik, A., Napierala, M. \& Wells, R. D. DNA triplet repeat expansion and mismatch repair. Annual review of biochemistry 84, 199-226 (2015).

119 Dragileva, E. et al. Intergenerational and striatal CAG repeat instability in Huntington's disease knock-in mice involve different DNA repair genes. Neurobiology of disease 33, 37-47 (2009).

120 Tome, S. et al. MSH3 polymorphisms and protein levels affect CAG repeat instability in Huntington's disease mice. PLoS genetics 9, e1003280 (2013).

121 Anderson, D. D., Quintero, C. M. \& Stover, P. J. Identification of a de novo thymidylate biosynthesis pathway in mammalian mitochondria. Proceedings of the National Academy of Sciences of the United States of America 108, 15163-15168 (2011).

122 Flower, $M$. et al. MSH3 modifies somatic instability and disease severity in Huntington's and myotonic dystrophy type 1. Brain 142, 1876-1886 (2019).

123 Andresen, J. M. et al. Replication of twelve association studies for Huntington's disease residual age of onset in large Venezuelan kindreds. J Med Genet 44, 44-50 (2007).

124 Holbert, S. et al. The Gln-Ala repeat transcriptional activator CA150 interacts with huntingtin: neuropathologic and genetic evidence for a role in Huntington's disease pathogenesis. Proceedings of the National Academy of Sciences of the United States of America 98, 1811-1816 (2001).

125 Kozlov, S. V. et al. Reactive Oxygen Species (ROS)-Activated ATM-Dependent Phosphorylation of Cytoplasmic Substrates Identified by Large-Scale Phosphoproteomics Screen. Molecular \& cellular proteomics : MCP 15, 1032-1047 (2016). 
126 Massey, T. H. \& Jones, L. The central role of DNA damage and repair in CAG repeat diseases. Disease Models \& Mechanisms 11 (2018).

127 Howes, T. R. \& Tomkinson, A. E. DNA ligase I, the replicative DNA ligase. Sub-cellular biochemistry 62, 327-341 (2012).

128 Lopez Castel, A., Tomkinson, A. E. \& Pearson, C. E. CTG/CAG repeat instability is modulated by the levels of human DNA ligase $I$ and its interaction with proliferating cell nuclear antigen: a distinction between replication and slipped-DNA repair. The Journal of biological chemistry 284, 26631-26645 (2009).

129 Tome, S. et al. Maternal germline-specific effect of DNA ligase I on CTG/CAG instability. Human molecular genetics 20, 2131-2143 (2011).

130 Gomes-Pereira, M., Fortune, M. T., Ingram, L., McAbney, J. P. \& Monckton, D. G. Pms2 is a genetic enhancer of trinucleotide CAG.CTG repeat somatic mosaicism: implications for the mechanism of triplet repeat expansion. Human molecular genetics 13, 1815-1825 (2004).

131 Bettencourt, C. et al. DNA repair pathways underlie a common genetic mechanism modulating onset in polyglutamine diseases. Ann Neurol 79, 983-990 (2016).

132 Morales, F. et al. A polymorphism in the MSH3 mismatch repair gene is associated with the levels of somatic instability of the expanded CTG repeat in the blood DNA of myotonic dystrophy type 1 patients. DNA repair 40, 57-66 (2016).

133 Nakatani, R., Nakamori, M., Fujimura, H., Mochizuki, H. \& Takahashi, M. P. Large expansion of $\mathrm{CTG} \bullet \mathrm{CAG}$ repeats is exacerbated by MutS $\beta$ in human cells. Scientific reports 5, 11020-11020 (2015).

134 Halabi, A., Fuselier, K. T. B. \& Grabczyk, E. GAA•TTC repeat expansion in human cells is mediated by mismatch repair complex MutL $\gamma$ and depends upon the endonuclease domain in MLH3 isoform one. Nucleic acids research 46, 4022-4032 (2018).

135 Panigrahi, G. B., Slean, M. M., Simard, J. P. \& Pearson, C. E. Human Mismatch Repair Protein hMutL Is Required to Repair Short Slipped-DNAs of Trinucleotide Repeats. Journal of Biological Chemistry 287, 41844-41850 (2012).

136 Lin, Y., Dion, V. \& Wilson, J. H. Transcription promotes contraction of CAG repeat tracts in human cells. Nature structural \& molecular biology 13, 179-180 (2006).

137 Lin, Y. \& Wilson, J. H. Diverse effects of individual mismatch repair components on transcription-induced CAG repeat instability in human cells. DNA repair $\mathbf{8}, \mathbf{8 7 8 - 8 8 5}$ (2009).

138 Gannon, A. M., Frizzell, A., Healy, E. \& Lahue, R. S. MutSbeta and histone deacetylase complexes promote expansions of trinucleotide repeats in human cells. Nucleic Acids Res 40, 10324-10333 (2012).

139 Keogh, N., Chan, K. Y., Li, G. M. \& Lahue, R. S. MutSbeta abundance and Msh3 ATP hydrolysis activity are important drivers of CTG*CAG repeat expansions. Nucleic Acids Res 45, 10068-10078 (2017).

140 Seriola, A. et al. Huntington's and myotonic dystrophy hESCs: down-regulated trinucleotide repeat instability and mismatch repair machinery expression upon differentiation. Human molecular genetics 20, 176-185 (2011).

141 Du, J., Campau, E., Soragni, E., Jespersen, C. \& Gottesfeld, J. M. Length-dependent CTG.CAG triplet-repeat expansion in myotonic dystrophy patient-derived induced pluripotent stem cells. Human molecular genetics 22, 5276-5287 (2013). 
142 Axford, M. M. et al. Detection of slipped-DNAs at the trinucleotide repeats of the myotonic dystrophy type I disease locus in patient tissues. PLoS genetics 9, e1003866 (2013).

143 Schmidt, M. H. \& Pearson, C. E. Disease-associated repeat instability and mismatch repair. DNA repair 38, 117-126 (2016).

144 Carethers, J. M. Microsatellite Instability Pathway and EMAST in Colorectal Cancer. Curr Colorectal Cancer Rep 13, 73-80 (2017).

145 Gacy, A. M., Goellner, G., Juranic, N., Macura, S. \& McMurray, C. T. Trinucleotide repeats that expand in human disease form hairpin structures in vitro. Cell 81, 533540 (1995).

146 Gonitel, R. et al. DNA instability in postmitotic neurons. Proceedings of the National Academy of Sciences of the United States of America 105, 3467-3472 (2008).

147 Gomes-Pereira, M. et al. Disease-associated CAG\{middle dot\}CTG triplet repeats expand rapidly in non-dividing mouse cells, but cell cycle arrest is insufficient to drive expansion. Nucleic Acids Research 42, 7047-7056 (2014).

148 Slean, M. M. et al. Absence of MutSbeta leads to the formation of slipped-DNA for CTG/CAG contractions at primate replication forks. DNA repair 42, 107-118 (2016).

149 Liu, G., Chen, X., Bissler, J. J., Sinden, R. R. \& Leffak, M. Replication-dependent instability at (CTG) $\times(C A G)$ repeat hairpins in human cells. Nature chemical biology 6 , 652-659 (2010).

150 Muro, Y., Sugiura, K., Mimori, T. \& Akiyama, M. DNA mismatch repair enzymes: genetic defects and autoimmunity. Clinica chimica acta; international journal of clinical chemistry 442, 102-109 (2015).

151 Sehgal, R. et al. Lynch syndrome: an updated review. Genes (Basel) 5, 497-507 (2014).

152 Buniello, A. et al. The NHGRI-EBI GWAS Catalog of published genome-wide association studies, targeted arrays and summary statistics 2019. Nucleic Acids Res 47, D1005D1012 (2019).

153 Ochaba, J. et al. PIAS1 Regulates Mutant Huntingtin Accumulation and Huntington's Disease-Associated Phenotypes In Vivo. Neuron 90, 507-520 (2016).

154 Group, T. H. s. D. C. R. A novel gene containing a trinucleotide repeat that is expanded and unstable on Huntington's disease chromosomes. The Huntington's Disease Collaborative Research Group. Cell 72, 971-983 (1993).

155 Lin, B. et al. Differential 3' polyadenylation of the Huntington disease gene results in two mRNA species with variable tissue expression. Human molecular genetics 2, 15411545 (1993).

156 Landles, C. et al. Proteolysis of Mutant Huntingtin Produces an Exon 1 Fragment That Accumulates as an Aggregated Protein in Neuronal Nuclei in Huntington Disease. The Journal of biological chemistry 285, 8808-8823 (2010).

157 Neueder, A. et al. The pathogenic exon $1 \mathrm{HTT}$ protein is produced by incomplete splicing in Huntington's disease patients. Scientific reports 7, 1307-1307 (2017).

158 Bates, G., Tabrizi, S. \& Jones, L. Huntington's disease. (Oxford University Press, 2014). 159 Beck, M. \& Hurt, E. The nuclear pore complex: understanding its function through structural insight. Nat Rev Mol Cell Biol 18, 73-89 (2017).

160 Basel-Vanagaite, L. et al. Mutated nup62 causes autosomal recessive infantile bilateral striatal necrosis. Ann Neurol 60, 214-222 (2006).

161 Cavazza, T. \& Vernos, I. The RanGTP Pathway: From Nucleo-Cytoplasmic Transport to Spindle Assembly and Beyond. Front Cell Dev Biol 3, 82 (2015). 
162 Hetzer, M., Gruss, O. J. \& Mattaj, I. W. The Ran GTPase as a marker of chromosome position in spindle formation and nuclear envelope assembly. Nat Cell Biol 4, E177184 (2002).

163 Hosp, F. et al. Quantitative interaction proteomics of neurodegenerative disease proteins. Cell Rep 11, 1134-1146 (2015).

164 Grima, J. C. et al. Mutant Huntingtin Disrupts the Nuclear Pore Complex. Neuron 94, 93-107 e106 (2017).

165 Zhang, Y. J. et al. C9ORF72 poly(GA) aggregates sequester and impair HR23 and nucleocytoplasmic transport proteins. Nat Neurosci 19, 668-677 (2016).

166 Shi, K. Y. et al. Toxic PRn poly-dipeptides encoded by the C9orf72 repeat expansion block nuclear import and export. Proceedings of the National Academy of Sciences of the United States of America 114, E1111-E1117 (2017).

167 Ruba, A. \& Yang, W. O-GlcNAc-ylation in the Nuclear Pore Complex. Cell Mol Bioeng 9, 227-233 (2016).

168 Haines, J. D. et al. Nuclear export inhibitors avert progression in preclinical models of inflammatory demyelination. Nat Neurosci 18, 511-520 (2015).

169 Zhang, K. et al. The C9orf72 repeat expansion disrupts nucleocytoplasmic transport. Nature 525, 56-61 (2015).

170 Archbold, H. C. et al. TDP43 nuclear export and neurodegeneration in models of amyotrophic lateral sclerosis and frontotemporal dementia. Sci Rep 8, 4606 (2018).

171 Guo, Q. et al. The cryo-electron microscopy structure of huntingtin. Nature 555, 117120 (2018).

172 Peters, M. F. \& Ross, C. A. Isolation of a 40-kDa Huntingtin-associated protein. The Journal of biological chemistry 276, 3188-3194 (2001).

173 Pal, A., Severin, F., Lommer, B., Shevchenko, A. \& Zerial, M. Huntingtin-HAP40 complex is a novel Rab5 effector that regulates early endosome motility and is up-regulated in Huntington's disease. The Journal of cell biology 172, 605-618 (2006).

174 Li, W., Serpell, L. C., Carter, W. J., Rubinsztein, D. C. \& Huntington, J. A. Expression and characterization of full-length human huntingtin, an elongated HEAT repeat protein. The Journal of biological chemistry 281, 15916-15922 (2006).

175 Andrade, M. A. \& Bork, P. HEAT repeats in the Huntington's disease protein. Nat Genet 11, 115-116 (1995).

176 Seong, I. S. et al. Huntingtin facilitates polycomb repressive complex 2. Human molecular genetics 19, 573-583 (2010).

177 Ratovitski, T. et al. Post-Translational Modifications (PTMs), Identified on Endogenous Huntingtin, Cluster within Proteolytic Domains between HEAT Repeats. J Proteome Res 16, 2692-2708 (2017).

178 Arbez, N. et al. Post-translational modifications clustering within proteolytic domains decrease mutant huntingtin toxicity. The Journal of biological chemistry 292, 1923819249 (2017).

179 Yee, L. M., Lively, T. G. \& McShane, L. M. Biomarkers in early-phase trials: fundamental issues. Bioanalysis 10, 933-944 (2018).

180 Rodrigues, F. B., Byrne, L. M. \& Wild, E. J. Biofluid Biomarkers in Huntington's Disease. Methods in molecular biology (Clifton, N.J.) 1780, 329-396 (2018).

181 Silajdzic, E. \& Bjorkqvist, M. A Critical Evaluation of Wet Biomarkers for Huntington's Disease: Current Status and Ways Forward. Journal of Huntington's disease 7, 109-135 (2018). 
182 Southwell, A. L. et al. Ultrasensitive measurement of huntingtin protein in cerebrospinal fluid demonstrates increase with Huntington disease stage and decrease following brain huntingtin suppression. Sci Rep 5, 12166 (2015).

183 Wild, E. J. et al. Quantification of mutant huntingtin protein in cerebrospinal fluid from Huntington's disease patients. The Journal of clinical investigation 125, 1979-1986 (2015).

184 Fodale, V. et al. Validation of Ultrasensitive Mutant Huntingtin Detection in Human Cerebrospinal Fluid by Single Molecule Counting Immunoassay. Journal of Huntington's disease 6, 349-361 (2017).

185 Byrne, L. M. et al. Evaluation of mutant huntingtin and neurofilament proteins as potential markers in Huntington's disease. Science translational medicine 10 (2018).

186 Tabrizi, S. J. et al. Targeting Huntingtin Expression in Patients with Huntington's Disease. New England Journal of Medicine 380, 2307-2316 (2019).

187 Shahim, P., Zetterberg, H., Tegner, Y. \& Blennow, K. Serum neurofilament light as a biomarker for mild traumatic brain injury in contact sports. Neurology 88, 1788-1794 (2017).

188 Constantinescu, R., Romer, M., Oakes, D., Rosengren, L. \& Kieburtz, K. Levels of the light subunit of neurofilament triplet protein in cerebrospinal fluid in Huntington's disease. Parkinsonism \& related disorders 15, 245-248 (2009).

189 Vinther-Jensen, T. et al. Selected CSF biomarkers indicate no evidence of early neuroinflammation in Huntington disease. Neurology-Neuroimmunology Neuroinflammation 3, e287 (2016).

190 Niemelä, V., Landtblom, A.-M., Blennow, K. \& Sundblom, J. Tau or neurofilament light-Which is the more suitable biomarker for Huntington's disease? PloS one 12, e0172762 (2017).

191 Byrne, L. M. et al. Neurofilament light protein in blood as a potential biomarker of neurodegeneration in Huntington's disease: a retrospective cohort analysis. The Lancet. Neurology 16, 601-609 (2017).

192 Rodrigues, F. B. et al. Cerebrospinal fluid inflammatory biomarkers reflect clinical severity in Huntington's disease. PloS one 11, e0163479 (2016).

193 Soylu-Kucharz, R. et al. Neurofilament light protein in CSF and blood is associated with neurodegeneration and disease severity in Huntington's disease R6/2 mice. Scientific reports 7, 14114 (2017).

194 Johnson, E. B. et al. Neurofilament light protein in blood predicts regional atrophy in Huntington disease. Neurology 90, e717-e723 (2018).

195 Vinther-Jensen, T., Budtz-Jorgensen, E., Simonsen, A. H., Nielsen, J. E. \& Hjermind, L. E. YKL-40 in cerebrospinal fluid in Huntington's disease--a role in pathology or a nonspecific response to inflammation? Parkinsonism \& related disorders 20, 13011303 (2014).

196 Rodrigues, F. B. et al. Cerebrospinal fluid total tau concentration predicts clinical phenotype in Huntington's disease. Journal of neurochemistry 139, 22-25 (2016).

197 Davis, M. Y., Keene, C. D., Jayadev, S. \& Bird, T. The co-occurrence of Alzheimer's disease and Huntington's disease: a neuropathological study of 15 elderly Huntington's disease subjects. Journal of Huntington's disease 3, 209-217 (2014).

198 Jellinger, K. A. Alzheimer-type lesions in Huntington's disease. J Neural Transm (Vienna) 105, 787-799 (1998). 
2250

2251

2252

2253

2254

2255

2256

2257

2258

2259

2260

2261

2262

2263

2264

2265

2266

2267

2268

2269

2270

2271

2272

2273

2274

2275

2276

2277

2278

2279

2280

2281

2282

2283

2284

2285

2286

2287

2288

2289

2290

2291

2292

2293

2294

2295

199 Vuono, R. et al. The role of tau in the pathological process and clinical expression of Huntington's disease. Brain 138, 1907-1918 (2015).

200 St-Amour, I., Turgeon, A., Goupil, C., Planel, E. \& Hebert, S. S. Co-occurrence of mixed proteinopathies in late-stage Huntington's disease. Acta Neuropathol 135, 249-265 (2018).

201 Fernandez-Nogales, M. et al. Huntington's disease is a four-repeat tauopathy with tau nuclear rods. Nature medicine 20, 881-885 (2014).

202 Blum, D. et al. Mutant huntingtin alters Tau phosphorylation and subcellular distribution. Human molecular genetics 24, 76-85 (2015).

203 Baskota, S. U., Lopez, O. L., Greenamyre, J. T. \& Kofler, J. Spectrum of tau pathologies in Huntington's disease. Lab Invest 99, 1068-1077 (2019).

204 ClinicalTrials.gov. Safety and Tolerability of WVE-120102 in Patients With Huntington's Disease - Full Text View - ClinicalTrials.gov. (2020).

205 ClinicalTrials.gov. Safety and Tolerability of WVE-120101 in Patients With Huntington's Disease - Full Text View - ClinicalTrials.gov. (2020).

206 ClinicalTrials.gov. A Study to Evaluate the Efficacy and Safety of Intrathecally Administered RO7234292 (RG6042) in Patients With Manifest Huntington's Disease Full Text View - ClinicalTrials.gov. (2020).

207 McColgan, P. \& Tabrizi, S. J. Huntington's disease: a clinical review. European journal of neurology : the official journal of the European Federation of Neurological Societies 25, 24-34 (2018).

208 Estévez-Fraga, C., Avilés Olmos, I., Mañanes Barral, V. \& López-Sendón Moreno, J. L. Therapeutic advances in Huntington's disease. Expert Opinion on Orphan Drugs 4, 809-821 (2016).

209 Reilmann, R. et al. Safety and efficacy of pridopidine in patients with Huntington's disease (PRIDE-HD): a phase 2, randomised, placebo-controlled, multicentre, doseranging study. The Lancet. Neurology 18, 165-176 (2019).

210 ClinicalTrials.gov. Randomized, Placebo Controlled Study Of The Efficacy And Safety Of PF-02545920 In Subjects With Huntington's Disease, <https://clinicaltrials.gov/ct2/show/results/NCT02197130?view=results> (2019).

211 Delnomdedieu, M. PDE10i and HD: Learnings from the Amaryllis studies, $<$ https://chdifoundation.org/2018-conference/\#delnomdedieu> (2018).

212 Wild, E. C. J. Pfizer Amaryllis trial ends in disappointment: no improvement in Huntington's disease symptoms, <https://en.hdbuzz.net/229> (2016).

213 McGarry, A. et al. A randomized, double-blind, placebo-controlled trial of coenzyme Q10 in Huntington disease. Neurology 88, 152-159 (2017).

214 Group, H. S. A randomized, placebo-controlled trial of coenzyme Q10 and remacemide in Huntington's disease. Neurology 57, 397-404 (2001).

215 Hersch, S. M. et al. The CREST-E study of creatine for Huntington disease: A randomized controlled trial. Neurology 89, 594-601 (2017).

216 Verny, C. et al. A randomized, double-blind, placebo-controlled trial evaluating cysteamine in Huntington's disease. Movement disorders : official journal of the Movement Disorder Society 32, 932-936 (2017).

217 Reilmann, R. et al. Safety and Tolerability of Selisistat for the Treatment of Huntington's Disease: Results from a Randomized, Double-Blind, Placebo-Controlled Phase II Trial (S47.004). Neurology 82, S47.004 (2014). 
218 Süssmuth, S. D. et al. An exploratory double-blind, randomized clinical trial with selisistat, a SirT1 inhibitor, in patients with Huntington's disease. British journal of clinical pharmacology 79, 465-476 (2015).

219 Investigators, H. S. G. R. H. Safety, tolerability, and efficacy of PBT2 in Huntington's disease: a phase 2, randomised, double-blind, placebo-controlled trial. The Lancet. Neurology 14, 39-47 (2015).

220 Lopez-Sendon Moreno, J. L. et al. A double-blind, randomized, cross-over, placebocontrolled, pilot trial with Sativex in Huntington's disease. Journal of neurology 263, 1390-1400 (2016).

221 Biotech, A. Active Biotech provides update on laquinimod in Huntington's disease, $<$ http://hugin.info/1002/R/2208124/858841.pdf> (2018).

222 Cicchetti, F. et al. Neural transplants in patients with Huntington's disease undergo disease-like neuronal degeneration. Proceedings of the National Academy of Sciences of the United States of America 106, 12483-12488 (2009).

223 Freeman, T. B. et al. Transplanted fetal striatum in Huntington's disease: phenotypic development and lack of pathology. Proceedings of the National Academy of Sciences of the United States of America 97, 13877-13882 (2000).

224 Bachoud-Levi, A. C. From open to large-scale randomized cell transplantation trials in Huntington's disease: Lessons from the multicentric intracerebral grafting in Huntington's disease trial (MIG-HD) and previous pilot studies. Prog Brain Res 230, 227-261 (2017).

225 Wild, E. J. \& Tabrizi, S. J. Therapies targeting DNA and RNA in Huntington's disease. Lancet Neurology 16, 837-847 (2017).

226 Tabrizi, S. J., Ghosh, R. \& Leavitt, B. R. Huntingtin Lowering Strategies for Disease Modification in Huntington's Disease. Neuron 102, 899 (2019).

227 Lee, J. M. et al. CAG repeat expansion in Huntington disease determines age at onset in a fully dominant fashion. Neurology 78, 690-695 (2012).

228 Kordasiewicz, H. B. et al. Sustained therapeutic reversal of Huntington's disease by transient repression of huntingtin synthesis. Neuron 74, 1031-1044 (2012).

229 Lu, X.-H. \& Yang, X. W. "Huntingtin holiday": progress toward an antisense therapy for Huntington's disease. Neuron 74, 964-966 (2012).

230 Stanek, L. M. et al. Antisense oligonucleotide-mediated correction of transcriptional dysregulation is correlated with behavioral benefits in the YAC128 mouse model of Huntington's disease. Journal of Huntington's disease 2, 217-228 (2013).

231 Miniarikova, J. et al. AAV5-miHTT gene therapy demonstrates suppression of mutant huntingtin aggregation and neuronal dysfunction in a rat model of Huntington's disease. Gene therapy 24, 630-639 (2017).

232 Gauthier, L. R. et al. Huntingtin controls neurotrophic support and survival of neurons by enhancing BDNF vesicular transport along microtubules. Cell 118, 127-138 (2004).

233 Duyao, M. P. et al. Inactivation of the mouse Huntington's disease gene homolog Hdh. Science (New York, N.Y.) 269, 407-410 (1995).

234 Dragatsis, I., Levine, M. S. \& Zeitlin, S. Inactivation of Hdh in the brain and testis results in progressive neurodegeneration and sterility in mice. Nat Genet 26, 300-306 (2000).

235 Hoffner, G., Kahlem, P. \& Djian, P. Perinuclear localization of huntingtin as a consequence of its binding to microtubules through an interaction with beta-tubulin: relevance to Huntington's disease. J Cell Sci 115, 941-948 (2002). 
236 Caviston, J. P., Ross, J. L., Antony, S. M., Tokito, M. \& Holzbaur, E. L. Huntingtin facilitates dynein/dynactin-mediated vesicle transport. Proceedings of the National Academy of Sciences of the United States of America 104, 10045-10050 (2007).

237 Colin, E. et al. Huntingtin phosphorylation acts as a molecular switch for anterograde/retrograde transport in neurons. The EMBO journal 27, 2124-2134 (2008).

238 Strehlow, A. N., Li, J. Z. \& Myers, R. M. Wild-type huntingtin participates in protein trafficking between the Golgi and the extracellular space. Human molecular genetics 16, 391-409 (2007).

239 Velier, J. et al. Wild-type and mutant huntingtins function in vesicle trafficking in the secretory and endocytic pathways. Exp Neurol 152, 34-40 (1998).

240 Brandstaetter, H., Kruppa, A. J. \& Buss, F. Huntingtin is required for ER-to-Golgi transport and for secretory vesicle fusion at the plasma membrane. Disease Models \& Mechanisms 7, 1335-1340 (2014).

241 Caviston, J. P. \& Holzbaur, E. L. Huntingtin as an essential integrator of intracellular vesicular trafficking. Trends in cell biology 19, 147-155 (2009).

242 Kegel, K. B. et al. Huntingtin is present in the nucleus, interacts with the transcriptional corepressor C-terminal binding protein, and represses transcription. The Journal of biological chemistry 277, 7466-7476 (2002).

243 Zuccato, C. et al. Huntingtin interacts with REST/NRSF to modulate the transcription of NRSE-controlled neuronal genes. Nat Genet 35, 76-83 (2003).

244 McFarland, K. N. et al. MeCP2: a novel Huntingtin interactor. Human molecular genetics 23, 1036-1044 (2014).

245 DiFiglia, M. et al. Huntingtin is a cytoplasmic protein associated with vesicles in human and rat brain neurons. Neuron 14, 1075-1081 (1995).

246 Marcora, E. \& Kennedy, M. B. The Huntington's disease mutation impairs Huntingtin's role in the transport of NF-kappaB from the synapse to the nucleus. Human molecular genetics 19, 4373-4384 (2010).

247 McKinstry, S. U. et al. Huntingtin is required for normal excitatory synapse development in cortical and striatal circuits. The Journal of neuroscience : the official journal of the Society for Neuroscience 34, $9455-9472$ (2014).

248 Anne, S. L., Saudou, F. \& Humbert, S. Phosphorylation of huntingtin by cyclindependent kinase 5 is induced by DNA damage and regulates wild-type and mutant huntingtin toxicity in neurons. The Journal of neuroscience : the official journal of the Society for Neuroscience 27, 7318-7328 (2007).

249 Harper, S. Q. et al. RNA interference improves motor and neuropathological abnormalities in a Huntington's disease mouse model. Proceedings of the National Academy of Sciences of the United States of America 102, 5820-5825 (2005).

250 Franich, N. R. et al. AAV vector-mediated RNAi of mutant huntingtin expression is neuroprotective in a novel genetic rat model of Huntington's disease. Molecular therapy: the journal of the American Society of Gene Therapy 16, 947-956 (2008).

251 McBride, J. L. et al. Preclinical safety of RNAi-mediated HTT suppression in the rhesus macaque as a potential therapy for Huntington's disease. Molecular therapy : the journal of the American Society of Gene Therapy 19, 2152-2162 (2011).

252 Grondin, R. et al. Six-month partial suppression of Huntingtin is well tolerated in the adult rhesus striatum. Brain 135, 1197-1209 (2012). 
253 Wang, G., Liu, X., Gaertig, M. A., Li, S. \& Li, X. J. Ablation of huntingtin in adult neurons is nondeleterious but its depletion in young mice causes acute pancreatitis. Proceedings of the National Academy of Sciences of the United States of America 113, 3359-3364 (2016).

254 Ambrose, C. M. et al. Structure and expression of the Huntington's disease gene: evidence against simple inactivation due to an expanded CAG repeat. Somat Cell Mol Genet 20, 27-38 (1994).

255 Gagnon, K. T. et al. Allele-selective inhibition of mutant huntingtin expression with antisense oligonucleotides targeting the expanded CAG repeat. Biochemistry 49, 10166-10178 (2010).

256 Yu, D. et al. Single-stranded RNAs use RNAi to potently and allele-selectively inhibit mutant huntingtin expression. Cell 150, 895-908 (2012).

257 Garriga-Canut, M. et al. Synthetic zinc finger repressors reduce mutant huntingtin expression in the brain of R6/2 mice. Proceedings of the National Academy of Sciences of the United States of America 109, E3136-3145 (2012).

258 van Bilsen, P. H. et al. Identification and allele-specific silencing of the mutant huntingtin allele in Huntington's disease patient-derived fibroblasts. Human gene therapy 19, 710-719 (2008).

259 Monteys, A. M., Ebanks, S. A., Keiser, M. S. \& Davidson, B. L. CRISPR/Cas9 Editing of the Mutant Huntingtin Allele In Vitro and In Vivo. Molecular therapy: the journal of the American Society of Gene Therapy 25, 12-23 (2017).

260 Shin, J. W. et al. Permanent inactivation of Huntington's disease mutation by personalized allele-specific CRISPR/Cas9. Human molecular genetics 25, 4566-4576 (2016).

261 Lindow, M. et al. Assessing unintended hybridization-induced biological effects of oligonucleotides. Nat Biotechnol 30, 920-923 (2012).

262 Kay, C. et al. Huntingtin Haplotypes Provide Prioritized Target Panels for Allele-specific Silencing in Huntington Disease Patients of European Ancestry. Molecular therapy: the journal of the American Society of Gene Therapy 23, 1759-1771 (2015).

263 Lombardi, M. S. et al. A majority of Huntington's disease patients may be treatable by individualized allele-specific RNA interference. Exp Neurol 217, 312-319 (2009).

264 Pfister, E. L. et al. Five siRNAs targeting three SNPs may provide therapy for threequarters of Huntington's disease patients. Current biology : CB 19, 774-778 (2009).

265 Setten, R. L., Rossi, J. J. \& Han, S. P. The current state and future directions of RNAibased therapeutics. Nature reviews. Drug discovery 18, 421-446 (2019).

$266 \mathrm{Ha}, \mathrm{M}$. \& Kim, V. N. Regulation of microRNA biogenesis. Nat Rev Mol Cell Biol 15, 509524 (2014).

267 Ahmadzada, T., Reid, G. \& McKenzie, D. R. Fundamentals of siRNA and miRNA therapeutics and a review of targeted nanoparticle delivery systems in breast cancer. Biophys Rev 10, 69-86 (2018).

268 Rodriguez-Lebron, E., Denovan-Wright, E. M., Nash, K., Lewin, A. S. \& Mandel, R. J. Intrastriatal rAAV-mediated delivery of anti-huntingtin shRNAs induces partial reversal of disease progression in R6/1 Huntington's disease transgenic mice. Molecular therapy : the journal of the American Society of Gene Therapy 12, 618-633 (2005).

269 Wang, Y. L. et al. Clinico-pathological rescue of a model mouse of Huntington's disease by siRNA. Neurosci Res 53, 241-249 (2005). 
270 DiFiglia, M. et al. Therapeutic silencing of mutant huntingtin with siRNA attenuates striatal and cortical neuropathology and behavioral deficits. Proceedings of the National Academy of Sciences of the United States of America 104, 17204-17209 (2007).

271 Machida, Y. et al. rAAV-mediated shRNA ameliorated neuropathology in Huntington disease model mouse. Biochem Biophys Res Commun 343, 190-197 (2006).

272 Boudreau, R. L. et al. Nonallele-specific silencing of mutant and wild-type huntingtin demonstrates therapeutic efficacy in Huntington's disease mice. Molecular therapy: the journal of the American Society of Gene Therapy 17, 1053-1063 (2009).

273 McBride, J. L. et al. Artificial miRNAs mitigate shRNA-mediated toxicity in the brain: implications for the therapeutic development of RNAi. Proceedings of the National Academy of Sciences of the United States of America 105, 5868-5873 (2008).

274 Drouet, V. et al. Sustained effects of nonallele-specific Huntingtin silencing. Ann Neurol 65, 276-285 (2009).

275 Stanek, L. M. et al. Silencing mutant huntingtin by adeno-associated virus-mediated RNA interference ameliorates disease manifestations in the YAC128 mouse model of Huntington's disease. Human gene therapy 25, 461-474 (2014).

276 de Fougerolles, A. R. Delivery vehicles for small interfering RNA in vivo. Human gene therapy 19, 125-132 (2008).

277 Wang, D., Tai, P. W. L. \& Gao, G. Adeno-associated virus vector as a platform for gene therapy delivery. Nature reviews. Drug discovery 18, 358-378 (2019).

278 Lykken, E. A., Shyng, C., Edwards, R. J., Rozenberg, A. \& Gray, S. J. Recent progress and considerations for AAV gene therapies targeting the central nervous system. J Neurodev Disord 10, 16 (2018).

279 Dufour, B. D., Smith, C. A., Clark, R. L., Walker, T. R. \& McBride, J. L. Intrajugular vein delivery of AAV9-RNAi prevents neuropathological changes and weight loss in Huntington's disease mice. Molecular therapy : the journal of the American Society of Gene Therapy 22, 797-810 (2014).

280 Deverman, B. E. et al. Cre-dependent selection yields AAV variants for widespread gene transfer to the adult brain. Nat Biotechnol 34, 204-209 (2016).

281 Matsuzaki, Y. et al. Intravenous administration of the adeno-associated virus-PHP.B capsid fails to upregulate transduction efficiency in the marmoset brain. Neuroscience letters 665, 182-188 (2018).

282 Jackson, A. L. \& Linsley, P. S. Recognizing and avoiding siRNA off-target effects for target identification and therapeutic application. Nature reviews. Drug discovery 9, 5767 (2010).

283 Grimm, D. et al. Fatality in mice due to oversaturation of cellular microRNA/short hairpin RNA pathways. Nature 441, 537-541 (2006).

284 Borel, F. et al. In vivo knock-down of multidrug resistance transporters ABCC1 and ABCC2 by AAV-delivered shRNAs and by artificial miRNAs. J RNAi Gene Silencing 7, 434-442 (2011).

285 Meng, Z. \& Lu, M. RNA Interference-Induced Innate Immunity, Off-Target Effect, or Immune Adjuvant? Front Immunol 8, 331 (2017).

286 Louis Jeune, V., Joergensen, J. A., Hajjar, R. J. \& Weber, T. Pre-existing anti-adenoassociated virus antibodies as a challenge in AAV gene therapy. Hum Gene Ther Methods 24, 59-67 (2013). 
2481

2482

2483

2484

2485

2486

2487

2488

2489

2490

2491

2492

2493

2494

2495

2496

2497

2498

2499

2500

2501

2502

2503

2504

2505

2506

2507

2508

2509

2510

2511

2512

2513

2514

2515

2516

2517

2518

2519

2520

2521

2522

2523

2524

2525

287 Rafii, M. S. et al. Adeno-Associated Viral Vector (Serotype 2)-Nerve Growth Factor for Patients With Alzheimer Disease: A Randomized Clinical Trial. JAMA neurology 75, 834-841 (2018).

288 Kristen, A. V. et al. Patisiran, an RNAi therapeutic for the treatment of hereditary transthyretin-mediated amyloidosis. Neurodegener Dis Manag 9, 5-23 (2019).

289 Adams, D. et al. Patisiran, an RNAi Therapeutic, for Hereditary Transthyretin Amyloidosis. The New England journal of medicine 379, 11-21 (2018).

290 Shankar, R., Joshi, M. \& Pathak, K. Lipid Nanoparticles: A Novel Approach for Brain Targeting. Pharm Nanotechnol 6, 81-93 (2018).

291 Cullis, P. R. \& Hope, M. J. Lipid Nanoparticle Systems for Enabling Gene Therapies. Molecular therapy : the journal of the American Society of Gene Therapy 25, 14671475 (2017).

292 Neves, A. R., Queiroz, J. F. \& Reis, S. Brain-targeted delivery of resveratrol using solid lipid nanoparticles functionalized with apolipoprotein E. J Nanobiotechnology 14, 27 (2016).

293 Salvalaio, M. et al. Targeted Polymeric Nanoparticles for Brain Delivery of High Molecular Weight Molecules in Lysosomal Storage Disorders. PLoS One 11, e0156452 (2016).

294 uniQure. uniQure Announces FDA Clearance of Investigational New Drug Application for AMT-130 in Huntingtonâ? ${ }^{T M}$ s Disease, <https://www.globenewswire.com/newsrelease/2019/01/22/1703263/0/en/uniQure-Announces-FDA-Clearance-of-

Investigational-New-Drug-Application-for-AMT-130-in-Huntington-s-Disease.html> (2019).

295 Evers, M. M. et al. AAV5-miHTT Gene Therapy Demonstrates Broad Distribution and Strong Human Mutant Huntingtin Lowering in a Huntington's Disease Minipig Model. Molecular therapy : the journal of the American Society of Gene Therapy 26, 21632177 (2018).

296 Hadaczek, P. et al. Widespread AAV1- and AAV2-mediated transgene expression in the nonhuman primate brain: implications for Huntington's disease. Mol Ther Methods Clin Dev 3, 16037 (2016).

297 Therapeutics, V. Voyager Therapeutics Announces Preclinical Data for Huntington's Disease and Amyotrophic Lateral Sclerosis Programs at the Congress of the European Society of Gene and Cell Therapy, <https://www.globenewswire.com/newsrelease/2018/10/16/1621781/0/en/Voyager-Therapeutics-Announces-PreclinicalData-for-Huntington-s-Disease-and-Amyotrophic-Lateral-Sclerosis-Programs-at-theCongress-of-the-European-Society-of-Gene-and-Cell-Therapy.html> (2018).

298 Bennett, C. F. \& Swayze, E. E. RNA targeting therapeutics: molecular mechanisms of antisense oligonucleotides as a therapeutic platform. Annual review of pharmacology and toxicology 50, 259-293 (2010).

299 Rinaldi, C. \& Wood, M. J. A. Antisense oligonucleotides: the next frontier for treatment of neurological disorders. Nature reviews. Neurology 14, 9-21 (2018).

300 Bennett, C. F. Therapeutic Antisense Oligonucleotides Are Coming of Age. Annu Rev Med 70, 307-321 (2019).

301 Wolf, D. A. et al. Dynamic dual-isotope molecular imaging elucidates principles for optimizing intrathecal drug delivery. JCI Insight 1, e85311 (2016). 
302 Finkel, R. S. et al. Treatment of infantile-onset spinal muscular atrophy with nusinersen: a phase 2, open-label, dose-escalation study. Lancet 388, 3017-3026 (2016).

303 Wang, N. et al. Neuronal targets for reducing mutant huntingtin expression to ameliorate disease in a mouse model of Huntington's disease. Nature medicine 20, 536-541 (2014).

304 Hammond, S. M. et al. Systemic peptide-mediated oligonucleotide therapy improves long-term survival in spinal muscular atrophy. Proceedings of the National Academy of Sciences of the United States of America 113, 10962-10967 (2016).

305 Min, H. S. et al. Systemic Brain Delivery of Antisense Oligonucleotides across the Blood-Brain Barrier with a Glucose-Coated Polymeric Nanocarrier. Angew Chem Int Ed Engl (2020).

306 Finkel, R. S. et al. Nusinersen versus Sham Control in Infantile-Onset Spinal Muscular Atrophy. The New England journal of medicine 377, 1723-1732 (2017).

307 Miller, T. M. et al. An antisense oligonucleotide against SOD1 delivered intrathecally for patients with SOD1 familial amyotrophic lateral sclerosis: a phase 1, randomised, first-in-man study. The Lancet. Neurology 12, 435-442 (2013).

308 ClinicalTrials.gov. An Efficacy, Safety, Tolerability, Pharmacokinetics and Pharmacodynamics Study of BIIB067 in Adults With Inherited Amyotrophic Lateral Sclerosis (ALS) - Full Text View - ClinicalTrials.gov. (2020).

309 Southwell, A. L. et al. Huntingtin suppression restores cognitive function in a mouse model of Huntington's disease. Science translational medicine 10 (2018).

310 Roche. AAN Presentation 2019: Translational pharmacokinetic/pharmacodynamic (PK/PD) modeling strategy to support RG6042 dose selection in Huntington's disease (HD), <https://medically.roche.com/en/search/pdfviewer.2e65a24a-ffc3-4736-915417d3383c8a60.html?cid=slprxx1905nehdaan2019> (2019).

311 Ducray, P. S. et al. Translational Pharmacokinetic/Pharmacodynamic (PK/PD) Modeling Strategy to Support RG6042 Dose Selection in Huntington's Disease (HD) (S16.005). Neurology 92, S16.005 (2019).

312 Schobel, S. A. et al. Motor, cognitive, and functional declines contribute to a single progressive factor in early HD. Neurology 89, 2495-2502 (2017).

313 Trundell, D. et al. F23 Validity, reliability, ability to detect change and meaningful within-patient change of the CUHDRS. Journal of Neurology, Neurosurgery \& Psychiatry 89, A48-A48 (2018).

314 Hersch, S. et al. Multicenter, Randomized, Double-blind, Placebo-controlled Phase 1b/2a Studies of WVE-120101 and WVE-120102 in Patients with Huntington's Disease (P2.006). Neurology 88, P2.006 (2017).

315 Datson, N. A. et al. The expanded CAG repeat in the huntingtin gene as target for therapeutic RNA modulation throughout the HD mouse brain. PLoS One 12, e0171127 (2017).

316 Jiang, J. et al. Gain of Toxicity from ALS/FTD-Linked Repeat Expansions in C9ORF72 Is Alleviated by Antisense Oligonucleotides Targeting GGGGCC-Containing RNAs. Neuron 90, 535-550 (2016).

317 Becanovic, K. et al. A SNP in the HTT promoter alters NF-kappaB binding and is a bidirectional genetic modifier of Huntington disease. Nat Neurosci 18, 807-816 (2015).

318 Bhattacharyya, A. Identification and development of orally administered, CNSpenetrant small molecules that lower huntingtin protein levels by inducing a novel 
splicing event that alters the stability of huntingtin mRNA, <https://chdifoundation.org/2019-conference/\#bhattacharyya> (2019).

319 Naryshkin, N. A. et al. Motor neuron disease. SMN2 splicing modifiers improve motor function and longevity in mice with spinal muscular atrophy. Science (New York, N.Y.) 345, 688-693 (2014).

320 ClinicalTrials.gov. A Study of R06885247 in Adult and Pediatric Patients With Spinal Muscular Atrophy (MOONFISH) - Full Text View - ClinicalTrials.gov. (2020).

321 ClinicalTrials.gov. A Study to Investigate the Safety, Tolerability, Pharmacokinetics and Pharmacodynamics of Risdiplam (RO7034067) Given by Mouth in Healthy Volunteers - Full Text View - ClinicalTrials.gov. (2020).

322 ClinicalTrials.gov. A Study of Risdiplam (RO7034067) in Adult and Pediatric Participants With Spinal Muscular Atrophy - Full Text View - ClinicalTrials.gov. (2020).

323 ClinicalTrials.gov. A Study to Investigate the Safety, Tolerability, Pharmacokinetics, Pharmacodynamics and Efficacy of Risdiplam (RO7034067) in Type 2 and 3 Spinal Muscular Atrophy (SMA) Participants - Full Text View - ClinicalTrials.gov. (2020).

324 ClinicalTrials.gov. Investigate Safety, Tolerability, PK, PD and Efficacy of Risdiplam (R07034067) in Infants With Type1 Spinal Muscular Atrophy - Full Text View ClinicalTrials.gov. (2020).

325 Liu, C. R. et al. Spt4 is selectively required for transcription of extended trinucleotide repeats. Cell 148, 690-701 (2012).

326 Cheng, H. M. et al. Effects on murine behavior and lifespan of selectively decreasing expression of mutant huntingtin allele by supt4h knockdown. PLoS genetics 11, e1005043 (2015).

327 Klug, A. The discovery of zinc fingers and their applications in gene regulation and genome manipulation. Annual review of biochemistry 79, 213-231 (2010).

328 Nemudryi, A. A., Valetdinova, K. R., Medvedev, S. P. \& Zakian, S. M. TALEN and CRISPR/Cas Genome Editing Systems: Tools of Discovery. Acta Naturae 6, 19-40 (2014).

329 Adli, M. The CRISPR tool kit for genome editing and beyond. Nature communications 9, 1911 (2018).

330 Malankhanova, T. B., Malakhova, A. A., Medvedev, S. P. \& Zakian, S. M. Modern Genome Editing Technologies in Huntington's Disease Research. Journal of Huntington's disease 6, 19-31 (2017).

331 Richard, G. F. et al. Highly specific contractions of a single CAG/CTG trinucleotide repeat by TALEN in yeast. PLoS One 9, e95611 (2014).

332 Fink, K. D. et al. Allele-Specific Reduction of the Mutant Huntingtin Allele Using Transcription Activator-Like Effectors in Human Huntington's Disease Fibroblasts. Cell transplantation 25, 677-686 (2016).

333 Heman-Ackah, S. M., Bassett, A. R. \& Wood, M. J. Precision Modulation of Neurodegenerative Disease-Related Gene Expression in Human iPSC-Derived Neurons. Sci Rep 6, 28420 (2016).

334 Dabrowska, M., Juzwa, W., Krzyzosiak, W. J. \& Olejniczak, M. Precise Excision of the CAG Tract from the Huntingtin Gene by Cas9 Nickases. Frontiers in neuroscience 12, 75 (2018).

335 Ledford, H. CRISPR babies: when will the world be ready? Nature 570, 293-296 (2019). 336 Zhang, X. H., Tee, L. Y., Wang, X. G., Huang, Q. S. \& Yang, S. H. Off-target Effects in CRISPR/Cas9-mediated Genome Engineering. Mol Ther Nucleic Acids 4, e264 (2015). 
Milone, M. C. \& O'Doherty, U. Clinical use of lentiviral vectors. Leukemia 32, 15292621 1541 (2018).

2622 